\title{
Microstructural and Mechanical Characterization of Multilayered Iron Electrodeposits
}

by

\author{
Catherine Chan
}

A thesis submitted in conformity with the requirements for the degree of Master of Applied Science

Graduate Department of Materials Science and Engineering University of Toronto

(C) Copyright by Catherine Chan 2011 


\title{
Microstructural and Mechanical Characterization of Multilayered Iron Electrodeposits \\ Catherine Chan \\ Master of Applied Science \\ Graduate Department of Materials Science and Engineering \\ University of Toronto
}

2011

\begin{abstract}
Multilayered iron electrodeposits composed of alternating layers of coarsegrained iron (grain size: $1.87 \mu \mathrm{m}$; (110) texture; hardness: $177 \mathrm{VHN}$ ) and fine-grained iron (grain size: $132 \mathrm{~nm}$; (211) texture; hardness: $502 \mathrm{VHN}$ ), with layer thicknesses ranging from $\sim 0.2-7 \mu \mathrm{m}$ were successfully synthesized. The average hardness of the multilayered electrodeposits increased from $234 \mathrm{VHN}$ to $408 \mathrm{VHN}$ with decreasing layer thickness, consistent with a Hall-Petch type behaviour. In three-point bending tests, they failed in a macroscopically brittle manner although local ductility was observed in certain layers. Fractography analysis has shown that strain incompatibility between alternating layers contributes to the brittle nature of these materials. This study has demonstrated the possibility of applying a multilayered structure design to tailor the microstructure and mechanical properties of electrodeposited iron.
\end{abstract}




\section{ACKNOWLEDGEMENTS}

First and foremost I would like to express my sincere gratitude to my supervisor, Professor U. Erb, for his guidance and encouragement to explore different research opportunities. I would also like to thank Dr. G. Palumbo and Dr. F. Gonzalez (Integran Technologies Inc.) for the sponsorship of this research and for the access to their facility. The electrodeposition expertise provided by Dr. J. McCrea and Mr. D. Woloshyn (Integran Technologies Inc.) is acknowledged. The assistance provided by Dr. Y. Yang, Mr. S. Boccia, and Dr. D. Grozea (Department of Materials Science and Engineering, University of Toronto) is also appreciated.

Thanks are due to Dr. P. Woo (Hitachi High-Technologies Canada, Inc.) and Mr. C. Kwan (Department of Materials Science and Engineering, University of Toronto) for their insightful discussions. I would also like to thank the members of Nanomaterials Research Group at the University of Toronto for an enjoyable research experience.

I would like to express many heartfelt thanks to Professor Y. Ikuhara (Institute of Engineering Innovation, University of Tokyo) and Professor T. Mizoguchi (Institute of Industrial Science, University of Tokyo) for their support of my research exchange and sharing their TEM expertise. Dr. T. Ishida (Fujita Laboratory, University of Tokyo) is acknowledged for preparing the FIB samples. I would also like to thank the members of the Crystal Interface Research Laboratory at the University of Tokyo for their hospitality.

Financial support from the Natural Sciences and Engineering Research Council of Canada's Industrial Postgraduate Scholarships (NSERC-IPS), the Ontario Research Fund (ORF-RE), the University of Toronto Open Fellowship, the Ontario International Education Opportunity Scholarship, and research equipment access provided by Hitachi High-Technologies Canada, Inc. is gratefully acknowledged.

Most importantly I would like to thank my parents, Chris and Leanne, for their guidance and support of all my endeavours. 


\section{TABLE OF CONTENTS}

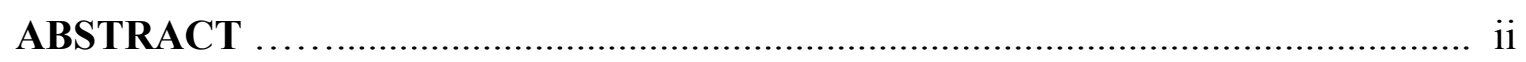

ACKNOWLEDGEMENTS .................................................. ii

TABLE OF CONTENTS ....................................................... iv

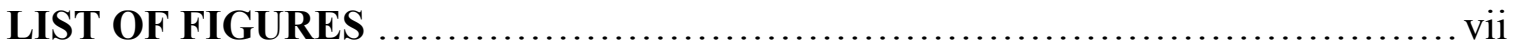

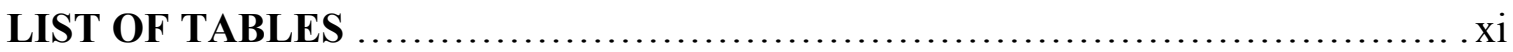

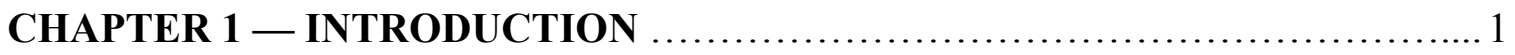

CHAPTER 2 - NANOCRYSTALLINE MATERIALS ......................... 4

2.1 SYNTHESIS OF NANOCRYSTALLINE MATERIALS …..................... 5

2.2 STRUCTURE OF NANOCRYSTALLINE MATERIALS $\ldots \ldots \ldots \ldots \ldots \ldots \ldots \ldots$

2.3 MECHANICAL PROPERTIES OF NANOCRYSTALLINE MATERIALS ....... 7

CHAPTER 3 - MULTILAYERED MATERIALS ........................... 10

$3.1 \quad$ SYNTHESIS OF MULTILAYERED MATERIALS .......................... 10

3.2 MICROSTRUCTURE OF MULTILAYERED MATERIALS ................... 13

3.3 MECHANICAL PROPERTIES OF MULTILAYERED MATERIALS ............ 14

CHAPTER 4 - IRON ELECTRODEPOSITS …............................ 17

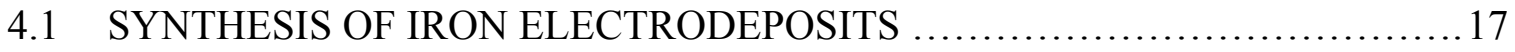

4.2 MICROSTRUCTURE OF IRON ELECTRODEPOSITS ........................ 19

4.3 MECHANICAL PROPERTIES OF IRON ELECTRODEPOSITS ..................22

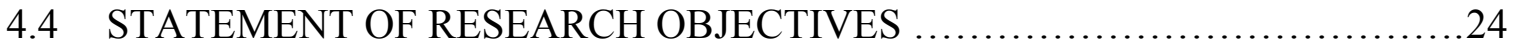

CHAPTER 5 - MATERIALS AND EXPERIMENTAL METHODS ..............25

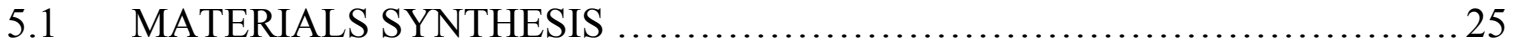

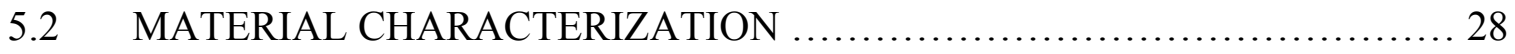


5.2.1 Infrared absorption analysis

5.2.2 Energy dispersive spectroscopy (EDS) and wavelength dispersive spectroscopy

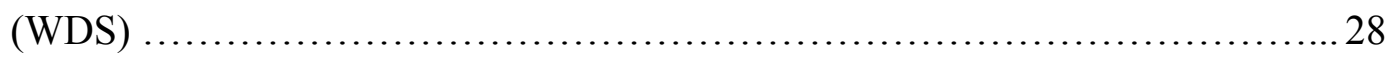

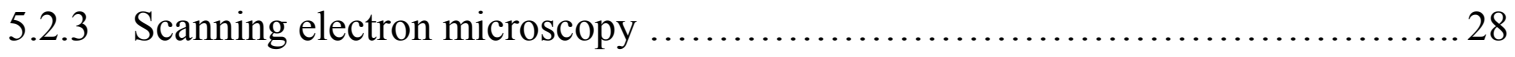

5.2.4 Transmission electron microscopy ............................................ 29

5.2.4.1 Plan-view analysis .......................................................... 29

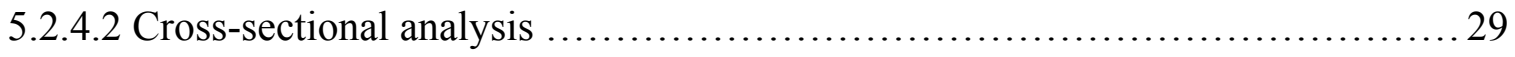

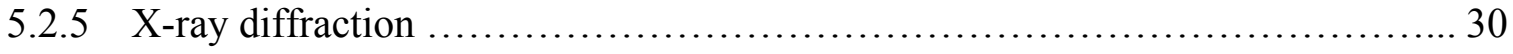

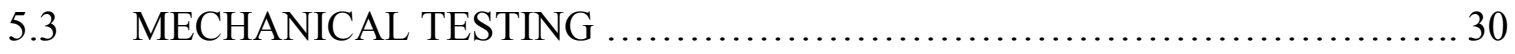

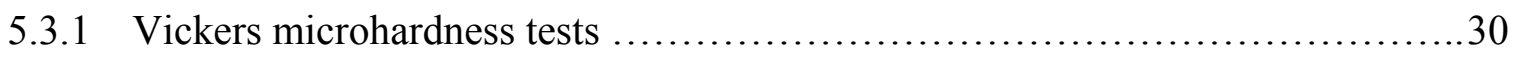

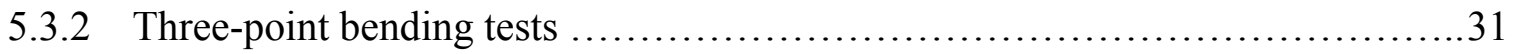

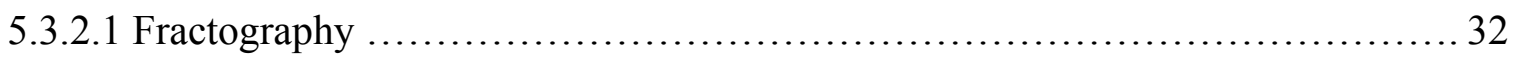

CHAPTER 6 - RESULTS AND DISCUSSION ............................. 33

6.1 CHEMICAL ANALYSIS OF IRON ELECTRODEPOSITS ..................... 33

6.2 MICROSTRUCTURAL CHARACTERIZATION OF IRON

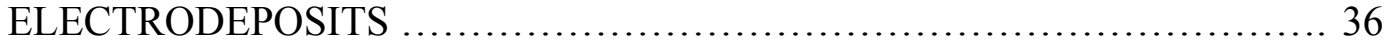

6.2.1 SEM analysis of soft and hard iron electrodeposits ...........................36

6.2.2 TEM analysis of soft and hard iron electrodeposits ...........................38

6.2.3 SEM analysis of multilayered iron electrodeposits .............................41

6.2.4 TEM analysis of multilayered iron electrodeposits ........................... 48

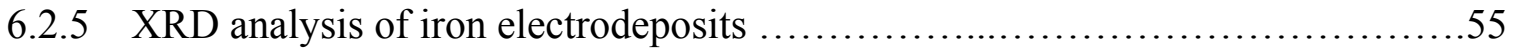

6.3 MECHANICAL CHARACTERIZATION OF IRON

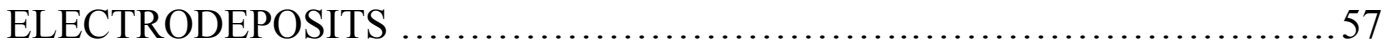




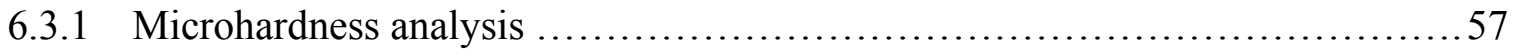

6.3.2 Flexural properties of multilayered iron electrodeposits .................... 62

6.3.2.1 SEM fracture surface analysis of iron electrodeposits $\ldots \ldots \ldots \ldots \ldots \ldots \ldots \ldots . \ldots 70$

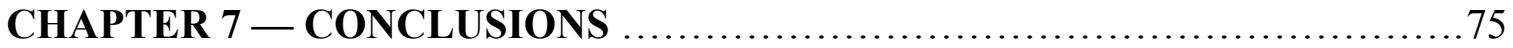

7.1 IRON ELECTRODEPOSITION AND MULTILAYERED STRUCTURE

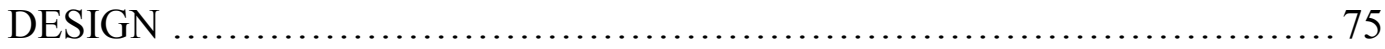

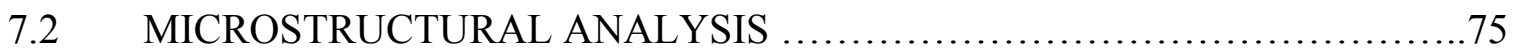

7.3 MECHANICAL PROPERTIES ........................................ 76

CHAPTER 8 - RECOMMENDATIONS FOR FUTURE WORK ............... 78

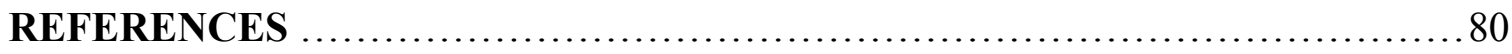

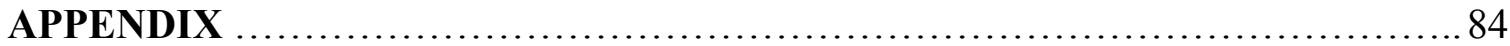




\section{LIST OF FIGURES}

Figure 2.1 Atomic structure of a nanocrystalline material. Atoms making up the crystalline regions (crystallites) are shown in black. Atoms making up the intercrystalline regions (grain boundaries and triple junctions) are represented as open circles (Gleiter 1989).

Figure 2.2 The effect of grain size on the calculated volume fractions of intercrystalline, grain boundary, and triple junction components, assuming a grain boundary thickness of $1 \mathrm{~nm}$ (after Palumbo et al. 1990).

Figure 2.3 The dependence of microhardess on grain size for electrodeposited iron (after Kozlov et al. 1968).

Figure 3.1 Typical apparatus used in (a) single-bath technique and (b) dual-bath technique for producing electrodeposited multilayers (modified from Roy 2009).

Figure 3.2 Scanning electron micrograph showing a layered structure in Ni-P electrodeposits (after Nee and Weil 1985).

Figure 3.3 Deformation mechanisms observed in multilayered materials with different microstructural length scales (Wang and Misra 2011).

Figure 3.4 Graph showing hardness as a function of layer thickness (h) in various copper multilayers. A linear fit $\longleftrightarrow$ of the Hall-Petch behaviour at larger $\mathrm{h}$ values. The model breaks down (----) at lower h values (Misra et al. 2002).

Figure 4.1 Cross-sectional view of electrodeposited iron showing (a) coarse, columnar structure (Cleaves and Thompson 1935), and (b) fibrous structure (Safranek 1974).

Figure 4.2 Cross-sections of iron electrodeposits showing (a) oxide inclusions causing the surrounding grains to bend inwards towards it (Hughes 1920), and (b) ferric hydroxide inclusions (Levy and MacInnis 1968).

Figure 4.3 Cross-sectional electron and optical micrographs of iron electrodeposits showing structural changes with increasing bulk electrolyte $\mathrm{pH}$ (Levy and MacInnis 1968).

Figure 5.1 Schematic diagram showing the typical electrodeposition apparatus used.

Figure 5.2 Schematic diagrams illustrating a variety of square-wave pulsed current modulations (Puippe and Leaman 1986).

Figure 5.3 Schematic diagram showing the cross-section of a multilayered electrodeposit composed of alternating layers of soft and hard iron. $t_{\text {Soft }}$ and $t_{\text {Hard }}$ represent the thicknesses of the soft and hard iron layers, respectively (modified from Erb 2006). 
Figure 5.4 Cross-sectional view of a FIBbed sample showing varying (stepped) coating thicknesses for better sample handling.

Figure 5.5 Schematic diagram of a dog-bone sample used in three-point bending tests.

Figure 6.1 Photographs of typical iron samples electrodeposited onto different cathodes (a) steel, (b) titanium (producing free-standing iron samples), and (c) polyamide.

Figure 6.2 EDS spectrum of a typical hard iron electrodeposit.

Figure 6.3 Backscattered SEM images showing grain-orientation contrast in monolithic iron electrodeposits. The steel substrate is observed at the bottom of the micrographs below the dotted lines. (a) Soft iron electrodeposit with coarse columnar structure and (b) hard iron electrodeposit with fine-grained structure.

Figure 6.4 (a) Bright field TEM image, (b) dark field TEM image, (c) SADP, and (d) grain size distribution of a soft iron electrodeposit.

Figure 6.5 (a) Bright field TEM image, (b) dark field TEM image, (c) SADP, and (d) grain size distribution of a hard iron electrodeposit.

Figure 6.6 Backscattered SEM images showing grain-orientation contrast in multilayered iron electrodeposits. The steel substrate is observed at the bottom of the micrographs below the dotted lines. Layer thickness of (a) $\sim 6.3 \mu \mathrm{m}$, (b) $\sim 0.92 \mu \mathrm{m}$, and (c) $\sim 0.57 \mu \mathrm{m}$. Grain growth through layer boundaries is circled.

Figure 6.6 Backscattered SEM images showing grain-orientation contrast in multilayered iron electrodeposits. The steel substrate is observed at the bottom of the micrographs below the dotted lines. Layer thickness of (d) $\sim 0.20 \mu \mathrm{m}$ and (e) $0.10 \mu \mathrm{m}$ (nominal)

Figure 6.7 Three growth modes describing the initial growth stages of electrodeposition. (a) Volmer-Weber growth via formation of individual islands, (b) Frank-van der Merwe growth via formation of individual layers, and (c) Stranski-Krastanov growth via initial formation of a single layer followed by individual island growth (Watanabe 2004).

Figure 6.8 Schematic diagram showing dendritic growth typical of electrodeposition (Argoul et al. 1988).

Figure 6.9 SEM images showing FIB preparation of a cross-sectional TEM sample. (a) A protective tungsten coating over the area of interest (i.e. rectangular box), (b) TEM sample partially cut away from bulk sample, and (c) stepped TEM sample mounted onto a copper TEM sample holder.

Figure 6.10 TEM images showing an ion-milled cross-section of a multilayered iron electrodeposit with a nominal layer thickness $\sim 0.25 \mu \mathrm{m}$. (a) BF image, (b) DF image, and (c) SADP. 
Figure 6.11 TEM images showing a FIBbed cross-section of a multilayered iron electrodeposit with a nominal layer thickness $\sim 0.25 \mu \mathrm{m}$. (a) BF image, (b) DF image, and (c) SADP.

Figure 6.12 BF TEM image showing the layered structure of a multilayered iron electrodeposit prepared by the ion milling method. Arrows indicate layer boundaries.

Figure 6.13 BF TEM images showing a layered structure in different regions of a multilayered electrodeposit prepared by the FIB method. Arrows indicate layer boundaries and grain growth through the boundaries are circled.

Figure 6.14 X-Ray diffraction patterns showing electrodeposited iron with a BCC crystal structure, and little texture variation with layer thickness in multilayered electrodeposits.

Figure 6.15 The dependence of hardness on layer thickness of multilayered electrodeposited iron. The average hardness of monolithic hard and soft iron is represent by (......) and (......), respectively. The average hardness for a 56\%soft-44\%hard multilayered iron electrodeposit, calculated from a rule of mixtures is represented by $(---)$.

Figure 6.16 Schematic diagram illustrating the Hall-Petch relationship for metals in different grain size regimes (modified from Kumar et al. 2003).

Figure 6.17 A comparison of the effectiveness of grain size and layer thickness as hardening mechanisms. Adapted from Kozlov et al. (1968). Linear fit showing HallPetch behaviour in monolithic iron (- - ) (Kozlov et al. 1968) and multilayered iron (.......) produced in the current study. $d$ is used interchangeably to represent both grain size and layer thickness.

Figure 6.18 Schematic diagram showing the cross-sectional view of a metal-polymer composite

Figure 6.19 Backscattered SEM micrographs showing the cross-sections of iron/polymer composites (a) monolithic soft iron sample (b) $\sim 7.0 \mu \mathrm{m}$ multilayered sample (c) $\sim 0.44$ $\mu \mathrm{m}$ multilayered sample.

Figure 6.20 Flexural properties of iron/polymer composites produced in the current study. (a) Comparison between monolithic soft iron, monolithic hard iron, multilayered iron, and polymer substrate. (b) Enlarged portion of (a) showing a comparison between monolithic hard iron and multilayered iron. Dips in the stress-strain curves are circled. Area under the stress-strain curve is indicated by dotted lines and represents toughness of the iron/polymer composites.

Figure 6.21 Photograph showing a typical iron/polymer composite after it has been fractured in a three-point bending test. The box indicates the fractured surface examined in the SEM. 
Figure 6.22 Secondary SEM micrographs showing cracking and delamination (circled) on the fractured surfaces of (a) a monolithic soft iron/polymer composite, (b) a monolithic hard iron/polymer composite, and (c) a multilayered iron/polymer composite.

Figure 6.23 Secondary SEM micrographs of the iron/polymer composites. (a) Fractured surface of a monolithic soft iron/polymer composite exhibiting ductile fracture features. Holes representing potential sites for microvoid coalescence are circled in black. (b) Fractured surface of a monolithic hard iron/polymer composite exhibiting brittle fracture features.

Figure 6.24 Secondary SEM micrographs of the fractured surface of a multilayered iron composite with $\sim 7.0 \mu \mathrm{m}$ thick layers. (a) At 1000x magnification showing regions of ductile and brittle fracture features. Arrows indicate regions of ductile fracture and brittle fracture occurs everywhere else. (b) At 11000x magnification showing an abrupt transition from ductile to brittle fracture.

Figure 6.25 Secondary SEM micrographs showing the brittle fracture features observed on the fractured surfaces of multilayered iron composites with (a) $\sim 0.78 \mu \mathrm{m}$ thick layers, and (b) $\sim 0.44 \mu \mathrm{m}$ thick layers.

Figure A.1 Backscattered SEM micrographs showing the cross-section of a multilayered iron/polymer composite with $\sim 0.44 \mu \mathrm{m}$ thick layers. (a) Layered structure near the surface of the iron coating and (b) layered structure near the polymer substrate. 


\section{LIST OF TABLES}

Table 5.1 Monolithic and multilayered iron electrodeposits produced with different electrodeposition conditions. Nominal thickness corresponds to total electrodeposit thickness and thickness of a single layer for monolithic and multilayered iron electrodeposits, respectively.

Table 6.1 Carbon and sulphur impurities measured in monolithic iron electrodeposits.

Table 6.2 Carbon and sulphur impurities measured in multilayered iron electrodeposits.

Table 6.3 Chemical analysis of electrolytic iron (i.e. anode material).

Table 6.4 Multilayered iron electrodeposits produced under different electrodeposition conditions. Actual layer thickness corresponds to thickness of a single layer measured from SEM micrographs.

Table 6.5 Influence of layer thickness on the average hardness of monolithic and multilayered iron electrodeposits.

Table 6.6 Iron/polymer composites produced under different electrodeposition conditions. Actual layer thickness corresponds to thickness of a single layer measured from SEM micrographs.

Table 6.7 Dependence of toughness (i.e. area under the stress-strain curve) on layer thickness for various iron/polymer composites. 


\section{CHAPTER 1 \\ INTRODUCTION}

Iron electrodeposition was developed over 150 years ago and has been used for repairing worn and under-gauge parts, printing plates, electroforming electrotypes, and soldering-iron tips (Bottger 1846, Safranek 1974). As iron is an abundant and economical metal, there continues to be an interest in further improving the physical and mechanical properties of electrodeposited iron in spite of challenges associated with maintaining control of the electrolyte chemistry. Physical and mechanical properties of electrodeposited iron originate from the process and microstructure. The microstructure of iron electrodeposits was traditionally controlled through processing methods and is typically columnar or fine-grained. Consequently, electrodeposited iron possesses either low strength and high ductility or high strength and low ductility. However, between these extreme cases the properties of electrodeposited iron are difficult to tailor through processing methods and therefore another approach for controlling the microstructure of electrodeposited iron will be investigated in this study.

Materials exhibiting a bimodal grain size distribution have been investigated as a means of improving the toughness of nanostructured materials by tailoring the microstructure. For example, Wang et al. (2002) reported that pure copper possessing a bimodal grain size distribution of micrometer-sized grains embedded in a nanocrystalline/ultrafine crystalline matrix $(<300 \mathrm{~nm})$ exhibit improved toughness. The nanoscale/ultrafine grains provide strengthening, while micron-sized grains accommodate strain leading to high ductility (Wang et al. 2002).

A multilayered material in which alternating layers exhibit distinct grain sizes is another example of a bimodal structure. In general, the purpose of a multilayered material is to combine the desirable properties of the constituent materials to form a composite material exhibiting improved properties over the constituent materials. Multilayered materials exhibit different and often enhanced properties from the constituent layers as a consequence of the structure modulation in the multilayer, 
the high density of interfaces, and possible interactions between the layers (e.g. magnetic coupling) (Ross 1994). Japanese steel swords consist of different layers of steel with varying hardness, and are practical examples of the application of a multilayered structure design to tailor the mechanical properties (Smith 1960).

Historically multilayered materials were produced via forging and welding techniques. However, in more recent years multilayered materials have also been synthesized by vacuum deposition or electrodeposition. This thesis will focus on electrodeposited multilayers. Advantages of electrodeposition over vacuum deposition methods include: low processing temperatures $\left(<100^{\circ} \mathrm{C}\right)$, high deposition rates, and the ability to tailor crystallographic texture and/or chemical composition (Ross 1994). Furthermore, electrodeposited multilayers often exhibit sharper interfaces since there is less interdiffusion between adjacent layers as a result of the lower processing temperatures (Ross 1994).

The focus of this study is to investigate the feasibility of a multilayered structure design for improved structure-mechanical property relationships in electrodeposited iron. More specificially, this research will examine whether a multilayered design strategy can be used to achieve good strength and reasonable ductility in electrodeposited iron. This thesis is organized in the following manner: Chapter Two presents a brief overview of nanocrystalline materials and some structure-dependent mechanical properties that make nanocrystalline materials desirable for many structural applications. Chapter Three summarizes the synthesis, structure and mechanical properties of multilayered electrodeposits. Chapter Four presents a review of previous iron electrodeposition studies. It is observed that impurities incorporated during the electrodeposition process have significant influence on the structure and mechanical properties of electrodeposited iron. A summary of the experimental methods used in this study to synthesize and characterize electrodeposited iron is presented in Chapter Five. Subsequently, Chapter Six presents the structure-mechanical property relationships observed in electrodeposited iron and addresses the possibility of using a multilayered structure design to tailor the mechanical properties of electrodeposited iron. The main conclusions from this study are 
presented in Chapter Seven and recommendations for future work are given in Chapter Eight. 


\section{CHAPTER 2}

\section{NANOCRYSTALLINE MATERIALS}

Nanocrystalline materials were described by Gleiter (1981) as a new class of materials consisting of a large volume fraction of defect cores and strained crystal lattice regions. Figure 2.1 is a two-dimensional representation of a nanocrystalline material. The white circles represent the intercrystalline regions (defect core regions) (Gleiter 1989). The intercrystalline regions are characterized by a reduced atomic density and interatomic spacings that deviate from the perfect lattice. The black circles represent the crystalline regions (crystal lattice regions) which consist of ordered atom arrangements. In other words, the microstructure of a nanocrystalline material consists of nanometersized crystalline regions (crystallites or grains) and the intercrystalline regions (grain boundaries and triple junctions) between adjacent crystallites. A significant volume fraction of atoms resides in the grain boundaries due to the small grain sizes of nanocrystalline materials. Consequently, nanocrystalline materials exhibit different and often improved properties over conventional polycrystalline materials (Suryanarayana 1991).

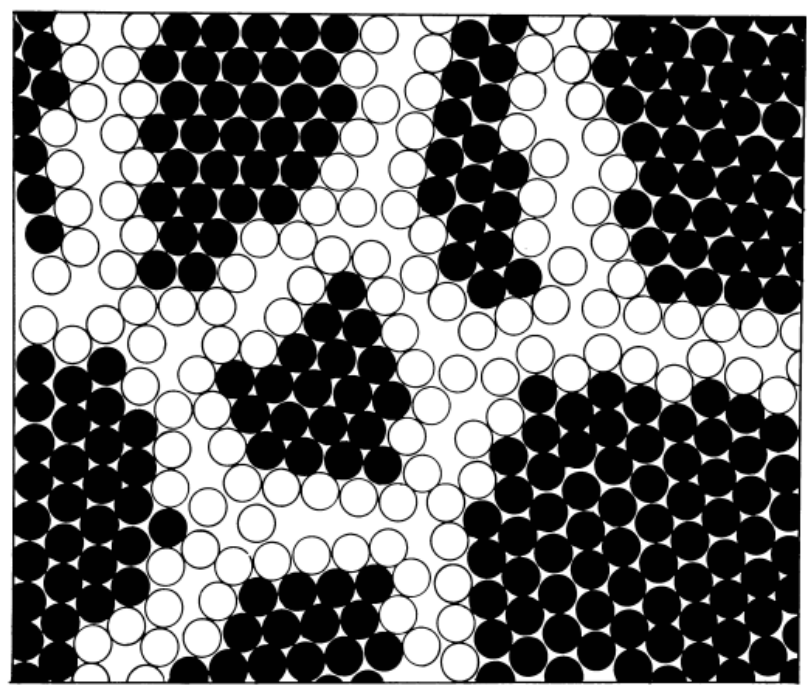

Figure 2.1 Atomic structure of a nanocrystalline material. Atoms making up the crystalline regions (crystallites) are shown in black. Atoms making up the intercrystalline regions (grain boundaries and triple junctions) are represented as open circles (Gleiter 1989). 


\subsection{SYNTHESIS OF NANOCRYSTALLINE MATERIALS}

Various production methods for nanocrystalline materials can be broadly categorized as either top-down or bottom-up approaches. A top-down approach involves modifying the microstructure of a bulk polycrystalline precursor material to achieve a nanocrystalline material. Comparatively, a bottom-up approach involves controlling the synthesis parameters to manipulate the atomic or molecular building blocks and creating a nanoscale microstructure by an atom-by-atom approach.

Synthesis methods of nanocrystalline materials can be further classified into categories based on processing techniques: vapour phase processing, liquid-phase processing, solid state processing, chemical synthesis, and electrochemical synthesis. Electrodeposition is a form of electrochemical synthesis which utilizes a bottom-up approach. Nanocrystalline materials produced by electrodeposition are its final form and do not require further secondary processing, unlike other production methods.

A basic electrodeposition setup consists of a cathode and an anode, both submerged in an aqueous solution containing metal ions, and connected by a power supply. Metal ions are reduced and deposited at the cathode while the anode dissolves and replenishes the aqueous solution as metal ions deposit onto the cathode. Electrocrystallization governs how metal ions are incorporated into a growing metal surface during the electrodeposition process. It occurs by two competing processes: i) by the build-up of existing crystals (i.e. growth); or ii) by the formation of new crystals (i.e. nucleation) (Bockris and Razumney 1967). The formation of nano-sized crystals is favoured in the nucleation controlled regime, and the rate determining steps are charge transfer at the electrode surface and surface diffusion of adions on the crystal surface (Choo et al. 1995). Nucleation can be promoted by varying the electrodeposition conditions (e.g. electrolyte chemistry, $\mathrm{pH}$, temperature, current density, agitation) to increase charge transfer or metal ion concentrations in the double layer. 


\subsection{STRUCTURE OF NANOCRYSTALLINE MATERIALS}

Palumbo et al. (1990) developed a model to describe the dependence of the volume fraction of the intercrystalline atoms (grain boundaries and triple junctions) on grain size. The model used a fourteen-sided tetrakaidecahedron to describe an equiaxed polycrystalline grain structure. The volume of grain boundaries and triple junctions (intersection of three grains) make up the total volume of the intercrystalline component. The relationship between the volume fraction of the intercrystalline component, $V_{t}^{i c}$, and the grain size, $\mathrm{d}$, is given by:

$$
V_{t}^{i c}=1-[(d-\Delta) / d]^{3}
$$

where $\Delta$ is the average grain boundary thickness.

The volume fraction of grain boundary the component, $V_{t}^{g b}$, is given by:

$$
V_{t}^{g b}=\left[3 \Delta(d-\Delta)^{2}\right] / d^{3}
$$

The volume fraction of the triple junctions, $V_{t}^{t l}$, is the difference between the volume fraction of the intercrystalline component and the volume fraction of the grain boundary component:

$$
V_{t}^{t l}=V_{t}^{i c}-V_{t}^{g b}
$$

Figure 2.2 illustrates the dependence of the volume fractions of the intercrystalline components on grain size, calculated for a grain boundary thickness of 1 nm. Polycrystalline materials (grain sizes $>1 \mu \mathrm{m}$ ) exhibit a very small intercrystalline volume fraction, less than $0.3 \%$. In comparison, nanocrystalline materials with a grain size less than $100 \mathrm{~nm}$ would exhibit an intercrystalline volume fraction of at least $3 \%$. The intercrystalline volume fraction increases rapidly for grain sizes less than $100 \mathrm{~nm}$ 
and reaches, for example, $87.5 \%$ at a grain size of $2 \mathrm{~nm}$. This very high intercrystalline volume is one of the reasons for the unique mechanical properties observed in nanocrystalline materials (Gleiter 1989, Suryanarayana 1995).

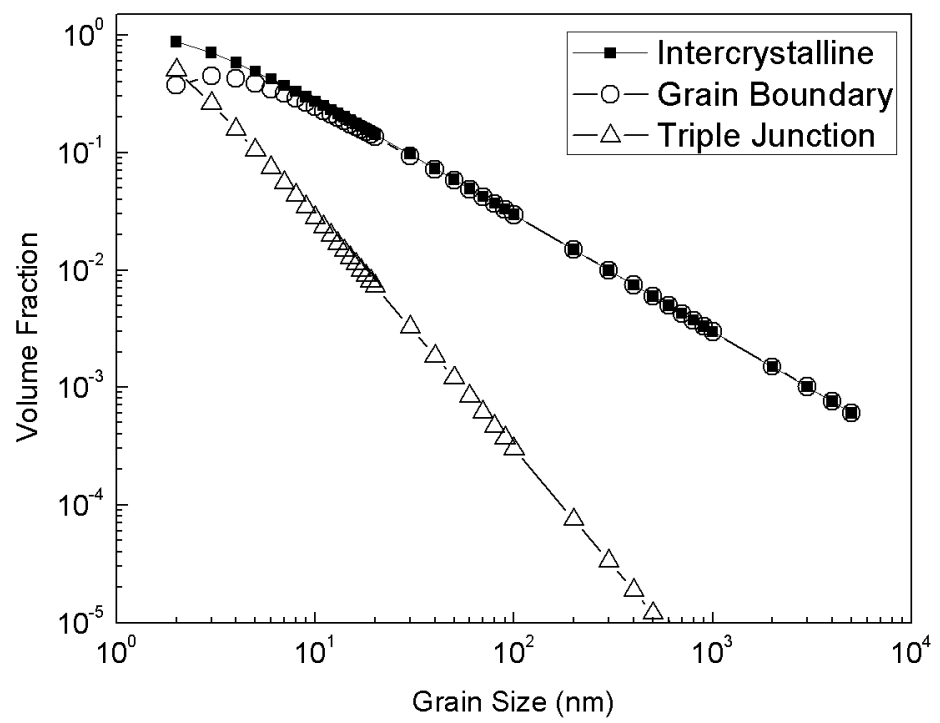

Figure 2.2 The effect of grain size on the calculated volume fractions of intercrystalline, grain boundary, and triple junction components, assuming a grain boundary thickness of $1 \mathrm{~nm}$ (after Palumbo et al. 1990).

\subsection{MECHANICAL PROPERTIES OF NANOCRYSTALLINE MATERIALS}

Nanocrystalline materials exhibit a fine microstructure and a high density of interfaces, resulting in different and often improved mechanical properties compared to conventional polycrystalline materials. Erb (1995) summarized the structure-mechanical property relationships for fully dense electrodeposited nanocrystalline metals, and also identified certain mechanical properties which have demonstrated a strong dependence on grain size. Wang et al. (1997) observed almost a twofold increase in strength as the grain size of electrodeposited nickel was reduced from 100 to $6 \mathrm{~nm}$; however, ductility was significantly reduced with grain size refinement. The hardness of electrodeposited nickel has also been shown to increase with decreasing grain sizes (El-Sherik et al. 1992). Furthermore, the abrasive wear resistance of electrodeposited nickel improved 
significantly as the grain size is reduced from polycrystalline to nanocrystalline (Jeong et al. 2001), which is consistent with the hardness behaviour (El-Sherik et al. 1992).

Strengthening (or hardening) with grain refinement of polycrystalline and ultrafine crystalline metals has been described by the classical Hall-Petch behaviour relationship (Hall 1951, Petch 1953, Ashby 1982). The enhanced resistance to plastic deformation with grain refinement is attributed to pile-ups of dislocations at obstacles such as grain boundaries. The volume of grain boundaries increases with grain refinement, resulting in greater dislocation motion impedance at the grain boundaries.

The Hall-Petch relationship (Hall 1951, Petch 1953) shows that strength (or hardness) increases with decreasing grain size according to the following relationship:

$$
\sigma=\sigma_{0}+k_{H} d^{n}
$$

where $\sigma$ is the $0.2 \%$ yield strength (or hardness), $\sigma_{0}$ is the lattice friction stress required to move individual dislocations (or hardness of a single crystal with grain size approaching infinity), $\mathrm{k}_{\mathrm{H}}$ is a constant (Hall-Petch intensity parameter), $\mathrm{d}$ is the average grain size, and $\mathrm{n}$ is the grain size exponent (generally -0.5 ).

An example of the classical Hall-Petch behaviour is observed in the iron electrodeposits produced by Kovloz et al. (1968). Figure 2.3 illustrates the effect of grain size on the microhardness of electrodeposited iron. In this study, the hardness of electrodeposited iron with grain sizes ranging from 1.4-16 $\mu \mathrm{m}$ was measured.

Although the Hall-Petch relationship was originally developed for polycrystalline metals, this dependence of strength/hardness on grain size has also been observed in nanocrystalline metals (El-Sherik et al. 1992, Jang and Koch 1990, Le Brun et al. 1992). However a reduction in hardness with decreasing grain size, referred to as the inverse Hall-Petch relationship, has been observd in nanocrystalline metals at very small grain 


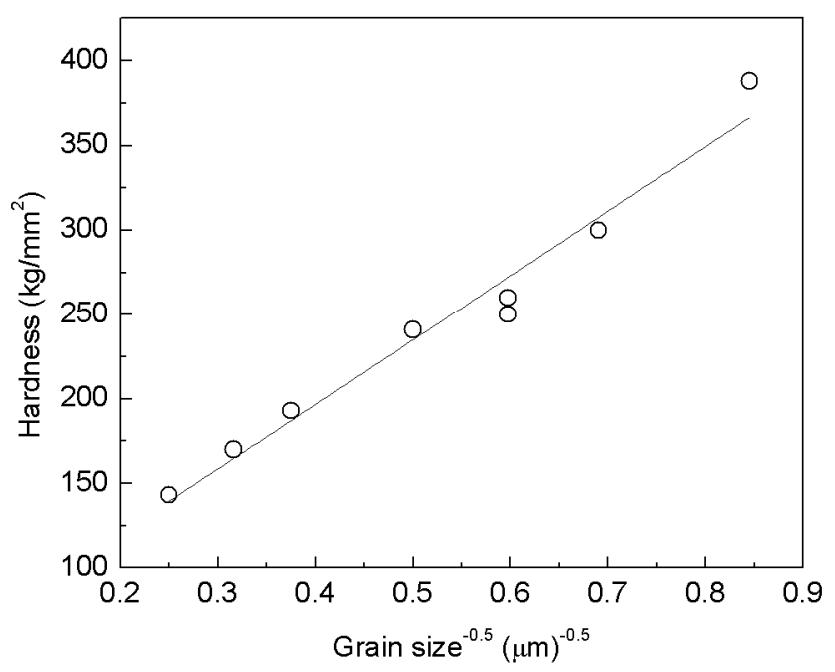

Figure 2.3 The dependence of microhardess on grain size for electrodeposited iron (after Kozlov et al. 1968).

sizes. The inverse Hall-Petch behaviour was originally observed by Chokshi et al. (1989) in nanocrystalline copper prepared by inert gas-condensation. In a review of the HallPetch and inverse Hall-Petch behaviours in nanocrystalline materials Suryanarayana (1995) observed: i) the strength of a material cannot exceed the theoretical strength limit; ii) relaxation that may occur at grain boundaries owing to the fine grain size may cause an inverse Hall-Petch relationship in which strength decreases with grain refinement; and iii) at very fine grain sizes (few nanometers) only a single dislocation may be accommodated in each grain, such that the Hall-Petch relationship may be invalid and other deformation mechanisms are responsible for any hardening and softening behaviours. 


\section{CHAPTER 3}

\section{MULTILAYERED MATERIALS}

Both graded and laminate materials exhibit striations or layers (Leseur et al. 1996). Graded materials are composed of layers that exhibit gradual structural or chemical compositional changes, resulting in diffuse interfaces. In contrast, laminate materials typically consist of two alternating materials and exhibit sharp interfaces (Leseur et al. 1996). Laminates are often produced via deposition or bonding methods. Deposition methods such as physical vapour deposition or electrodeposition can be used to produce ultrathin laminates, with alternate layer thicknesses between 0.0015-1 $\mu \mathrm{m}$ (Leseur et al. 1996). Thick laminates, with alternate layers between 50-1000 $\mu \mathrm{m}$, are often produced with bonding methods such as roll bonding (Leseur et al. 1996). The focus of this thesis is on ultrathin laminate metallic coatings produced via electrodeposition. Synthesis and properties of such electrodeposited multilayers will be discussed in the following sections.

\subsection{SYNTHESIS OF MULTILAYERED MATERIALS}

Electrodeposited multilayers can be produced by using either single-bath or dualbath techniques (Blum 1921, Ross 1994). Figure 3.1(a) shows a schematic diagram illustrating the single-bath technique for producing electrodeposited multilayers. In a single-bath technique, deposition is performed in a single electrolyte containing ions of the different constituents of the multilayer, and deposition parameters (e.g. deposition potential) are alternated to create layers. A schematic diagram illustrating the dual-bath technique is presented in Figure 3.1(b). In a dual-bath technique, constituents from two separate electrolytes are alternatively deposited by transferring the substrate between the separate electrolytes to build up layers. 
(a)

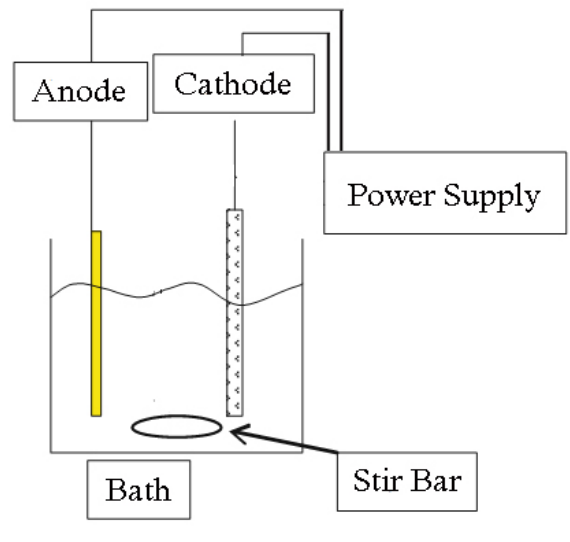

(b)

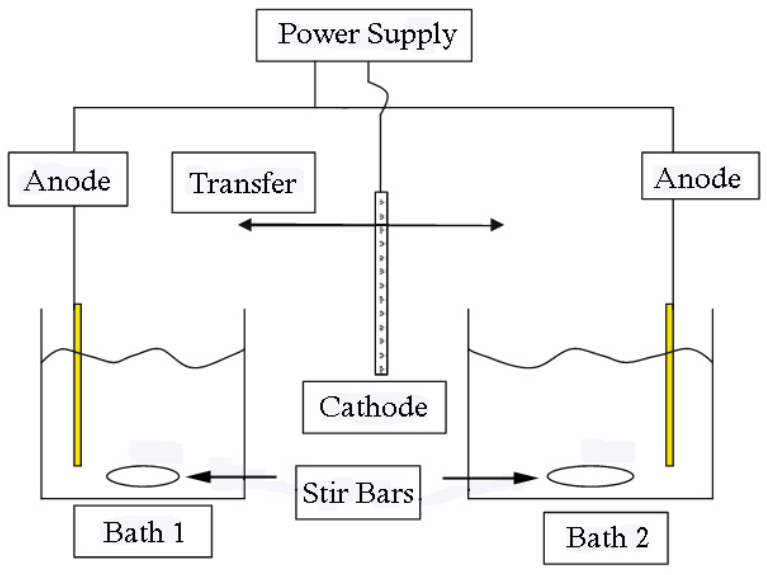

Figure 3.1 Typical apparatus used in (a) single-bath technique and (b) dual-bath technique for producing electrodeposited multilayers (modified from Roy 2009).

The single-bath technique is often preferred over the dual-bath technique because it requires a simpler setup. However single-bath techniques have a limited number of metal pairs and compositional ranges that can be deposited, arising from electrolyte compatibility issues (Ross 1994). Additionally, the electrode potential of the two alternating materials must be separated sufficiently (at least $0.1 \mathrm{~V}$ ) in order for pure layers to be electrodeposited (Ross 1994). Despite the limitations of the single-bath technique, it is often preferred owing to complications associated with the dual-bath technique: undesirable surface reactions occurring during substrate transfer; substrate cleaning to avoid mutual contamination of electrolytes; and potential displacement reactions (Ross 1994). 
With the single-bath technique, it is possible to deposit a multilayered coating by periodically varying the deposition parameters. Practically all electrodeposited multilayers are produced by modulating the current or potential, which may be combined with a change in the agitation conditions (Ross 1994). The layer thickness is controlled by current density, plating time, and current efficiency; however, the structure and composition of individual layers is controlled by current density, $\mathrm{pH}$, and/or temperature (Ross 1994). Multilayered coatings are typically electrodeposited to a thickness less than $200 \mu \mathrm{m}$, with alternating layers between 2-100 nm thick (Ross 1994).

Burgess and Watts (1906) studied layered iron electrodeposits produced from a single bath technique. The layered structure was created by introducing interruptions or significant changes during the deposition process. More specifically, iron electrodeposits composed of striations were produced whenever the current was interrupted or if the cathodes were removed for any period of time.

Spontaneous formation of layers or striations has been observed in nickel, gold, chromium, nickel-phosphorus, cobalt-phosphorus, nickel-cobalt, and copper-lead electrodeposits (Ross 1994). Even though the electrodeposition parameters are kept constant, composition or structural modulations originating from small periodic fluctuations in the metal or additive concentration, $\mathrm{pH}$, agitation or polarization at the cathode surface are often observed during the electrodeposition process (Ross 1994). Consequently, layers and striations form as a result of these spontaneous fluctuations. An example of a Ni-P electrodeposit exhibiting a layered structure is presented in Figure 3.2. The formation of layers in Ni-P electrodeposits have been attributed to variations in the phosphorus content. Alternate metal ion depletion and enrichment in the diffusion layer caused by hydrogen evolution variations occurs during the electrodeposition process (Nee and Weil 1985). This cyclic change in composition results in the formation of a layered structure corresponding to higher and lower concentrations of phosphorus (Nee and Weil 1985). 


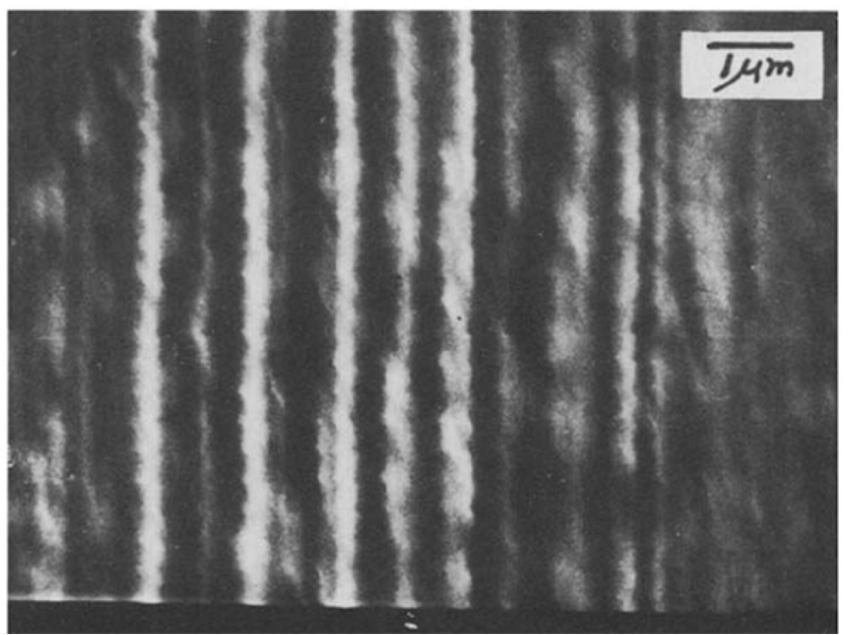

Figure 3.2 Scanning electron micrograph showing a layered structure in Ni-P electrodeposits (after Nee and Weil 1985).

\subsection{MICROSTRUCTURE OF MULTILAYERED MATERIALS}

Electrodeposited multilayers with thicker layers often have a polycrystalline microstructure and each layer consist of grains with a preferred orientation. The texture can be varied depending on the electrolyte composition and deposition conditions. By varying the texture and/or grain size, multilayers with structural moduluation can be produced. Copper/copper multilayers exhibiting grain size modulation have been produced by Blum (1921).

For electrodeposited multilayers with compositional modulation, layer planarity and uniformity are affected by the nucleation ability of one component on the other as well as the degree of preferred orientation (Ross 1994). For example, it has been observed that silver/palladium multilayers can still maintain layer planarity in spite of small disruptions (compared to diffusion layer thickness) in the electrodeposit, resulting from the incorporation of inclusions (Cohen 1983). However, larger disruptions may be amplified as growth is favoured in the surrounding areas of an inclusion site (Cohen 1983). Consequently, surface roughness increases as deposition continues and planarity may be lost. 


\subsection{MECHANICAL PROPERTIES OF MULTILAYERED MATERIALS}

The structure-mechanical property relationships in multilayered materials depend on the microstructural length scales of the multilayers (i.e. grain size, layer thickness). A schematic diagram illustrating the dependence of deformation mechanism on layer thickness is presented in Figure 3.3. The Hall-Petch relationship based on dislocation pile-ups is applicable at layer thicknesses greater than $\sim 50-100 \mathrm{~nm}$ (Wang and Misra 2011). A confined layer slip deformation mechanism, involving the propagation of a single dislocation loop parallel to the interface between two layers is applicable at layer thicknesses between 5-100 nm (Wang and Misra 2011). For layer thicknesses below 5 $\mathrm{nm}$, the deformation mechanism relies on single dislocations crossing the interface (Wang and Misra 2011).

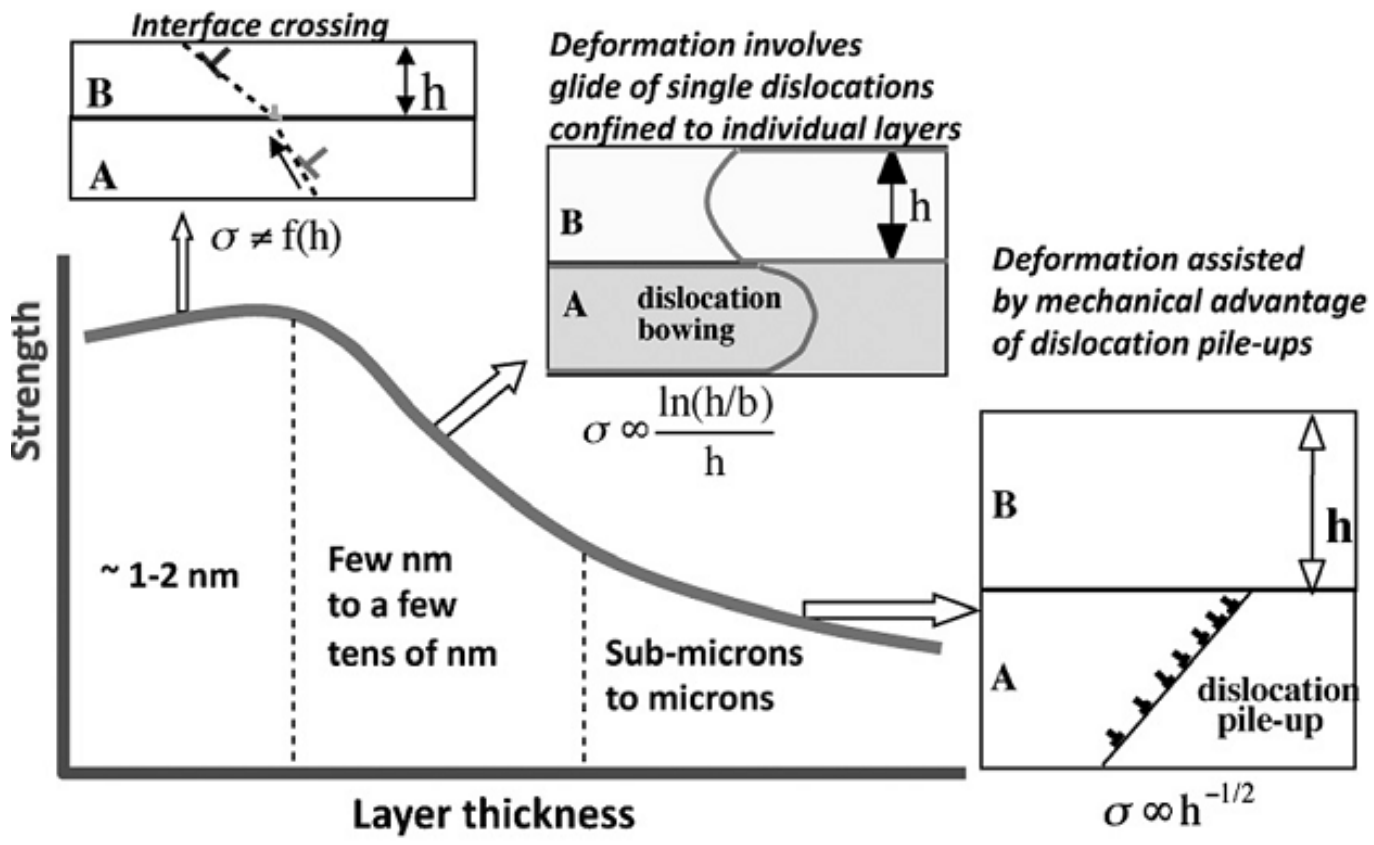

Figure 3.3 Deformation mechanisms observed in multilayered materials with different microstructural length scales (Wang and Misra 2011).

In a review of the mechanical properties of electrodeposited multilayers, Ross (1994) cited numerous studies which have shown an enhancement in the tensile strength of multilayers as the layer thickness decreases. Additionally, Menezes and Anderson (1990) have observed the tensile strength of electrodeposited copper/nickel multilayers 
with a repeat layer (nickel + copper layer) thickness of $20 \mathrm{~nm}$ to be 3 and 4.5 times greater than that for homogeneous nickel and copper electrodeposits, respectively. The enhanced tensile strength is attributed to the presence of interfaces and the finer microstructure of multilayered electrodeposits (Ross 1994). Interfaces provide barriers for dislocation glide (i.e. dislocation pinning) and a Hall-Petch type relationship is observed between strength and layer thickness (Ross 1994). Hardness values for copper multilayers exhibiting a Hall-Petch type behaviour are presented in Figure 3.4 (Misra et al. 2002). Hardness initially increases according to $H \propto h^{-1 / 2}$, where $\mathrm{H}$ is the hardness and $\mathrm{h}$ is the layer thickness. However, at lower $\mathrm{h}$ values a breakdown in this relationship is observed. The strength of metallic multilayers also exhibits the same behaviour (Misra 2001).

While electrodeposited multilayers exhibit improved tensile strength with decreasing layer thickness, they typically become less ductile as well. Wang and Singh (1999) reported that as the layer thickness of nickel/tin multilayers is reduced from 8.35 $\mu \mathrm{m}$ to $0.115 \mu \mathrm{m}$, the total strain at fracture decreased from $4.5 \%$ to $1.5 \%$. The mean glide distance for dislocations becomes shorter as the layer thickness is reduced. Consequently, plastic deformation becomes more difficult and the multilayers are observed to be less ductile (Wang and Singh 1999).

Yang et al. (1977) first reported an enhancement of the elastic modulus (i.e. "super modulus" effect) in electrodeposited multilayers, where the elastic modulus of the multilayer is several times that of its constituent layers. More than a twofold increase for $\mathrm{Au} / \mathrm{Ni}$ multilayers and a fourfold increase for $\mathrm{Cu} / \mathrm{Pd}$ multilayers was reported (Yang et al. 1977). However, past reports of a "super modulus" effect observed in electrodeposited multilayers are now regarded as artefacts resulting from errors associated with the measurement technique used (bulge testing) (Mann 2004, Cammarata et al. 1990, Davis et al. 1991). More recently, enhancements of the elastic modulus only up to $15 \%$ have been reported in metallic multilayers (Mann 2004). 
Ruff and Wang (1989) have shown that there is increase wear resistance to unlubricated sliding wear against steel in electrodeposited copper/nickel multilayers, compared to either monolithic copper or nickel electrodeposits. The increased wear resistance arises from interfaces acting as barriers to dislocation glide. Furthermore, Ruff and Wang (1989) reported the wear resistance of copper/nickel multilayers improved as the layer thickness was reduced from 100 to $10 \mathrm{~nm}$. The improvements were attributed to the increase in the required flow stress needed for plastic deformation due to an enhancement of image forces as the layer thickness becomes smaller.

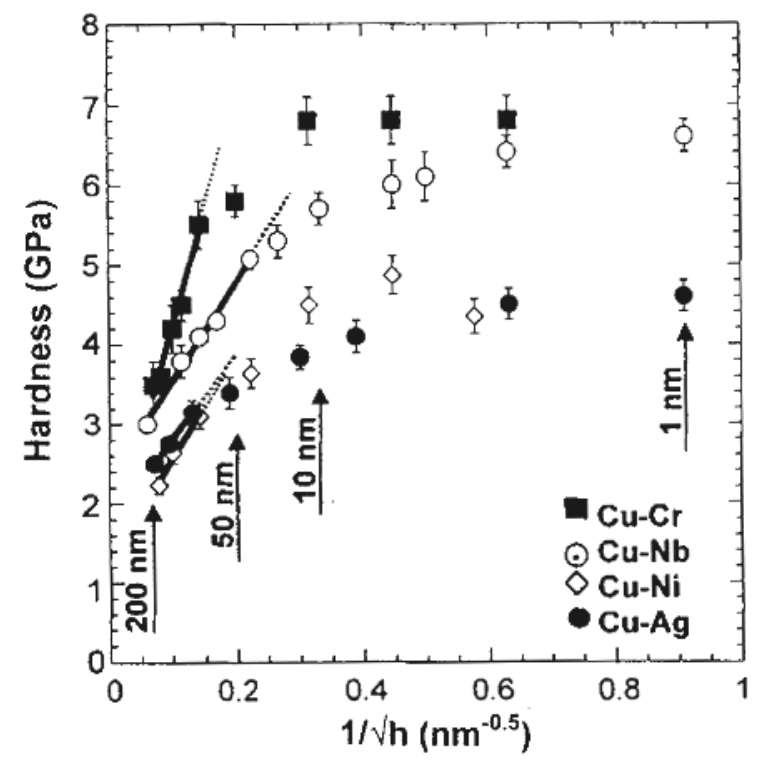

Figure 3.4 Graph showing hardness as a function of layer thickness (h) in various copper multilayers. A linear fit (-) of the Hall-Petch behaviour at larger h values. The model breaks down (---- ) at lower $h$ values (Misra et al. 2002). 


\section{CHAPTER 4}

\section{IRON ELECTRODEPOSITS}

Iron electrodeposition was first reported in 1846 (Bottger 1846). Since then commercial applications have been primarily limited to electroforming electrotypes and building up worn or undergauged parts (Safranek 1974). However iron is cheap and abundant compared to other plateable metals (i.e. nickel, copper). Therefore there has been continued interest in investigating the mechanical and physical properties of electrodeposited iron.

\subsection{SYNTHESIS OF IRON ELECTRODEPOSITS}

Traditionally, iron has been electrodeposited from some variations of ferrous sulphate/ferrous chloride baths. Sulphate baths operate at much lower temperatures and do not oxidize as readily as chloride baths (Hughes 1921). Iron electrodeposited from sulphate baths is typically hard and brittle, and is often used for building undersized machine parts (Thomas 1941). Chloride baths on the other hand can be made more concentrated, owing to the more soluble ferrous chloride salt, and higher current densities can be used (Hughes 1921).

It has been described by Bockris et al. (1961) that iron electrodeposition occurs with the following mechanisms:

Reaction at the anode

$$
\begin{aligned}
& \mathrm{Fe}+\mathrm{OH}^{-} \Leftrightarrow \mathrm{FeOH}+e_{o}^{-} \\
& \mathrm{FeOH} \stackrel{\text { R.D.S. }}{\longrightarrow} \mathrm{FeOH} H^{+}+e_{o}^{-} \\
& \mathrm{FeOH} H^{+} \Leftrightarrow \mathrm{Fe}^{2+}+\mathrm{OH}^{-}
\end{aligned}
$$


Reaction at the cathode

$$
\begin{gathered}
\mathrm{Fe}^{2+}+\mathrm{H}_{2} \mathrm{O} \Leftrightarrow \mathrm{FeOH}^{+}+\mathrm{H}^{+} \\
\mathrm{FeOH}{ }^{+}+e_{o}^{-} \stackrel{\text { R.D.S. }}{\longrightarrow} \mathrm{FeOH} \\
\mathrm{FeOH}+\mathrm{H}^{+}+e_{o}^{-} \Leftrightarrow \mathrm{Fe}+\mathrm{H}_{2} \mathrm{O}
\end{gathered}
$$

The mechanisms presented above indicate that hydroxide and hydrogen impurities can be incorporated into electrodeposited iron. Therefore it is expected that the structure and mechanical properties of electrodeposited iron will be influenced by these impurities.

Oxidation and precipitation are common bath control issues associated with iron electrolytes. Iron is electrodeposited from baths containing ferrous ions; however, ferric ions are always present as a consequence of the reaction between ferrous ions and oxygen in the air (Gadad and Harris 1998). Furthermore, ferric hydroxide precipitates at a $\mathrm{pH}$ $\sim 3.5$ while ferrous hydroxide precipitates at a $\mathrm{pH} \sim 6$ (Lowenheim 1974). Past investigations have reported on the use of organic and/or inorganic additives to buffer the cathode $\mathrm{pH}$ to prevent precipitation by forming a complex with ferrous ions (Watts and Li 1914, Gadad and Harris 1998). However, studies on the usage of addition agents suggest that the benefits are debatable. While addition agents may successfully function as buffering and complexing agents, they are also attributed to cause cracked, stressed or nodular iron electrodeposits (Watts and Li 1914).

The poor deposit quality likely results from the incorporation of addition agents into the deposits, suggesting additives may diminish rather than improve deposit quality. Furthermore, the effectiveness of addition agents is limited and co-deposition of precipitates is only partially prevented. Gadad and Harris (1998) reported that iron electrodeposits contain lower concentrations of oxygen with the usage of boric acid in 
iron electrolytes. However oxygen is still detected in the iron electrodeposits, indicating that the presence of hydroxides and the addition agents only had a limited effect.

In addition to the electrolyte chemistry affecting the properties of electrodeposited iron, current density, electrolyte temperature, electrolyte agitation, and deposit thickness have also been reported to influence the structure and properties (Hughes 1923). Typical iron electrodeposits show either coarse, columnar or fibrous structures, depending on the electrodeposition parameters applied (Safranek 1974).

\subsection{MICROSTRUCTURE OF IRON ELECTRODEPOSITS}

The structures of iron electrodeposits vary in terms of grain form and shape (Hughes 1921). The most commonly observed structures are columnar and fibrous. Columnar structures appear to be composed of $\mathrm{V}$-shaped grains while fibrous structures have fibre shaped (i.e. fibrous) grains (Hughes 1921). Figure 4.1 shows cross-sectional views of iron deposits exhibiting columnar and fibrous structures. Iron electrodeposited from simple iron baths (i.e. free of grain refiners) exhibit coarse, columnar structures when electrodeposited at low current densities, high solution temperatures, or with a stationary cathode; the opposite parameters generally result in electrodeposited iron exhibiting fibrous structures.

The structure of electrodeposited iron is affected by inclusions and impurities. Incorporated oxides, hydroxides, hydrogen, and carbon inclusions are commonly observed in electrodeposited iron (Hughes 1920). Oxides and hydroxides result from solution oxidation. As shown in Figure 4.2, the grain morphology changes to accommodate oxide and hydroxide inclusions (Hughes 1920, Levy and MacInnis 1968). As a result of oxide inclusions, the surrounding iron crystals bend inwards towards the inclusion. Hydrogen is produced at the cathode during electrodeposition. Levy and Macinnis (1968) observed more hydrogen ions are adsorbed onto the cathode surface of the iron electrodeposits with decreasing pH. Yoshimura et al. (1994) observed that the co-deposition of hydrogen into electrodeposited iron inhibit adatom diffusion on the surface and crystal growth, referred to as a "Pinning Effect". The formation of new 
nuclei is favoured instead, resulting in the formation of many small crystallites and deposits exhibiting fine crystal structures. As illustrated in Figure 4.3, iron electrodeposits exhibit smaller grain sizes when produced at lower $\mathrm{pH}$ (Levy and MacInnis 1968). Carbon inclusions found in electrodeposited iron originate from either a component of the electrolyte or the anodes used. Hughes (1920) reported that carbon inclusions in electrodeposited iron can exist as "free" carbon, carbides, or even combine with oxygen to form occluded gases (i.e. carbon monoxide or carbon dioxide). However, inclusions of carbon or carbon compounds were not observed to cause any structural effects; rather, they just reduced the overall purity of the deposits (Hughes 1920).

(a)

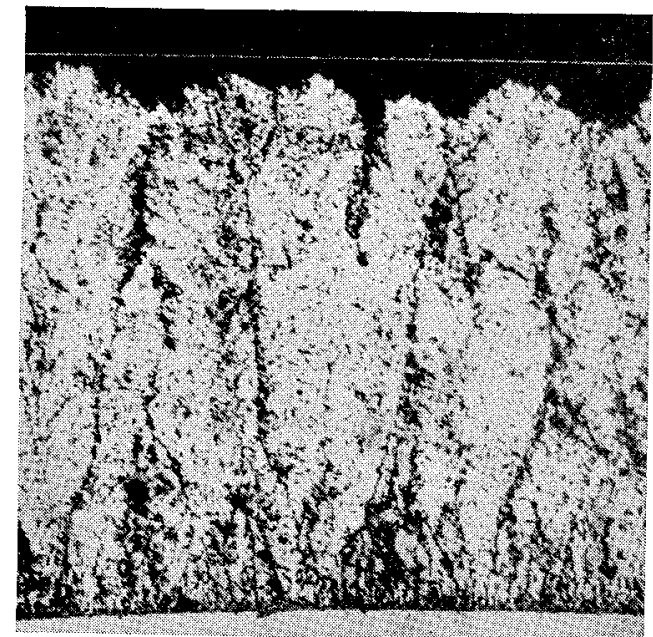

(b)



Figure 4.1 Cross-sectional view of electrodeposited iron showing (a) coarse, columnar structure (Cleaves and Thompson 1935), and (b) fibrous structure (Safranek 1974). 
(a)

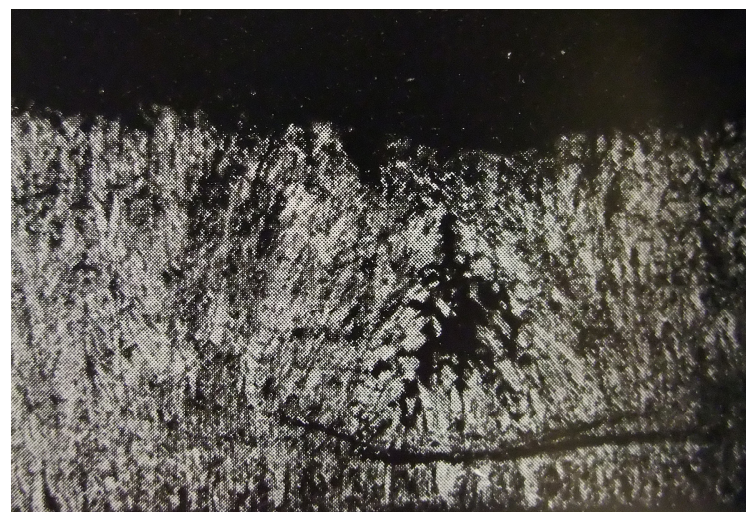

(b)

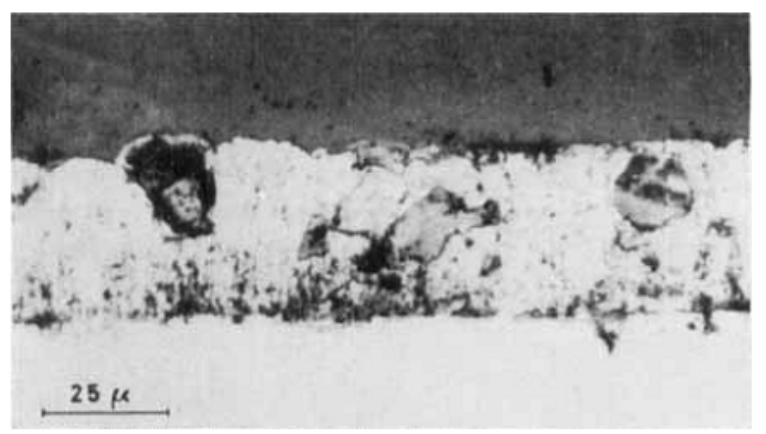

Figure 4.2 Cross-sections of iron electrodeposits showing (a) oxide inclusions causing the surrounding grains to bend inwards towards it (Hughes 1920), and (b) ferric hydroxide inclusions (Levy and MacInnis 1968).

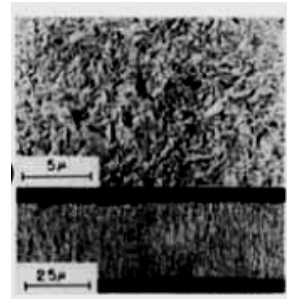

$3 \cdot 2$
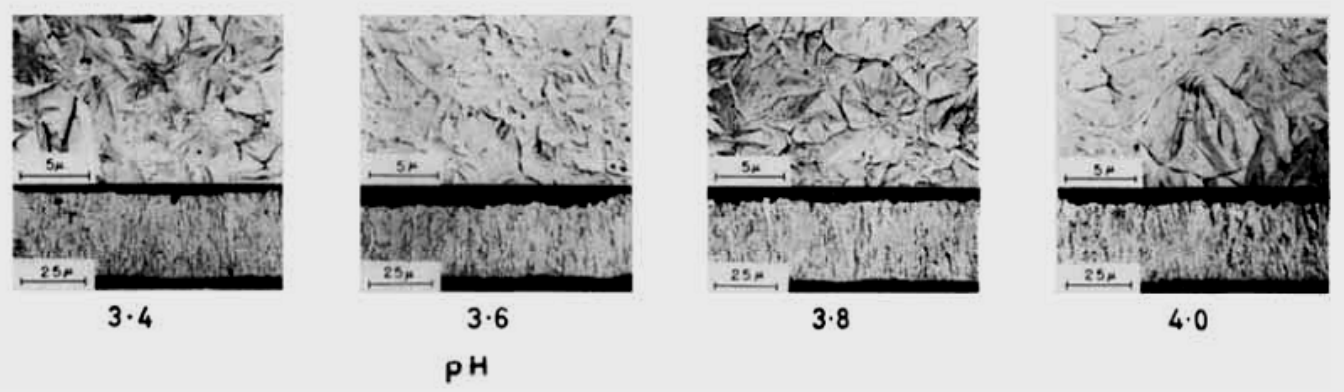

Figure 4.3 Cross-sectional electron and optical micrographs of iron electrodeposits showing structural changes with increasing bulk electrolyte $\mathrm{pH}$ (Levy and MacInnis 1968). 


\subsection{MECHANICAL PROPERTIES OF IRON ELECTRODEPOSITS}

In the past, the mechanical properties of electrodeposited iron have been described in a relative sense and separated into two categories: soft and hard iron. Electrodeposited iron with coarse-grained structures are referred to as soft iron, and exhibit hardness values between $120-180 \mathrm{~kg} / \mathrm{mm}^{2}$ and tensile strengths less than 56 $\mathrm{kg} / \mathrm{mm}^{2}$ (Safranek 1974). On the other hand, electrodeposited iron with fine-grained structures are referred to as hard iron, and exhibit hardness values between 400-1100 $\mathrm{kg} / \mathrm{mm}^{2}$ and tensile strengths up to $109 \mathrm{~kg} / \mathrm{mm}^{2}$ (Safranek 1974). Soft iron electrodeposits are typically ductile and can exhibit up to 50 percent elongation to fracture; in comparison, hard iron electrodeposits are typically brittle and exhibit very little or no ductility (Safranek 1974).

Inclusions not only affect the microstructure of iron electrodeposits they also influence the mechanical properties. Hard iron electrodeposits generally contain iron oxide or hydroxide inclusions, which are in part responsible for the hardening effect (Safranek 1974). Additionally, adsorbed hydrogen has been reported in numerous studies to cause hydrogen embrittlement of electrodeposited iron, resulting in lower ultimate tensile strengths and smaller percentage elongations to fracture (Levy and MacInnis 1968, Lowenheim 1974, Safranek 1974, Schaffert and Gonser 1943).

The mechanical properties of electrodeposits are dependent on both the microstructure and the internal stress within grains (Gow et al. 1979). Internal stress is a form of macrostress (i.e. tensile or compressive) which may develop during electrodeposition (Weil 1989). There are two main causes of internal stress: i) defects, such as impurity atoms and dislocations, which can incorporate into the crystals during growth and cause volume expansion or shrinkage of the deposit; and ii) misorientation between adjacent grains resulting in poor fit (Gow et al. 1979, Weil 1989). Various electrodeposition parameters such as temperature, $\mathrm{pH}$, current density, and electrolyte chemistry can contribute to the magnitude of internal stress that develops during electrodeposition (Gow et al. 1979). It has been observed by Gow et al. (1979) that electrodeposited iron produced with increasing current densities exhibit higher 
microstructural defect concentrations, resulting in higher internal stresses. Furthermore, stress and hardness increase proportionally in electrodeposited iron. Internal stress increases with increasing current density or with decreasing solution temperature (Safranek 1974). In the absence of a stress-relieving compound, electrodeposited iron can exhibit internal stress from $12-80 \mathrm{~kg} / \mathrm{mm}^{2}$ (Safranek 1974). Lower internal stress values have been attributed to stress relief via cracking in the electrodeposits (Safranek 1974). 


\subsection{STATEMENT OF RESEARCH OBJECTIVES}

Past studies of iron electrodeposition have focused on controlling the microstructure via the electrodeposition conditions (electrolyte chemistry, current density, $\mathrm{pH}$, or temperature). This has led to the production of iron with either columnar or fibrous structures. Consequently, electrodeposited iron are either soft and possess low strength but good ductility, or hard and possess high strength but poor ductility. It is an objective of this thesis to attempt to develop electrodeposited iron that exhibit a combination of high strength and high ductility. The strategy for tailoring the mechanical properties will be to use a multilayered structure design; whereby, the electrodeposited iron samples are composed of alternating layers of hard and soft iron. A schematic diagram illustrating such a multilayered structure is presented in Figure 4.4. It is speculated that a multilayer strategy may be successful for designing tough iron electrodeposits owing to a rule-of-mixtures principal in which hard iron layers will provide strength and soft iron layers will provide ductility.

Multilayered electrodeposits provide an excellent opportunity to study structuremechanical property relationships, simply by varying the layer thickness. The size effects (i.e. layer thickness) on the mechanical properties of electrodeposited iron will therefore be examined in this study. Furthermore past investigations of multilayered electrodeposits have reported improvements in strength and hardness over the bulk constituents. It will be of interest to investigate whether this enhancement will also apply to multilayered electrodeposited iron.

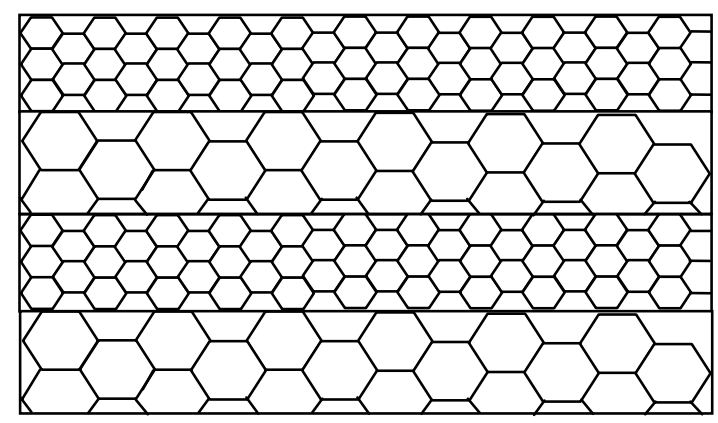

Figure 4.4 A multilayered structure design composed of alternating layers with different grain sizes (Erb 2006). 


\section{CHAPTER 5}

\section{MATERIALS AND EXPERIMENTAL METHODS}

As described in the literature review, electrodeposited iron can be categorized by their mechanical properties as: soft and hard iron. Monolithic soft and hard iron electrodeposits, as well as multilayered iron electrodeposits composed of alternating layers of soft and hard iron were investigated in the current study. This chapter will discuss the synthesis of monolithic and multilayered iron electrodeposits, and the characterization methods used to analyze the microstructure and mechanical properties.

\subsection{MATERIALS SYNTHESIS}

The iron electrodeposits used in this study were electrodeposited from an ironsulphate electrolyte supplied by Integran Technologies Inc. A schematic diagram illustrating the apparatus used in the electrodeposition process is presented in Figure 5.1. Electrolytic iron was used as the anode material. Iron was electrodeposited to a thickness of $\sim 80-100 \mu \mathrm{m}$ onto mild steel, titanium, and polyamide cathodes. Cathodes were selected based on their suitability for different characterization methods. For example, iron coatings that were electrodeposited onto the titanium cathode were subsequently mechanically stripped to produce free-standing electrodeposits for chemical analysis.

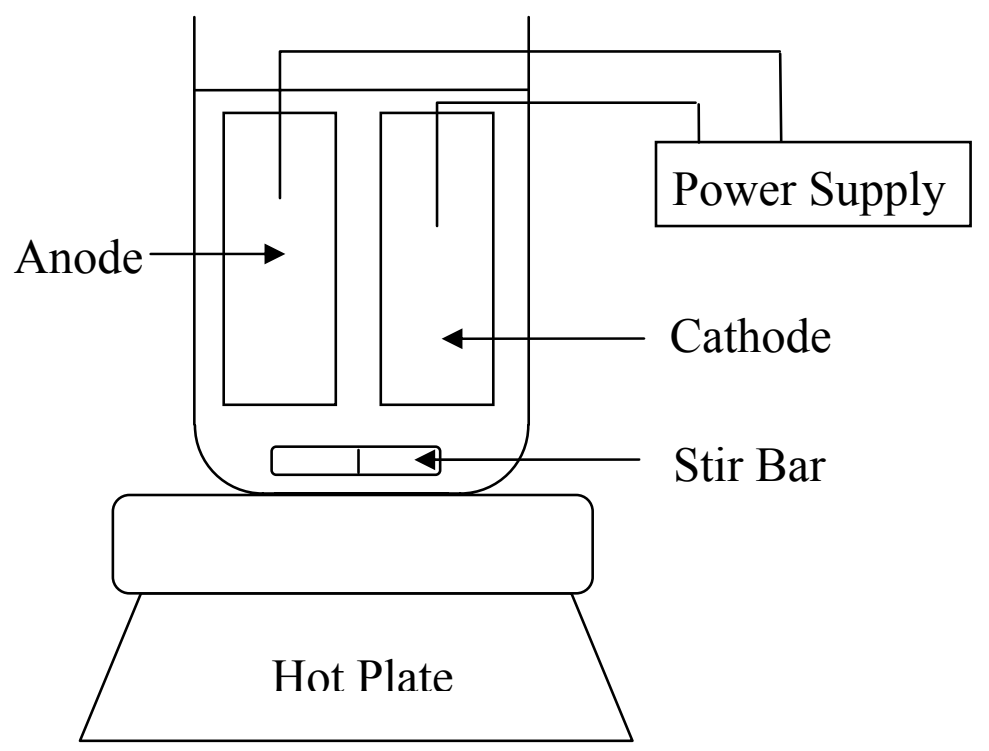

Figure 5.1 Schematic diagram showing the typical electrodeposition apparatus used. 
In the past, soft iron and hard iron electrodeposits have been produced using pulse current (Safranek 1957, Puippe and Leaman 1986) and direct current (Stoddard Jr. 1947), respectively. Modern pulse-plating equipment allows for a large variety of square-wave pulsed current modulations, some of which are shown in Figure 5.2.

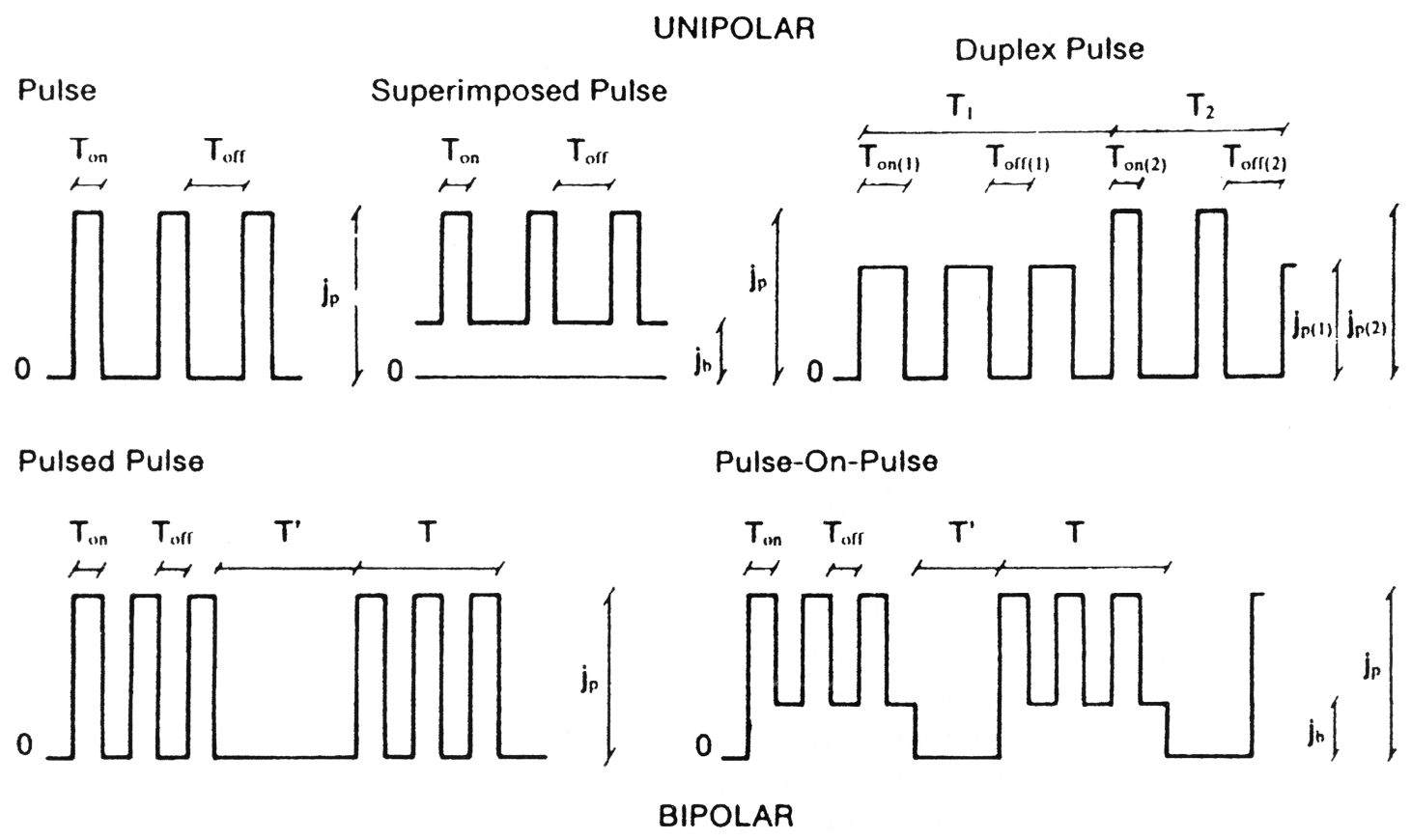

Pulse Reverse

Pulse Reverse (with off-time)

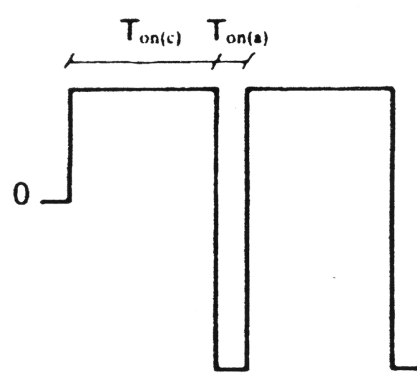

Pulsed Pulse Reverse

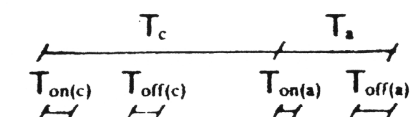

$T_{\text {on(c) }} T_{\text {on(a) }} \quad T_{\text {orf(c) }} T_{\text {off(a) }}$

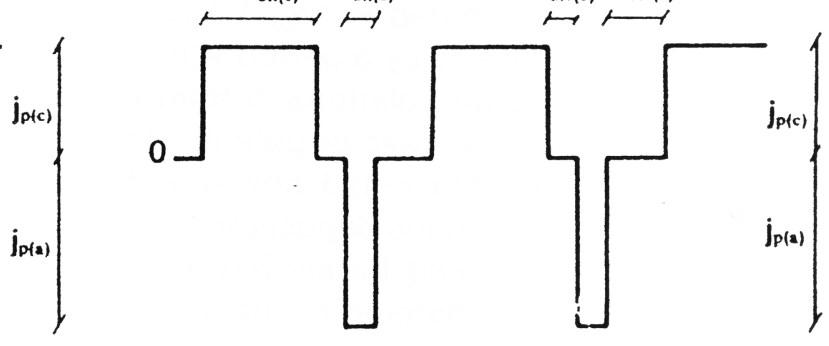

Pulse-On-Pulse Reverse
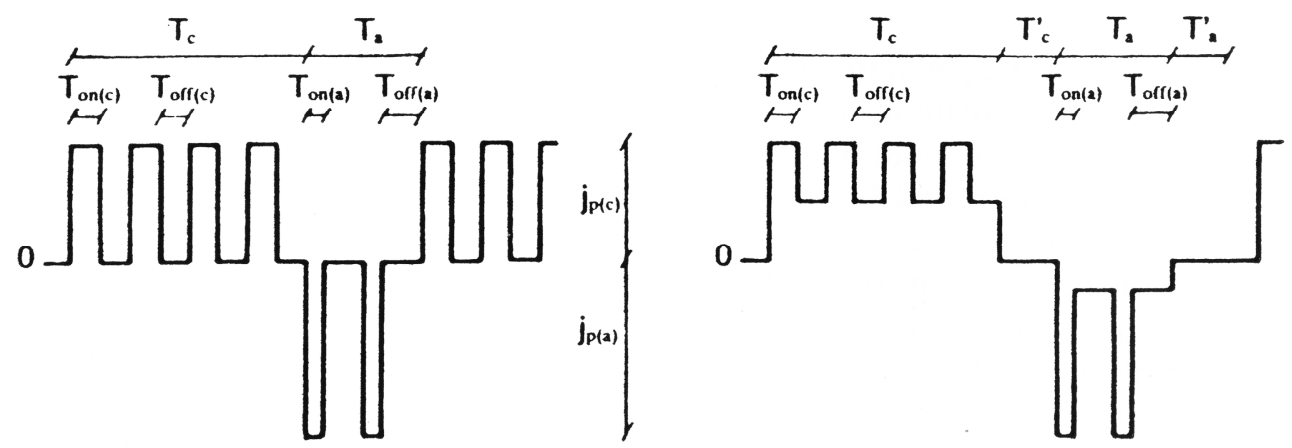

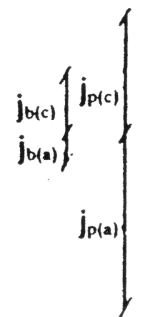

Figure 5.2 Schematic diagrams illustrating a variety of square-wave pulsed current modulations (Puippe and Leaman 1986). 
In this study, monolithic soft and hard iron as well as multilayered iron was produced by proprietary pulse waveforms developed by Integran Technologies Inc. A schematic diagram illustrating the layer arrangements in multilayered iron is presented in Figure 5.3. The alternating layers were created via computer-controlled variations of the current density and time during the deposition process. Two types of monolithic iron and five types of multilayered iron were synthesized by varying the electrodeposition conditions. The electrodeposition parameters (i.e. current density, duty cycle, frequency, etc.) were selected in an attempt to produce multilayered iron composed of equal volumes/thicknesses of soft and hard iron (i.e. $\mathrm{t}_{\text {Soft }}=\mathrm{t}_{\text {Hard }}$ ), and with the nominal layer thicknesses presented in Table 5.1. Exact conditions selected cannot be disclosed as Integran's proprietary process was used to produce the iron electrodeposits.
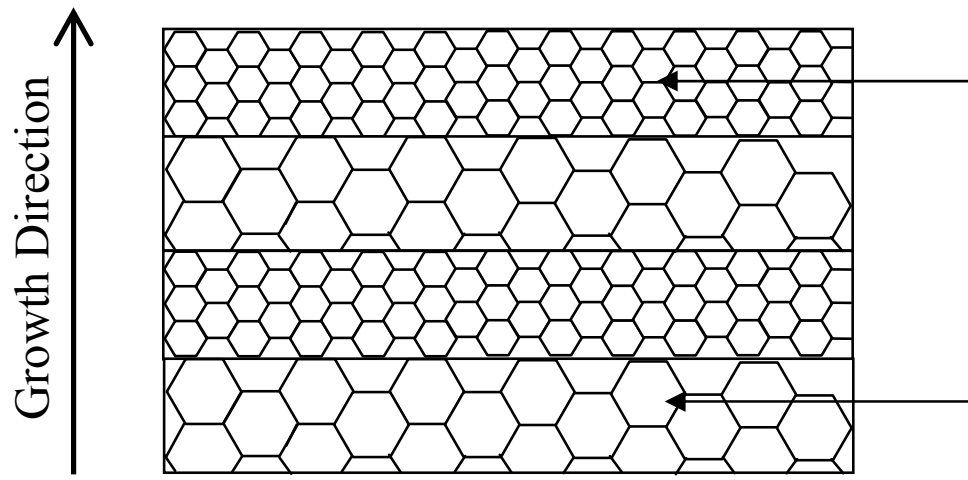

Hard Iron Layer $\left(\mathrm{t}_{\text {Hard }}\right)$

Soft Iron Layer $\left(t_{\text {Soft }}\right)$

Figure 5.3 Schematic diagram showing the cross-section of a multilayered electrodeposit composed of alternating layers of soft and hard iron. $t_{\text {Soft }}$ and $t_{\text {Hard }}$ represent the thicknesses of the soft and hard iron layers, respectively (modified from Erb 2006).

Table 5.1 Monolithic and multilayered iron electrodeposits produced with different electrodeposition conditions. Nominal thickness corresponds to total electrodeposit thickness and thickness of a single layer for monolithic and multilayered iron electrodeposits, respectively.

\begin{tabular}{|ccc|c|c|c|c|}
\hline Electrodeposition Condition & Type of Electrodeposit & $\begin{array}{c}\text { Nominal Layer } \\
\text { Thickness }(\mu \mathrm{m})\end{array}$
\end{tabular}

\begin{tabular}{|lcc|}
\hline 1 & monolithic soft iron & 100 \\
2 & monolithic hard iron & 100 \\
3 & multilayered iron & 10 \\
4 & multilayered iron & 1.0 \\
5 & multilayered iron & 0.50 \\
6 & multilayered iron & 0.25 \\
7 & multilayered iron & 0.10 \\
\hline
\end{tabular}

assuming 100\% current efficiency 


\subsection{MATERIAL CHARACTERIZATION}

The iron electrodeposits produced in this study were characterized in terms of composition, overall morphology, grain size, crystallographic texture, microhardness, and flexural mechanical properties. The specific techniques use to evaluate these microstructural features and mechanical properties are presented in the following sections.

\subsubsection{Infrared absorption analysis}

Carbon and sulphur are typical impurities found in electrodeposited iron (Hughes 1920). Concentrations of carbon and sulphur impurities were determined via infrared absorption analysis using a LECO CS244 system. Carbon and sulphur in the iron samples are oxidized to form carbon dioxide $\left(\mathrm{CO}_{2}\right)$ and sulphur dioxide $\left(\mathrm{SO}_{2}\right)$, respectively. The $\mathrm{CO}_{2}$ and $\mathrm{SO}_{2}$ produced are subsequently measured by infrared detectors. Free-standing iron electrodeposits weighing $\sim 1 \mathrm{~g}$ each were analyzed.

\subsubsection{Energy dispersive spectroscopy (EDS) and wavelength dispersive spectroscopy (WDS)}

The compositions of the iron electrodeposits were analyzed using a Hitachi SU6600 analytical field emission scanning electron microscope (FE-SEM) equipped with energy dispersive spectroscopy (EDS) and wavelength dispersive spectroscopy (WDS). The EDS and WDS systems were Oxford X-Max 80 and INCA Wave, respectively.

\subsubsection{Scanning electron microscopy}

The overall grain structure and morphology of the iron electrodeposits produced were examined via scanning electron microscopy. Backscattered SEM images showing grain-orientation contrast were obtained with a Hitachi SU6600 analytical field emission scanning electron microscope (FE-SEM) operating at $5 \mathrm{kV}$. For this analysis, crosssectional iron samples electrodeposited onto mild steel and titanium cathodes were used. SEM samples were ground flat and polished to produce a mirror-like finish, and subsequently ion milled using a Hitachi IM-3000 flat ion milling system at $6 \mathrm{kV}$ and $80^{\circ}$ tilt angle for 40 minutes. 


\subsubsection{Transmission electron microscopy}

Analytical transmission electron microscopy and TEM sample preparation were conducted at the University of Tokyo. A JEOL 2010F field emission transmission electron microscope (FE-TEM) operating at $200 \mathrm{kV}$ was used to obtain bright field, dark field, and selected area diffraction patterns for microstructural characterization.

\subsubsection{Plan-view analysis}

The structure of monolithic iron electrodeposits was analyzed on plan-view TEM samples. Plan-view samples were first mechanically thinned to $\sim 50 \mu \mathrm{m}$ and mounted onto a $3 \mathrm{~mm}$ stainless steel TEM grid with $\sim 1.2 \mathrm{~mm}$ centre hole diameter. The central area of the sample was then thinned to $\sim 20 \mu \mathrm{m}$ with a Gatan $656 \mathrm{~N}$ Dimple Grinder. The dimpled sample was subsequently perforated via dual-beam thinning with a Gatan 691 Precision Ion Polishing System (PIPS) operating with argon ions at an accelerating voltage of $3.5-4 \mathrm{kV}$, and a glancing angle of $5-8^{\circ}$. The grain size of the deposit was measured directly from dark field TEM micrographs.

\subsubsection{Cross-sectional analysis}

The structures of multilayered iron electrodeposits were analyzed on crosssectional TEM samples. Cross-sectional samples were prepared using an ion milling method as well as a focused ion beam (FIB) method. For the ion milling method, two electrodeposited iron samples were sandwiched together using Gatan G-2 epoxy hardener. After epoxy curing, thin slices of the sandwiched sample were cut using a diamond cutter and mechanically thinned to $\sim 50 \mu \mathrm{m}$. Samples were subsequently thinned and perforated as described in section 5.2.4.1.

A Hitachi FB-2100 Focused Ion Beam (FIB) System with a focused gallium beam was used to prepare cross-sectional TEM specimens. A bulk sample $\left(\sim 1 \mathrm{~cm}^{2}\right)$ was inserted into the SEM and an area of interest was identified and coated with a protective layer of tungsten. Subsequently, trenches were created around the area of interest using a $40 \mathrm{kV}$ gallium beam. A FIB micromanipulator is then attached to the sample, allowing 
the final edges to be cut to produce a $15 \mu \mathrm{m}$ wide $\mathrm{x} 5 \mu \mathrm{m}$ high $\mathrm{x} 20 \mu \mathrm{m}$ long sample. The micromanipulator lifts out the cut sample from the bulk and positions it onto a copper carrier TEM mesh. Once on the TEM mesh, the cross-sectional sample is thinned to form a stepped-bar with the thinnest section $\sim 100 \mathrm{~nm}$, as shown Figure 5.4.

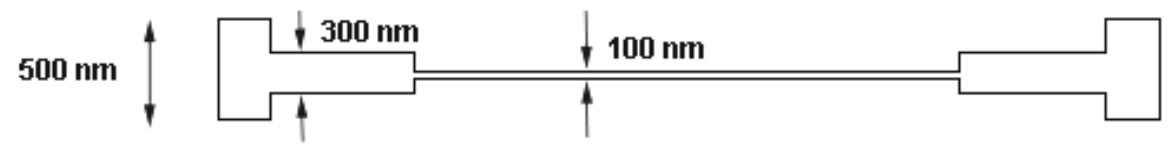

Figure 5.4 Cross-sectional view of a FIBbed sample showing varying (stepped) coating thicknesses for better sample handling.

\subsubsection{X-ray diffraction}

The crystallographic textures of the as-deposited iron electrodeposits were determined from X-Ray Diffraction (XRD) patterns collected with a Rigaku Miniflex $\theta$ $2 \theta$ X-ray diffractometer using Co- $\mathrm{K}_{\alpha}$ radiation $(\lambda=0.179 \mathrm{~nm})$ over a $2 \theta$ range of $0^{\circ}$ to $140^{\circ}$.

\subsection{MECHANICAL TESTING}

\subsubsection{Vickers microhardness tests}

Microhardness measurements of iron samples electrodeposited onto mild steel substrates were performed using a Buehler Microhardness Tester. The microhardness measurements were conducted according to ASTM E 38 - 99, Standard Test Method for Microindentation Hardness of Materials [2000]. Five planar hardness measurements were taken for each sample and the average value was determined. The applied load was $1000 \mathrm{~g}$ and the dwell time of the Vickers indenter was 15 seconds. Hardness measurements were conducted to ensure the penetration depth was sufficient to measure the influence of layer thickness on hardness, while maintaining negligible substrate effects. 
The average penetration depth $(\delta)$ was estimated from (Matsuda and Kaneta 1996):

$$
\delta=d /\left[\left(2^{3 / 2}\right) \tan \left(136^{\circ} / 2\right)\right]
$$

where $d$ is the diagonal length of an indentation and $136^{\circ}$ is the face angle of the diamond indenter.

\subsubsection{Three-point bending tests}

There is currently considerable interest in developing light weight composites that combine the strength of metallic coatings and the design flexibility of polymers for potential applications in automotive and aerospace components as well as in consumer goods. To investigate the potential of iron electrodeposits as a coating for such composite materials, approximately $100 \mu \mathrm{m}$ of iron was electrodeposited onto polyamide (PA) substrates. The polyamide substrates were provided by Integran Technologies Inc. and were previously made conductive by a proprietary metal spray process. The flexural properties of the iron composites were measured via a three-point bending test on an Instron 3365 Dual Column Tabletop Universal Testing System. The three-point bending tests were carried out according to ASTM D 790-07, Standard Test Methods for Flexural Properties of Unreinforced and Reinforced Plastics and Electrical Insulating Materials [Metric] [2007]. A schematic diagram of the dog-bone shaped samples used for flexural testing is shown in Figure 5.5. It should be noted that the geometry requirements specified by the ASTM standard is a rectangular bar with at least a 16:1 span-to-depth ratio, conditions that are satisfied by the dog-bone shaped specimen used. Samples were tested at room temperature using a $5 \mathrm{kN}$ load cell, $10 \mathrm{~mm}$ loading pin diameter, and a cross-head speed of $1.7 \mathrm{~mm} / \mathrm{min}$.

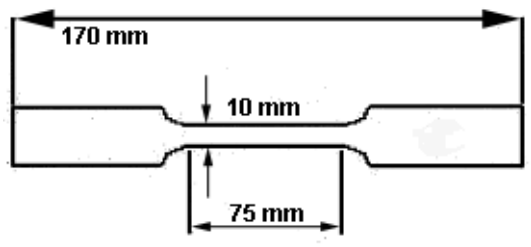

Figure 5.5 Schematic diagram of dog-bone sample used in three-point bending tests. 


\subsubsection{Fractography}

Scanning electron microscopy was performed to examine the fractured surfaces of the iron/PA composites. Secondary SEM images were obtained with a Hitachi SU6600 FE-SEM operating at $10 \mathrm{kV}$. 


\section{CHAPTER 6}

\section{RESULTS AND DISCUSSION}

As discussed in Chapter 5.1, iron was electrodeposited onto a variety of cathodes. Typical iron electrodeposits produced in the current study are presented in Figure 6.1

(a)

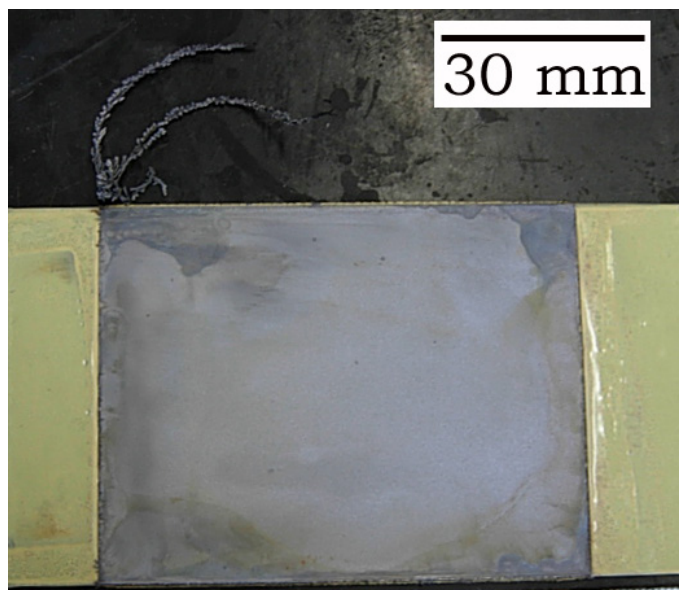

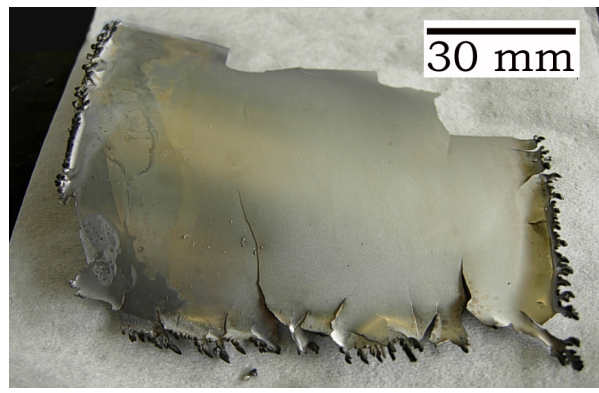

(b)

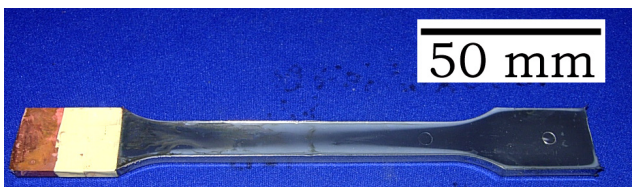

(c)

Figure 6.1 Photographs of typical iron samples electrodeposited onto different cathodes (a) steel, (b) titanium (producing free-standing iron samples), and (c) polyamide.

\subsection{CHEMICAL ANALYSIS OF IRON ELECTRODEPOSITS}

Infrared absorption analysis was performed on selected free-standing iron electrodeposits which were produced by the conditions presented in Table 5.1. The carbon and sulphur impurity concentrations in monolithic soft and hard iron and multilayered iron are presented in Table 6.1 and in Table 6.2, respectively.

Table 6.1 Carbon and sulphur impurities measured in monolithic iron electrodeposits.

\begin{tabular}{|ccc|}
\hline Sample & Carbon $(\mathbf{p p m})$ & Sulphur $(\mathbf{p p m})$ \\
\hline soft iron & 471 & 207 \\
hard iron & 800 & 499 \\
\hline
\end{tabular}


Table 6.2 Carbon and sulphur impurities measured in multilayered iron electrodeposits.

\begin{tabular}{|ccc|}
\hline Sample & Carbon (ppm) & Sulphur (ppm) \\
\hline $10 \mu$ m layers & 486 & 326 \\
$0.50 \mu$ m layers & 848 & 291 \\
\hline
\end{tabular}

Soft iron electrodeposits contain significantly lower concentrations of carbon and sulphur than hard iron electrodeposits. On the other hand, layered iron electrodeposits contain intermediate concentrations of impurities; however, there appears to be no correlation between the concentration of carbon and sulphur impurities and the layer thickness. Kuriki et al. (1971) showed that the concentration of sulphur impurities in electrodeposited iron is diffusion controlled and electrodeposition parameters that increase the diffusion rate of sulphur will promote sulphur incorporation into iron electrodeposits. Therefore impurity concentrations differences observed in the iron electrodeposits produced in this study likely result from the different electrodeposition parameters used (Table 5.1). Common impurity sources in iron electrodeposition include the anodes or constituents of the electrolyte used, e.g. organic additives (Hughes 1920). It is believed that the impurities found in the iron electrodeposits produced in the current study originate from the organic additives used in the electrolyte because high purity electrolytic iron was used as anode. Table 6.3 shows the chemical analysis of the electrolytic iron anodes used.

Energy dispersive spectroscopy (EDS) measurements were performed to obtain further information on the chemical composition of the coatings. An EDS spectrum of a typical hard iron sample is presented in Figure 6.2, showing predominantly iron peaks. A small oxygen peak at $0.53 \mathrm{keV}$ is also observed in this figure. To resolve the oxygen peaks observed, wavelength dispersive spectroscopy (WDS) measurements were conducted. The analysis showed there is approximately half the amount of oxygen in soft iron electrodeposits compared to hard iron electrodeposits. Kasper (1937) reported on the structure-mechanical properties of iron electrodeposits and observed that soft iron electrodeposits contained less oxygen, and were larger-grained than hard iron electrodeposits. It is believed the different oxygen concentrations observed here will 
have a similar influence on the microstructures and properties of the soft and hard iron electrodeposits produced here.

Hughes (1920) studied the effects of inclusions (oxides, iron hydroxides, carbon, etc.) on the structure of electrodeposited iron. He reported that inclusions can considerably alter the structure by impeding deposit growth and may also increase the brittleness of deposits. A detailed discussion on the influence of inclusions on the structure and resulting mechanical properties of electrodeposited iron will be given in Chapters 6.2 and 6.3 .

Table 6.3 Chemical analysis of electrolytic iron (i.e. anode material).

\begin{tabular}{|cc|}
\hline Element & Concentration (ppm) \\
\hline $\mathrm{C}$ & 7 \\
$\mathrm{Si}$ & 27 \\
$\mathrm{Mn}$ & 5 \\
$\mathrm{P}$ & 4 \\
$\mathrm{~S}$ & 27 \\
$\mathrm{Ni}$ & 26 \\
$\mathrm{Cu}$ & 11 \\
$\mathrm{~N}$ & 11 \\
$\mathrm{Fe}$ & Balance \\
\hline
\end{tabular}

Allied Metals Corporation. Certificate of Analysis. (2009)

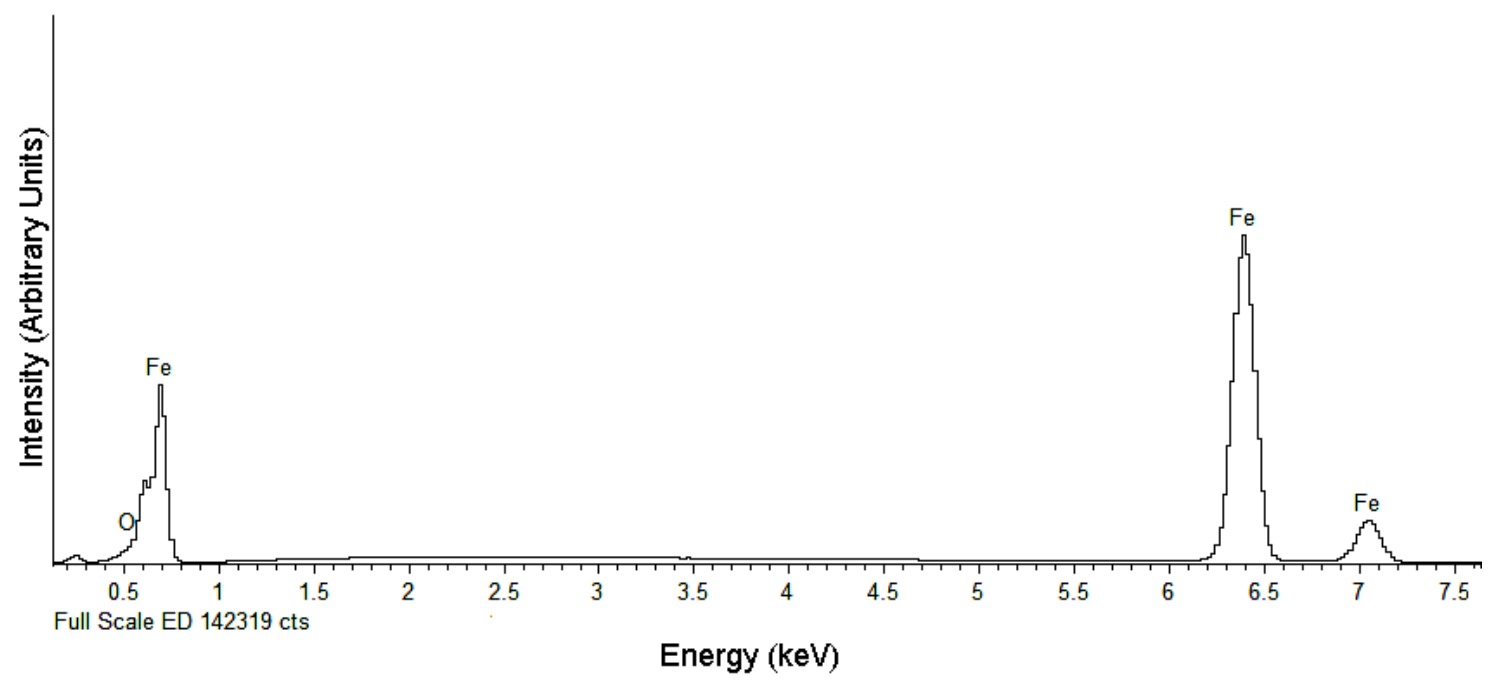

Figure 6.2 EDS spectrum of a typical hard iron electrodeposit. 


\subsection{MICROSTRUCTURAL CHARACTERIZATION OF IRON}

\section{ELECTRODEPOSITS}

\subsubsection{SEM analysis of soft and hard iron electrodeposits}

The microstructures of monolithic iron electrodeposits were assessed in the SEM. Backscattered SEM micrographs, obtained using grain orientation contrast, are presented in Figure 6.3(a) and (b). From these cross-sectional micrographs, it can be observed that soft iron electrodeposits exhibit a coarse, columnar structure. In comparison, hard iron electrodeposits exhibit a fine-grained microstructure throughout the entire cross-section.
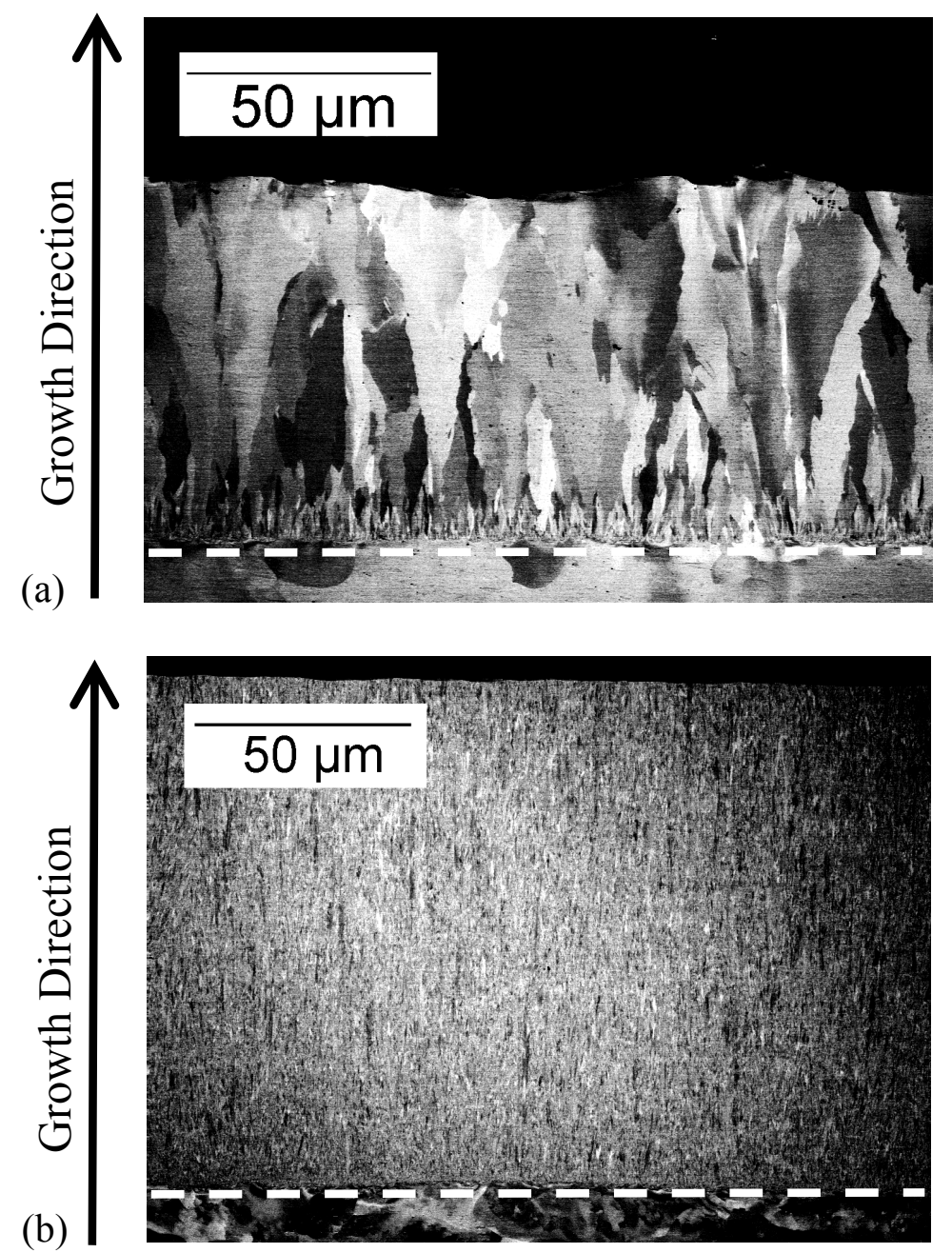

Figure 6.3 Backscattered SEM images showing grain-orientation contrast in monolithic iron electrodeposits. The steel substrate is observed at the bottom of the micrographs below the dotted lines. (a) Soft iron electrodeposit with coarse columnar structure and (b) hard iron electrodeposit with fine-grained structure. 
Microstructural differences observed between the soft and hard iron electrodeposits are attributed to the different deposition parameters applied (Table 5.1), resulting in different nucleation and growth rates, as well as compositional differences. It has been well documented that the mechanical properties of electrodeposited materials are affected by the microstructure (Dini 1993, Watanabe 2004, Weil 1989). Columnar electrodeposits generally exhibit higher ductility but lower strength and hardness as compared to fibrous or fine-grained deposits (Dini 1993). In comparison, fine-grained electrodeposits are typically harder, stronger, but more brittle (Dini 1993).

Electrodeposits with columnar structures often exhibit fine grains near the substrate and develop coarse, columnar grains as the electrodeposits grow in thickness. Figure 6.3(a) is a cross-sectional view of a soft iron electrodeposit possessing this structural development. As explained by Paunovic and Schlesinger (1998), columnar growth results from growth competition between adjacent grains. Low surface energy grains grow faster than high surface energy grains. In other words, low surface energy grains grow at the expense of high surface energy grains, resulting in an increase in the average grain size. Columnar grains generally grow along the fastest growth direction, resulting with a structure exhibiting a preferred orientation.

Metal hydroxide or hydrogen co-deposition interferes with crystal growth and promotes nucleation, resulting in fine-grained growth. The current waveform applied can also influence the co-deposition process. When a pulse reverse current waveform is applied, co-deposited hydrogen is removed during the anodic current period (i.e. dissolution period) (Dobrev et. al. 2001). However, when direct current is applied the adsorbed hydrogen remains co-deposited. Thus it is believed that the different deposition parameters used to produce soft and iron (see Table 5.1) likely result in varying amounts of co-deposited hydrogen. Additionally the dissolution of iron has been shown to produce $\mathrm{FeOH}^{+}$ions, which can be absorbed onto the cathode during the electrodeposition process (Bockris et al. 1963, Dobrev et al. 2001). It is speculated that the oxygen detected in the iron samples (i.e. via WDS) comes mainly from $\mathrm{FeOH}^{+}$. As shown in Chapter 6.1, hard iron electrodeposits contain more oxygen than the soft iron 
electrodeposits. Therefore, higher concentrations of co-deposited metal hydroxides (i.e. $\left.\mathrm{FeOH}^{+}\right)$in the hard iron electrodeposits likely contribute to the finer microstructure observed in Figure 6.3(b).

\subsubsection{TEM analysis of soft and hard iron electrodeposits}

Plan-view TEM micrographs of a soft iron electrodeposit are presented in Figure 6.4. Metals composed of grain sizes greater than a micrometer are defined as microcrystalline metals (Kumar et al. 2003). All subsequent references to microcrystalline metals will refer to metals with structures in this grain sizes regime. Bright field (BF) and dark field (DF) TEM images confirm soft iron electrodeposits exhibit a microcrystalline structure. The average grain size, as measured from several DF micrographs, is $\sim 1.87 \pm 0.63 \mu \mathrm{m}$. A grain size distribution is presented in Figure 6.4(d). When comparing the grain size determined by TEM with the SEM micrograph (Figure 6.3(a)) it is apparent that the TEM sample was thinned to electron transparency at a plane very close to the titanium substrate. It is speculated the holes near some of the grain boundaries are caused by co-deposited iron hydroxides that may have fallen out during the ion-milling step in the TEM sample preparation. Preferential etching can occur when the sample being ion-milled contains second phase particles, owing to different sputtering rates (Watanabe 2004). Similar structures were observed in optical micrographs of iron electrodeposits containing oxide inclusions (Hughes 1920). The inclusions fell out during the etching process, resulting in cavities in the structure. Figure 6.4(c) presents a selected area diffraction pattern (SADP) showing spots from several grains in the region shown in the BF and DF images of the soft iron electrodeposit. Many spots were indexed and shown to belong to the bcc iron structure. However, second phase particles (likely iron oxide hydroxide $\mathrm{FeO}(\mathrm{OH})$ ) (JCPDS card \#22-0353) are also present in the soft iron sample, which produce extra diffraction spots in the SADP.

Plan-view TEM micrographs of a hard iron electrodeposit are presented in Figure 6.5. Ultrafine crystalline (or ultrafine grained) metals are composed of grain sizes between 100-1000 nm (Kumar et al. 2003). Subsequent references to ultrafine crystalline or ultrafine grained metals will refer to metals with grain sizes in this regime. Bright 
field (BF) and dark field (DF) TEM images confirm that hard iron electrodeposits exhibit an ultra fine-grained structure. The average grain size, as measured from several DF micrographs, is $\sim 132 \pm 129 \mathrm{~nm}$. A grain size distribution is presented in Figure 6.5(d). The hard iron electrodeposit exhibits a broader grain size distribution compared to the soft iron electrodeposit.

(a)
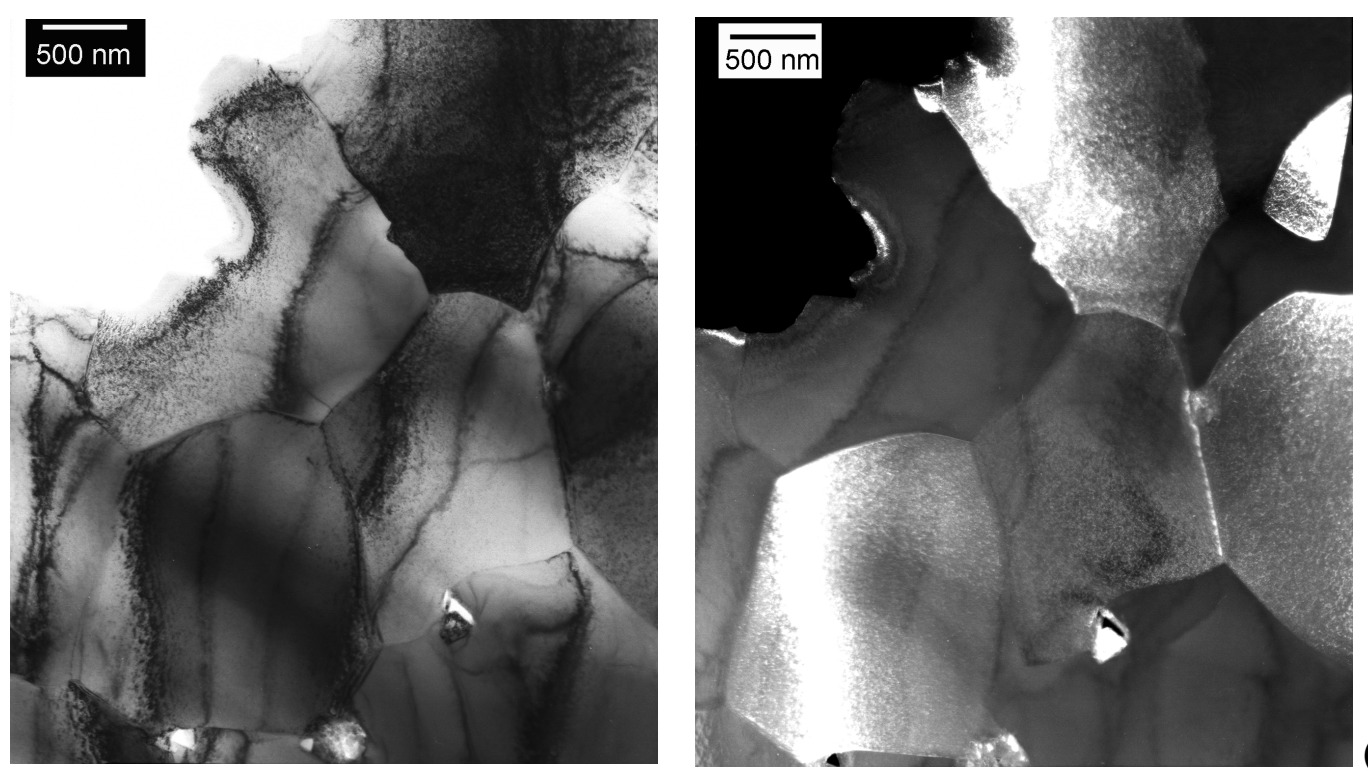

(b)
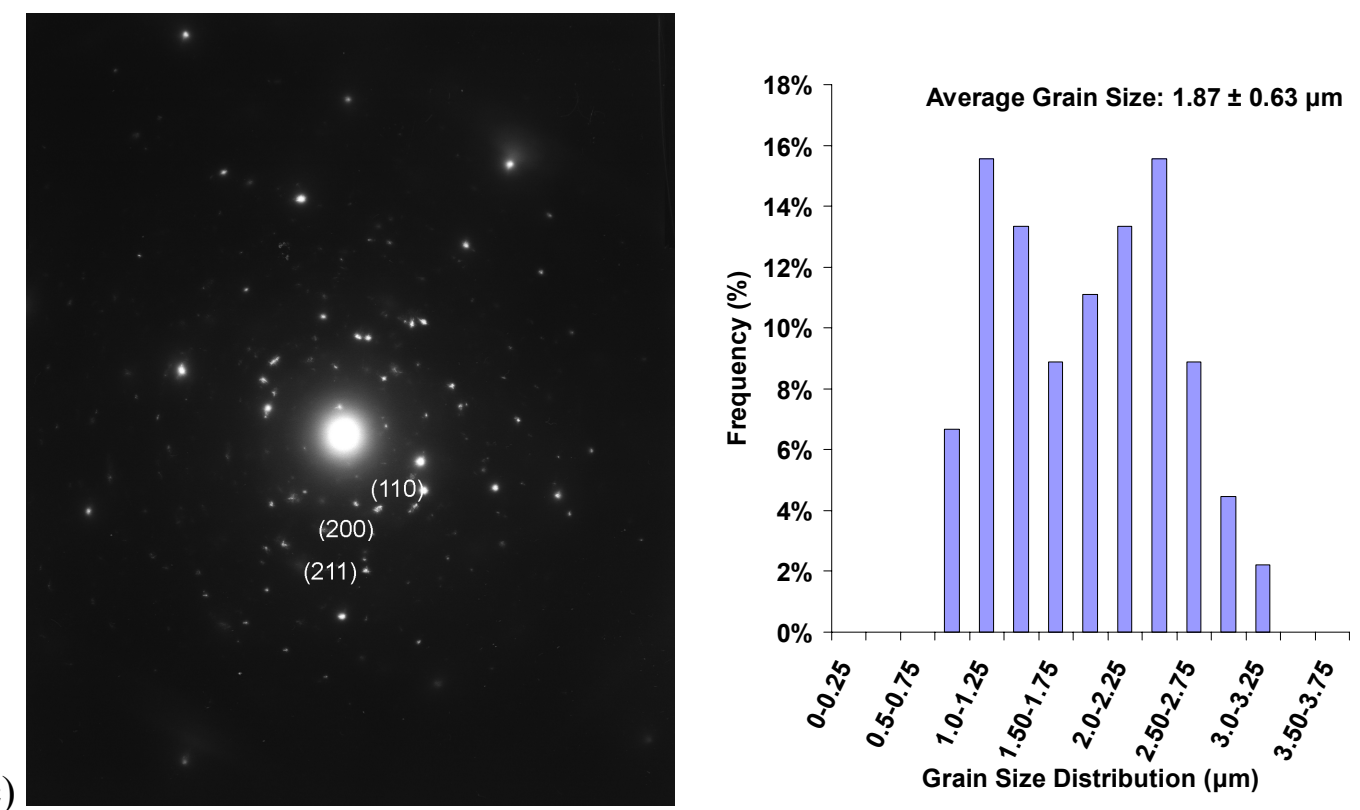

Figure 6.4 (a) Bright field TEM image, (b) dark field TEM image, (c) SADP, and (d) grain size distribution of a soft iron electrodeposit. 
A SADP corresponding to the region represented by the BF and DF images of the hard iron electrodeposit is presented in Figure 6.5(c). The SADP shows well defined diffraction rings which belong to the bcc iron structure. There appear to be extra diffraction rings that correspond to iron oxide hydroxide $\mathrm{FeO}(\mathrm{OH})$ (JCPDS card \#220353), indicating the presence of second phase particles resulting from co-deposited impurities in the deposit.

(a)

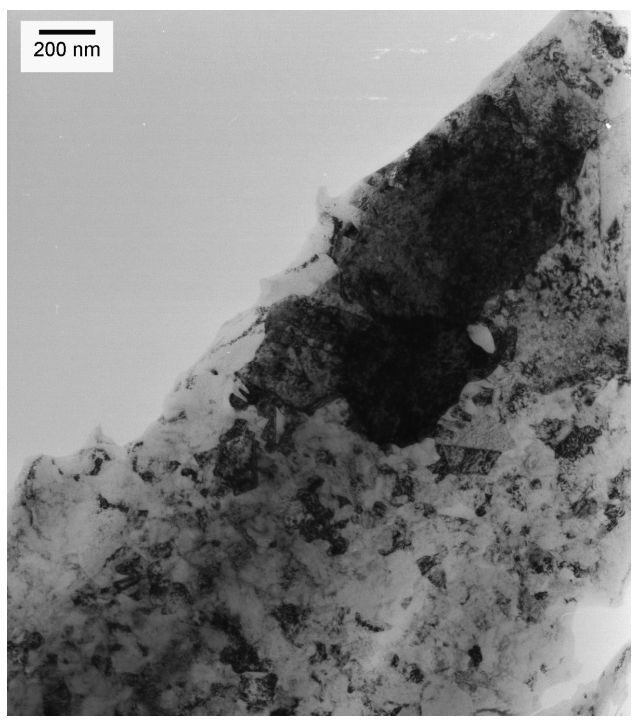

(c)

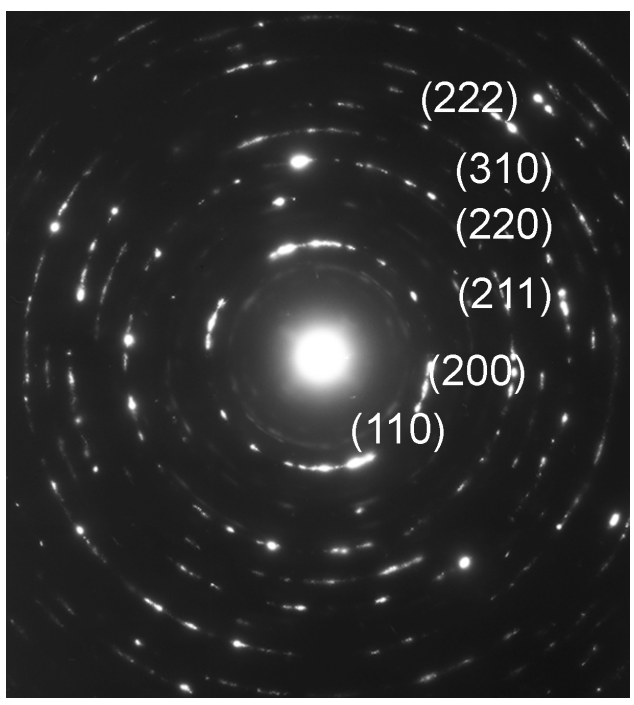

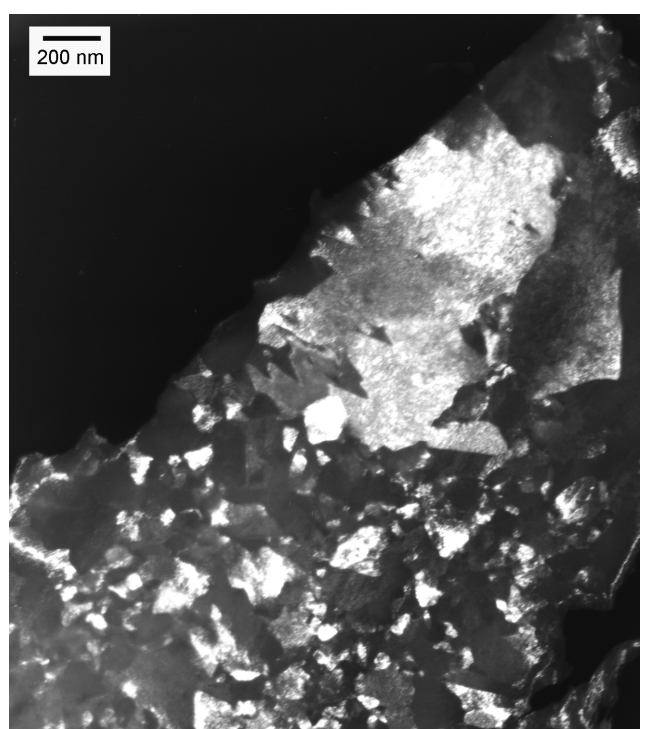

(b)

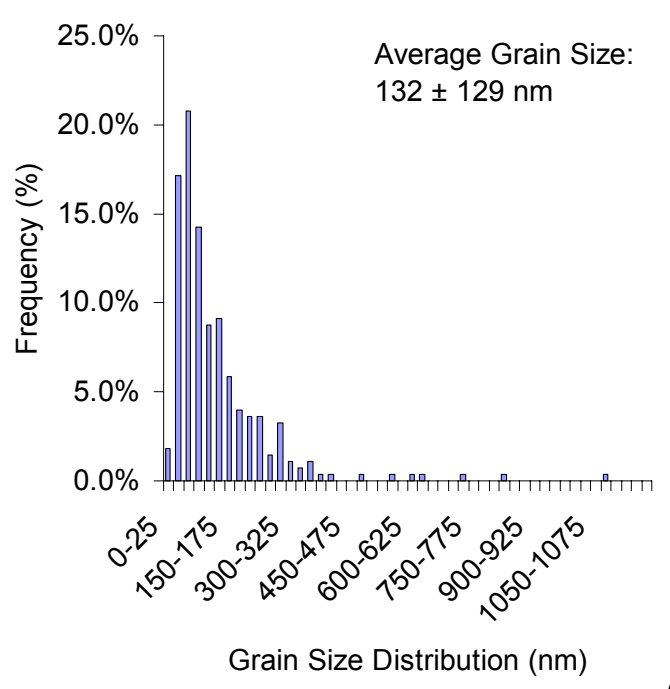

(d)

Figure 6.5 (a) Bright field TEM image, (b) dark field TEM image, (c) SADP, and (d) grain size distribution of a hard iron electrodeposit. 


\subsubsection{SEM analysis of multilayered iron electrodeposits}

Figure 6.6 presents backscattered SEM micrographs showing the cross-sectional views of multilayered iron electrodeposited with varying layer thicknesses. The actual layer thicknesses were measured from SEM micrographs and the values are listed in Table 6.4 together with the nominal thicknesses. The microstructures of the multilayered iron electrodeposits are quite different from the structures of monolithic iron electrodeposits. In fact, the microstructures of the multilayered iron electrodeposits are combinations of the two distinct microstructures. As observed in Figure 6.6(a), the layered electrodeposits are composed of alternating layers of columnar and fine-grained structure. The columnar and fine-grained structures correspond to the soft and hard iron layers, respectively. Furthermore, the structure within a single layer gradually coarsens as the layer grows thicker. Hughes (1923) has observed similar columnar growth in layered iron electrodeposits. Each new layer starts off with small crystals which become coarser as deposition continues. The concentration of metal ions at the cathode surface is the greatest at the start of each layer, and is gradually exhausted as deposition continues (Hughes 1923). Consequently, structural variations are observed within each layer (Hughes 1923).

Not only is the microstructure of multilayered iron electrodeposits different from the monolithic iron electrodeposits, it also varies with layer thickness. The period uniformity and interface sharpness diminish as the layer thickness is reduced (Figure 6.6). Furthermore these cross-sectional images reveal that as the layer thickness is reduced, the overall structure evolves from layered, to layered-like, and finally to fibrous-columnar. Figure 6.6(a) corresponds to a layered electrodeposit composed of $\sim 6.3 \mu \mathrm{m}$ thick layers, and clearly shows the layered structure throughout the entire deposit thickness. It is observed in Figure 6.6(b) to (e) that layered electrodeposits composed of submicron thick layers exhibit a more fibrous structure with regions that are fine-grained structure. Furthermore, the layered structure disappears as the deposit grows for layered electrodeposits composed of layers below $\sim 0.20 \mu \mathrm{m}$, as observed in Figure 6.6(e). Figure 6.6(e) shows an unexpected result as the layered structure that is initially observed grows out of existence with increasing deposit thickness. 
(a)

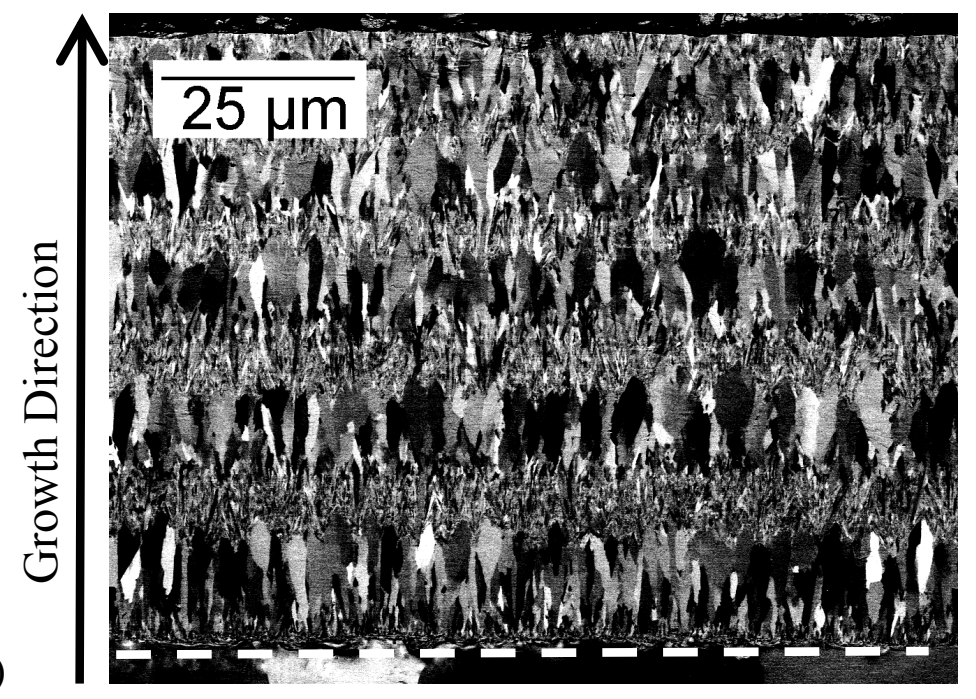

(b)

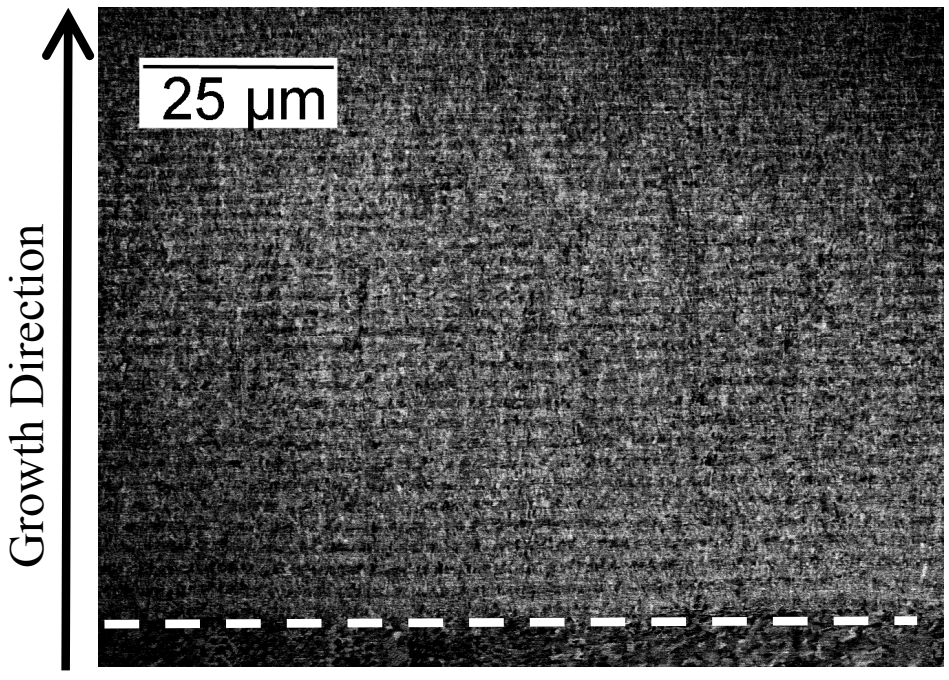

(c)

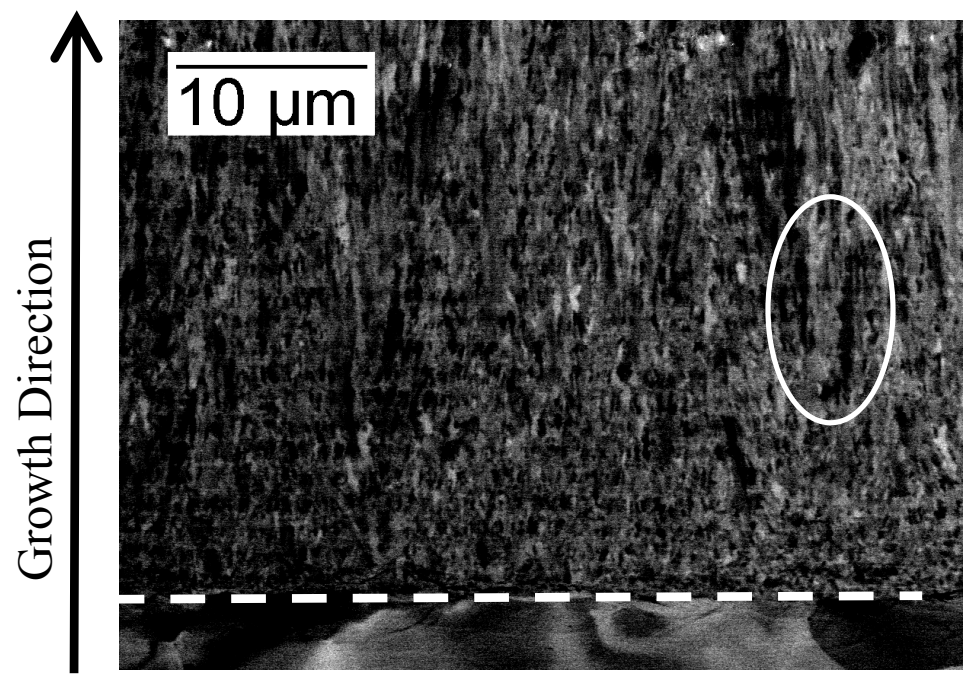

Figure 6.6 Backscattered SEM images showing grain-orientation contrast in multilayered iron electrodeposits. The steel substrate is observed at the bottom of the micrographs below the dotted lines. Layer thickness of (a) $\sim 6.3 \mu \mathrm{m}$, (b) $\sim 0.92 \mu \mathrm{m}$, and (c) $\sim 0.57 \mu \mathrm{m}$. Grain growth through layer boundaries is circled. 
(d)
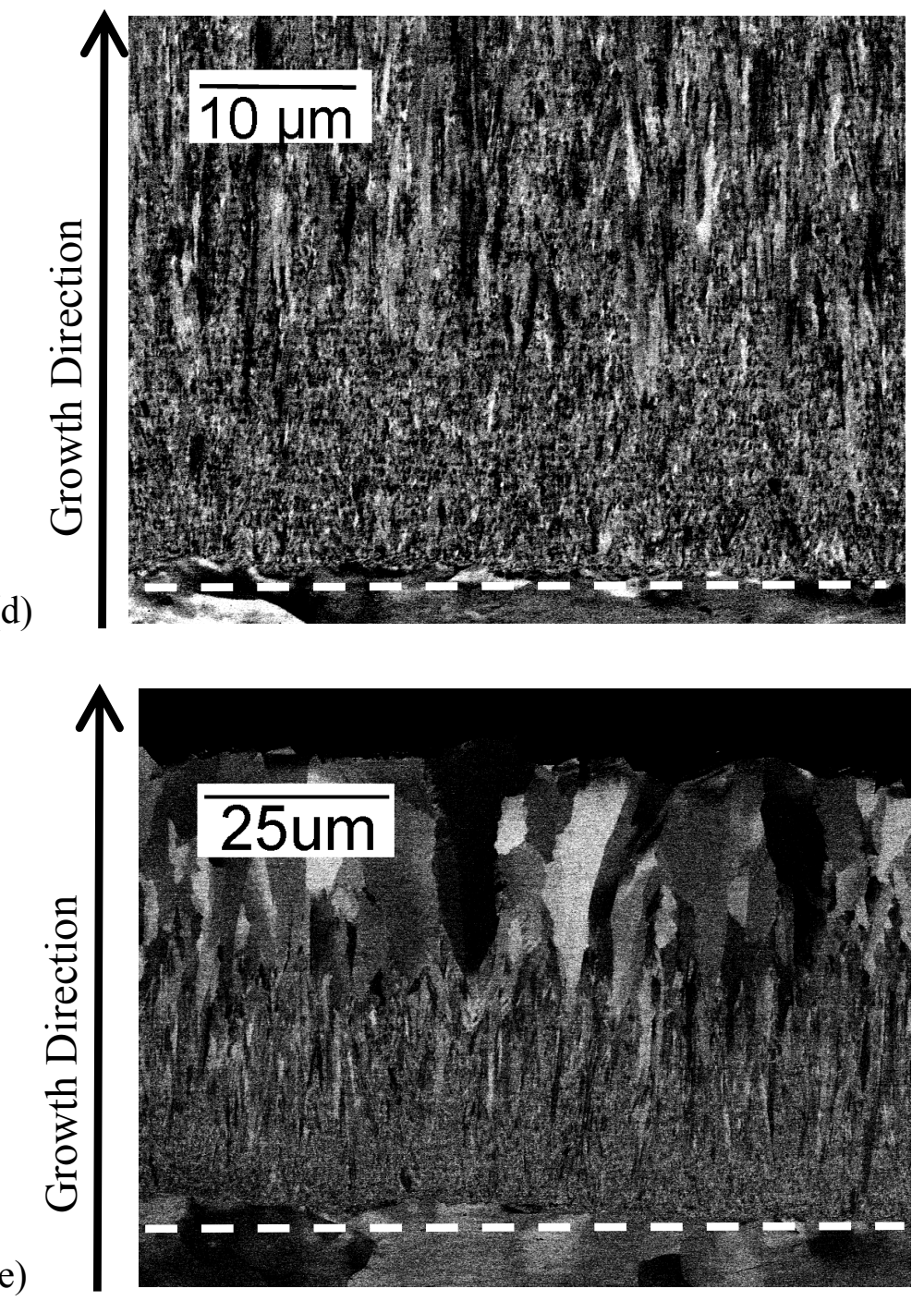

Figure 6.6 Backscattered SEM images showing grain-orientation contrast in multilayered iron electrodeposits. The steel substrate is observed at the bottom of the micrographs below the dotted lines. Layer thickness of (d) $\sim 0.20 \mu \mathrm{m}$ and (e) $0.10 \mu \mathrm{m}$ (nominal)

Table 6.4 Multilayered iron electrodeposits produced under different electrodeposition conditions. Actual layer thickness corresponds to thickness of a single layer measured from SEM micrographs.

\begin{tabular}{|cccc|}
\hline $\begin{array}{c}\text { Electrodeposition } \\
\text { Condition }\end{array}$ & $\begin{array}{c}\text { Type of Iron } \\
\text { Electrodeposit }\end{array}$ & $\begin{array}{c}\text { Nominal } \\
\text { Layer } \\
\text { Thickness } \\
(\boldsymbol{\mu m})\end{array}$ & $\begin{array}{c}\text { Actual Layer } \\
\text { Thickness } \\
(\boldsymbol{\mu m})\end{array}$ \\
\hline 3 & multilayered & 10 & $\sim 6.3$ \\
4 & multilayered & 1.0 & $\sim 0.92$ \\
5 & multilayered & 0.50 & $\sim 0.57$ \\
6 & multilayered & 0.25 & $\sim 0.20$ \\
7 & multilayered & 0.10 & NA \\
\hline
\end{tabular}


The reduced interface sharpness with decreasing layer thickness may be attributed to the initial nucleation stage of the electrodeposition process. Three growth modes have been applied to describe the initial nucleation and growth stages of the electrodeposition process: (i) Volmer-Weber (V-W); (ii) Frank-van der Merwe (F-M); and (iii) StranskiKrastanov (S-K) growth types. These growth modes are illustrated in Figure 6.7. The initial nucleation stage for multilayered electrodeposits often occurs via a Volmer-Weber growth mechanism (Watanabe 2004). In the Volmer-Weber mode, electrodeposit growth is initiated through island formation. The minimum thickness required to cover the whole substrate surface corresponds to the thickness at which island coalescence is completed. Consequently, the minimum layer thickness in multilayered electrodeposits is equivalent to the height of the coalesced islands (Watanabe 2004). Thus it is speculated that the interface quality is affected by the Volmer-Weber growth mechanism such that a minimum deposit thickness is required to form a continuous layer. Below this minimum thickness individual islands are still present on the surface and cause surface roughness.

In addition to the Volmer-Weber mode promoting island growth, the reduced period uniformity and interface sharpness could also be a consequence of dendritic growth. Dendrite formation occurs in electrodeposition under low metal concentration and high current density conditions, or under low current density conditions (Watanabe 2004). Aggregates that form are often tree-like and develop at the corners and edges of the deposit (i.e. regions of high current densities). A schematic diagram illustrating such aggregates is presented in Figure 6.8. Similar dendritic growth is observed at the corners and edges of the iron electrodeposits produced in the current study, as observed in Figure 6.1(a) and (b), respectively. Dendritic growth reduces the amount of material that is electrodeposited onto the flat surface, thus reducing period uniformity and interface sharpness. Péter et al. (2001) has also reported a similar interference by dendritic growth on the period uniformity of $\mathrm{Co}-\mathrm{Cu} / \mathrm{Cu}$ multilayered electrodeposits. 

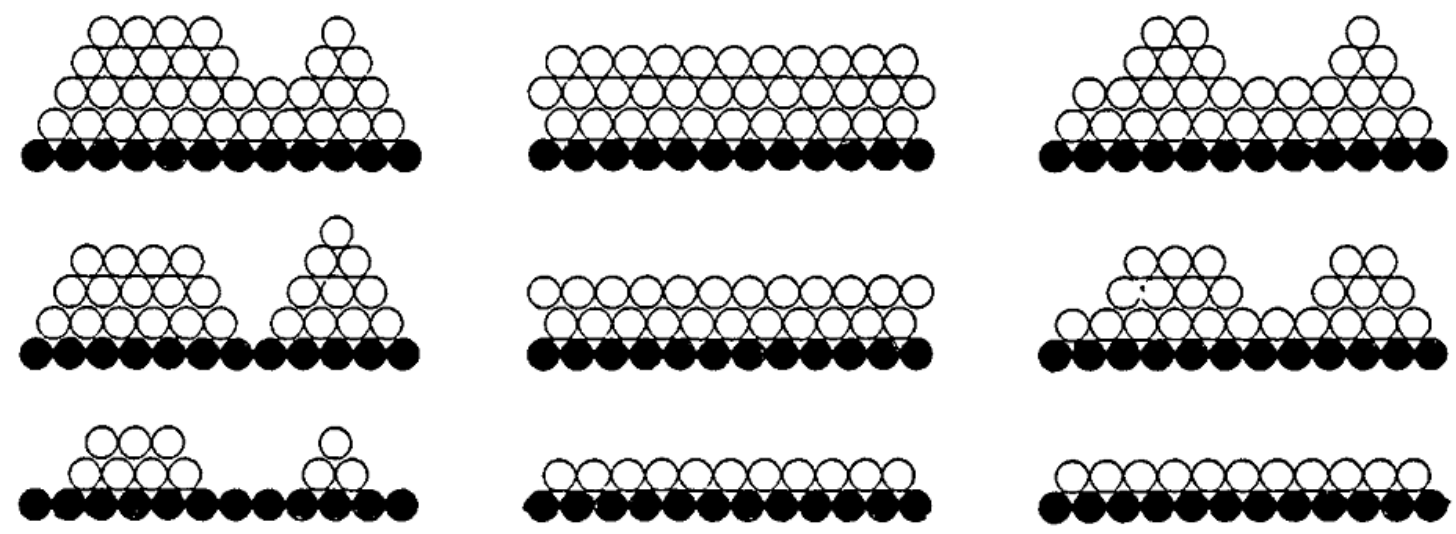

(a) Volmer-Weber type

(b) Frank-van der Merwe type

(c) Stranski-Krastanov type

Figure 6.7 Three growth modes describing the initial growth stages of electrodeposition. (a) VolmerWeber growth via formation of individual islands, (b) Frank-van der Merwe growth via formation of individual layers, and (c) Stranski-Krastanov growth via initial formation of a single layer followed by individual island growth (Watanabe 2004).

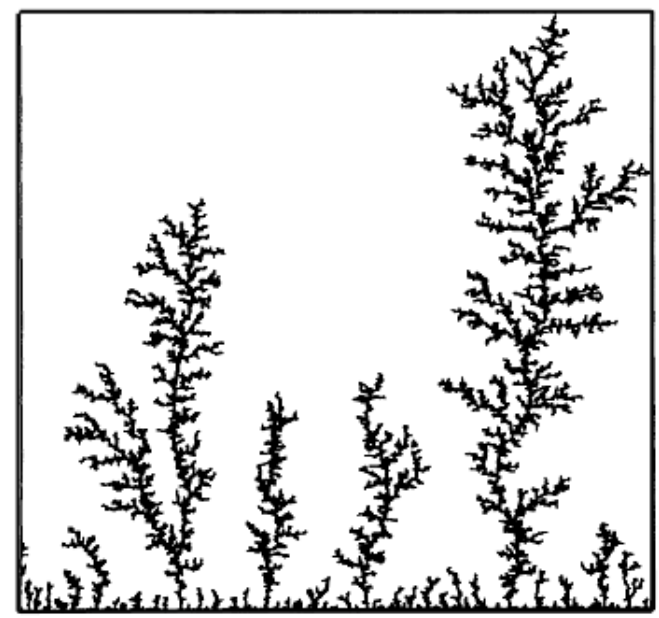

Figure 6.8 Schematic diagram showing dendritic growth typical of electrodeposition (Argoul et al. 1988).

In addition to a reduction in period uniformity and interface sharpness, changes in the overall microstructural morphology with the growth of the deposit have also been observed from the cross-sectional micrographs (Figure 6.6). The structural evolution from layered to fibrous-columnar may be attributed to the tendency for columnar growth with increasing deposit thickness. Columnar growth within individual layers can be observed in Figure 6.6(a). Watanabe (2004) observed an increase in surface roughness with increasing film thickness, caused by preferential electrodeposition at protrusions. 
The film thickness increases locally as deposition occurs at preferential sites (protrusions) (Watanabe 2004). Simultaneously, valley regions develop where metal ions are deficient and no film growth occurs in these regions (Watanabe 2004). Such surface morphology changes would also result in changes in the microstructural morphology of the crosssection, likely resulting in columnar growth. For the multilayered iron electrodeposits produced in the current study, columnar growth within individual layers is likely amplified as the layer thickness is reduced. Ultimately, a fibrous-columnar structure results when a new layer is too thin to smooth over the surface roughness of the previous layer.

As observed from the cross-sectional SEM micrographs presented in Figure 6.6, multilayered electrodeposits composed of finer layers exhibit fibrous structures. Fibrous structures are a refinement of columnar structures, resulting from deposition parameters that favour the formation of new nuclei rather than growth of existing grains (Dini 1993). The finer structure in these layered electrodeposits likely results from the interference of grain growth by co-deposited metal hydroxide or hydrogen.

The grain size within the layered structures with relatively large layer thicknesses is generally confined within each layer. This is most clearly observed in the crosssectional micrograph of the layered electrodeposit with the thickest layers, presented in Figure 6.6(a). However, as the layer thickness is reduced grain growth is no longer confined by the layer boundaries and crystal growth through the layer boundaries is observed instead, as shown in the circled area from Figure 6.6(c). Consequently, diffused and discontinuous interfaces result and electrodeposits exhibit fibrous-columnar structures. As discussed previously, surface irregularities develop with increasing deposit thickness and are amplified as the deposition process continues. Surface irregularities likely promote grain growth beyond the layer boundaries, and such growth is more prominent in layered electrodeposits composed of finer layers as finer layers are less likely to smooth over surface irregularities. It is suggested that grain growth occurs mainly in the direction perpendicular but not parallel to the layers because of the tendency for columnar growth to occur, similar to the growth of soft iron electrodeposits. 
Cross-sectional examination of multilayered iron electrodeposits in the SEM allowed for direct measurement of the layer thickness. The actual layer thicknesses (listed in Table 6.4), varied from the nominal thicknesses that can be theoretically calculated from Faraday's Law.

Faraday's law states the amount of material deposited is proportional to the amount of electric charge flowing through the electrolytic cell:

$$
W=\frac{I t A}{z F}
$$

where $\mathrm{I}$ is the applied current density, $\mathrm{t}$ is the deposition time, $\mathrm{A}$ is the atomic weight, $\mathrm{z}$ is number of electrons that are involved in the reaction, F is Faraday's constant (96485 $\mathrm{C} / \mathrm{mol})$

The amount of material deposited is proportional to the material density, thus the theoretical thickness of the electrodeposit can be calculated from:

$$
W=\text { area } \times \text { thickness } \times \text { density }
$$

The cathode current efficiency is the ratio of the actual amount of material deposited to the theoretically possible amount. The cathode current efficiency of the iron electrodeposition process used in this study is less than $100 \%$ efficient, as a consequence of some of the current being used to reduce $\mathrm{H}^{+}$to $\mathrm{H}_{2}$ and $\mathrm{Fe}^{3+}$ to $\mathrm{Fe}^{2+}$.

The discrepancy between the actual and nominal thickness is mainly a consequence of a reduced cathode current efficiency and dendritic growth (Figure 6.1). It is observed in Figure 6.6 that the multilayered iron electrodeposits are also composed of slightly unequal volumes of soft and hard iron, owing to discrepancies between the actual and nominal layer thicknesses. The volume ratio of soft iron to hard iron was determined based on the thickness of the respective layers. The nominal volume ratio of soft iron to 
hard iron in the multilayed iron electrodeposits produced is about 50/50. The actual volume ratio, based on layer thickness measurements estimated from the SEM micrographs presented in Figure 6.6, is closer to $\sim 56 / 44$. Throughout the remainder of this thesis the layer thicknesses given for multilayered electrodeposits will refer to the average thickness of both soft and hard iron layers, measured along the deposit thickness.

\subsubsection{TEM analysis of multilayered iron electrodeposits}

To further examine the microstructure of multilayered electrodeposits, crosssectional TEM samples were prepared. Many metallic TEM samples are prepared via electropolishing methods; however, ion milling or focused ion-beam (FIB) methods have also been used. Electropolishing methods are often used to prepare plan-view TEM samples because it creates the least amount of damage on the samples, compared to the other two methods (Watanabe 2004). Electropolishing methods may change the surface chemistry of a sample, but very little or no mechanical damage is induced (Williams 2009). However, it is more difficult to apply electropolishing methods to prepare multilayered cross-sectional TEM samples owing to potentially large differences in etching rates of the alternating layers.

In this study, cross-sectional TEM samples of the multilayered iron electrodeposit with a nominal layer thickness of $\sim 0.25 \mu \mathrm{m}$ were prepared by both the ion milling and FIB methods. Samples prepared by the ion milling method were first pre-thinned with a mechanical dimpler. The aim of pre-thinning is to thin the center of the disk while minimizing damage to the surface of the sample. After the sample is pre-thinned, final thinning is completed with ion milling. Since the centre of the sample is the thinnest, it is preferentially bombarded with argon ions and material is sputtered off the sample until it is thin enough to be viewed in the TEM (i.e. electron transparent). TEM samples prepared by ion milling likely have less damage and ion implantation owing to the lower accelerating voltage applied, $4 \mathrm{keV}$ compared to $40 \mathrm{kV}$ with the FIB. 
The FIB used was a Hitachi FB-2100 FIB System, which is an SEM with a builtin ion mill. Rather than using argon ions as with ion milling, gallium ions are used instead. The various stages of the FIB sample preparation process are presented in Figure 6.9. Figure 6.9(a) shows the selected sample area (i.e. boxed area) coated in a layer of tungsten, (b) shows the FIB micromanipulator attached to the sample, allowing the remaining two sides to be cut away, and (c) shows a cross-sectional view of the TEM sample that has been lifted out from the bulk and mounted onto a copper TEM sample holder by the FIB micromanipulator.

The last stage of the FIB sample preparation process involves thinning the crosssectional sample to the final thickness with the gallium ion beam, after the sample has been mounted onto the TEM sample holder. A schematic diagram showing the crosssection of the final FIBbed TEM sample is presented in Figure 5.4. The thickness at the edge of the sample is $\sim 500 \mathrm{~nm}$ and the thickness at centre of the sample is $\sim 100 \mathrm{~nm}$. The final FIBbed TEM sample is thicker at the edges, thus reducing the risk of losing the sample during lift-out as compared to lifting out a uniformly thin sample (i.e. $100 \mathrm{~nm}$ ).

The TEM images and SADPs presented in Figure 6.10 and Figure 6.11 pertain to samples prepared via the ion milling method and the FIB method, respectively. Both methods successfully produced TEM samples with areas that are electron transparent; however, these areas are fairly small. Consequently it is difficult to observe the microstructure of the multilayered iron electrodeposit in detail, over a large area. The SADPs presented in Figure 6.10 and Figure 6.11 are similar: ring patterns consisting of bcc iron rings with additional spots, likely coming from second phase particles (iron oxide hydroxide $\mathrm{FeO}(\mathrm{OH})$ ) (JCPDS card \#22-0353) as observed in monolithic iron discussed in section 6.2.2.

Evidence of a layered structure can be observed from the TEM images presented in Figure 6.12 and Figure 6.13, which show cross-sections of the multilayered iron electrodeposit with a nominal layer thickness of $\sim 0.25 \mu \mathrm{m}$. Figure 6.12 shows the cross- 
(a)
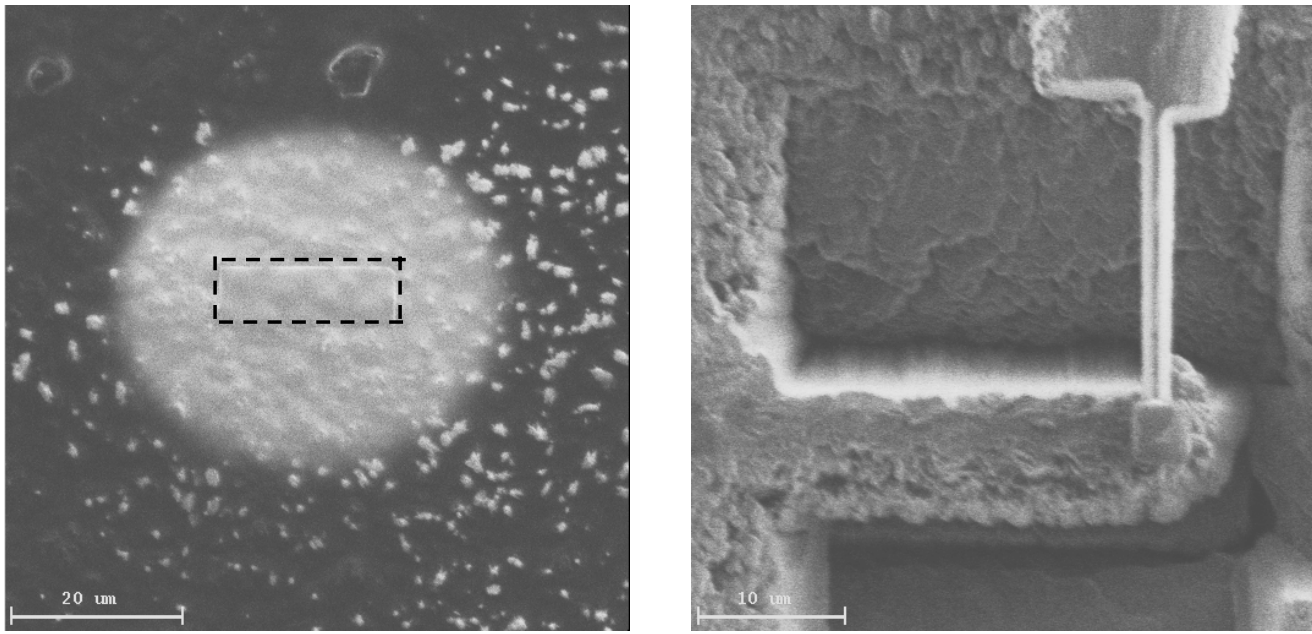

(b)

(c)

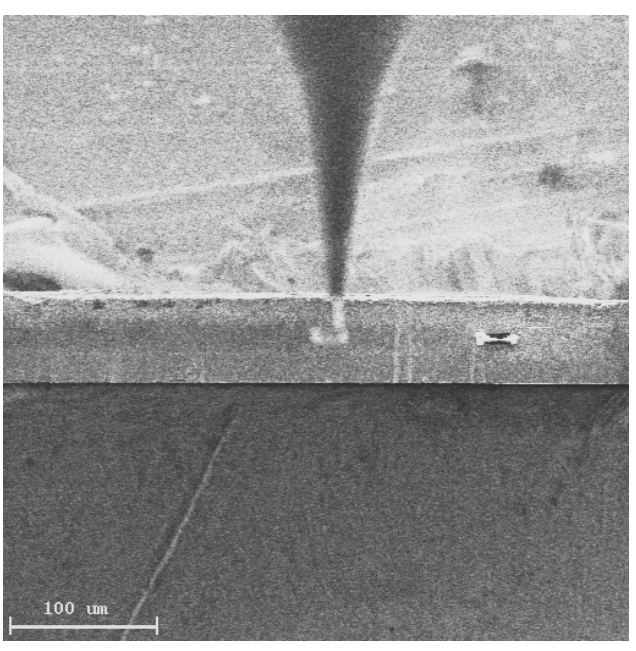

Figure 6.9 SEM images showing FIB preparation of a cross-sectional TEM sample. (a) A protective tungsten coating over the area of interest (i.e. rectangular box), (b) TEM sample partially cut away from bulk sample, and (c) stepped TEM sample mounted onto a copper TEM sample holder. 


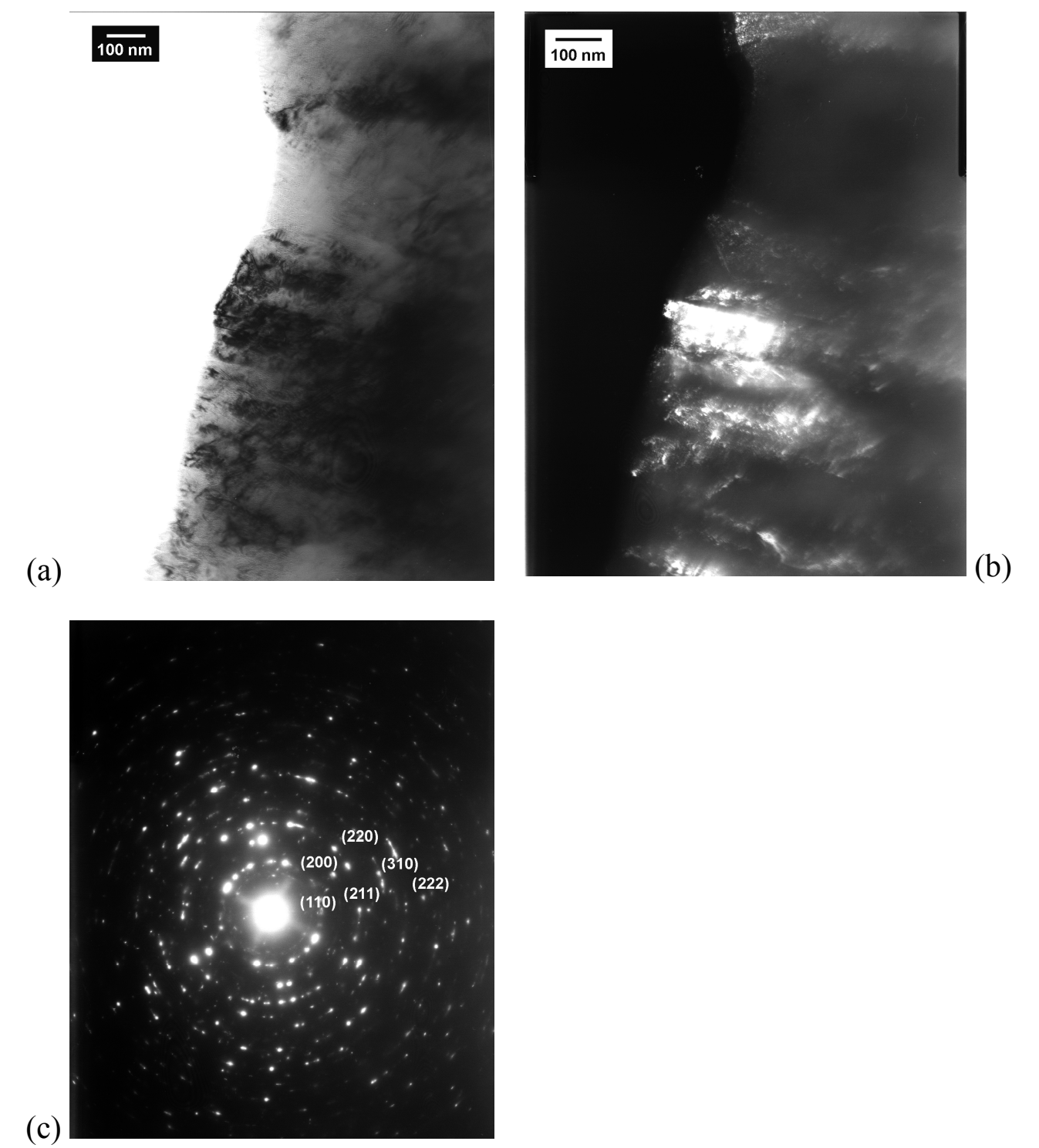

Figure 6.10 TEM images showing an ion-milled cross-section of a multilayered iron electrodeposit with a nominal layer thickness $\sim 0.25 \mu \mathrm{m}$. (a) BF image, (b) DF image, and (c) SADP. 
(a)
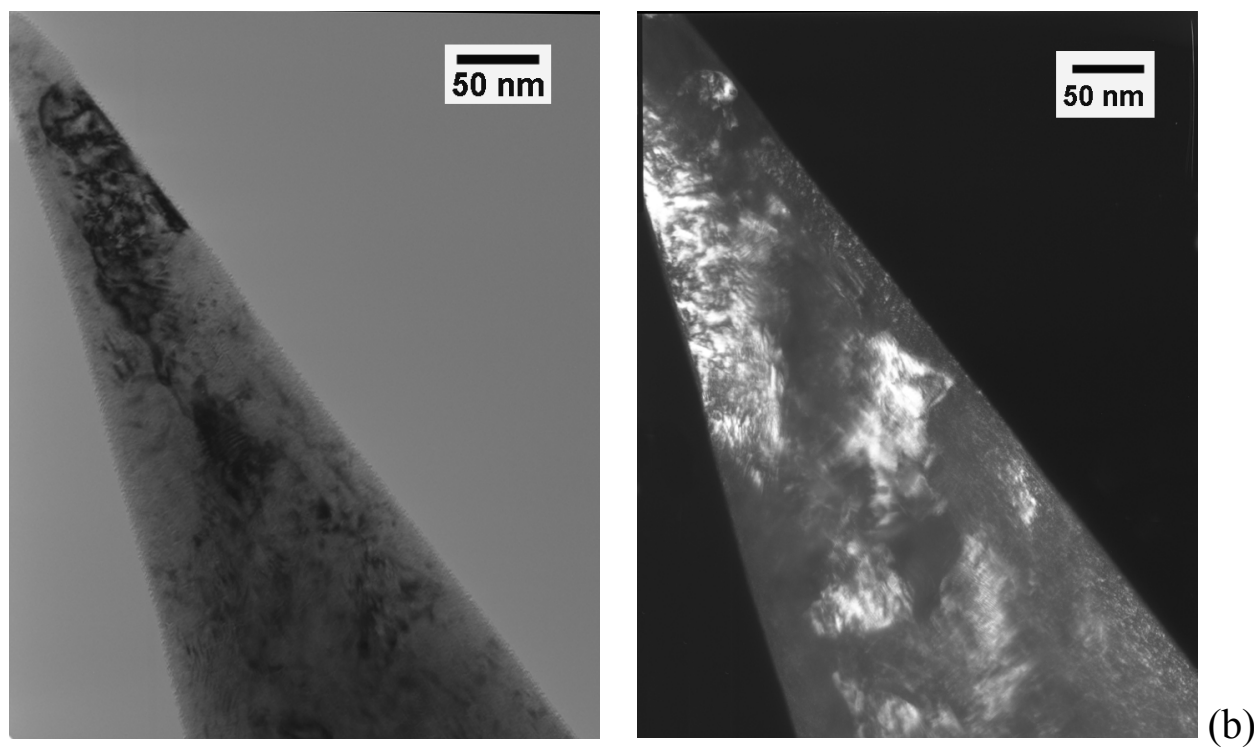

(c)

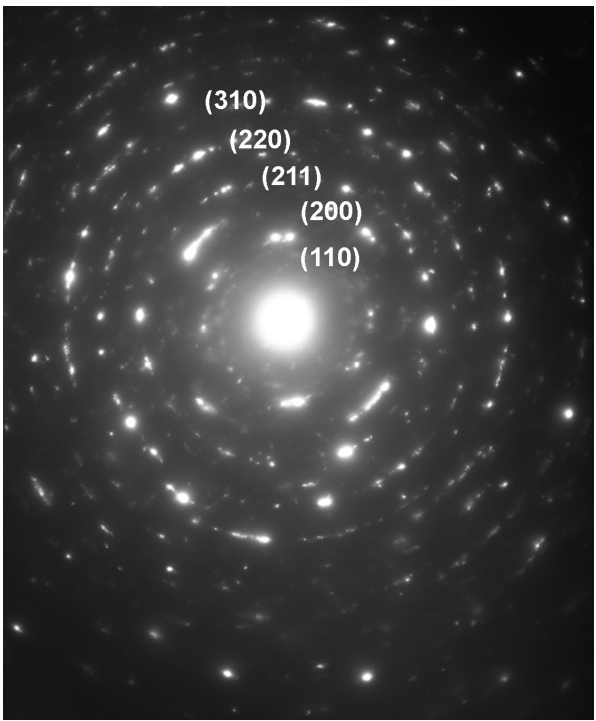

(b)

Figure 6.11 TEM images showing a FIBbed cross-section of a multilayered iron electrodeposit with a nominal layer thickness $\sim 0.25 \mu \mathrm{m}$. (a) BF image, (b) DF image, and (c) SADP. 
section of TEM sample prepared by the ion milling method. In this BF TEM image, the thickness of the layers appears to be thinner than the average layer thickness estimated from the SEM micrograph presented in Figure 6.6(d). It is speculated that the discrepancy in layer thickness is likely attributed to the difficulty in resolving such fine features (i.e. layers) using the electron channelling contrast imaging (i.e. grain orientation contrast) technique to obtain the SEM micrographs (Figure 6.6). A similar layered structure is observed in Figure 6.13 which shows the cross-section of a TEM sample prepared by the FIB method. Again, discrepancy between the average layer thickness observed in the TEM image and the average layer thickness that can be estimated from Figure 6.6(d) is attributed to the limited resolution obtained using the electron

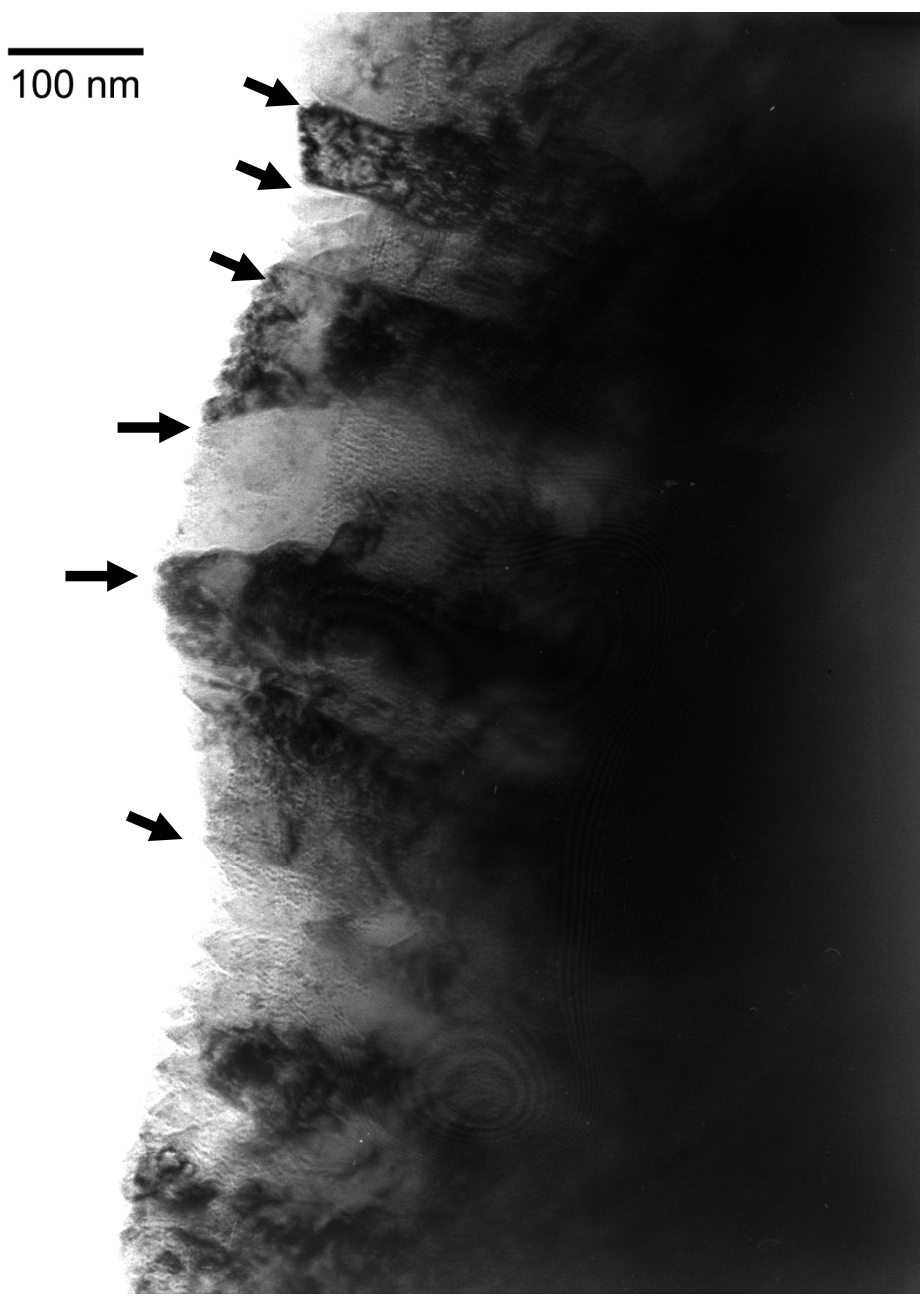

Figure 6.12 BF TEM image showing the layered structure of a multilayered iron electrodeposit prepared by the ion milling method. Arrows indicate layer boundaries. 

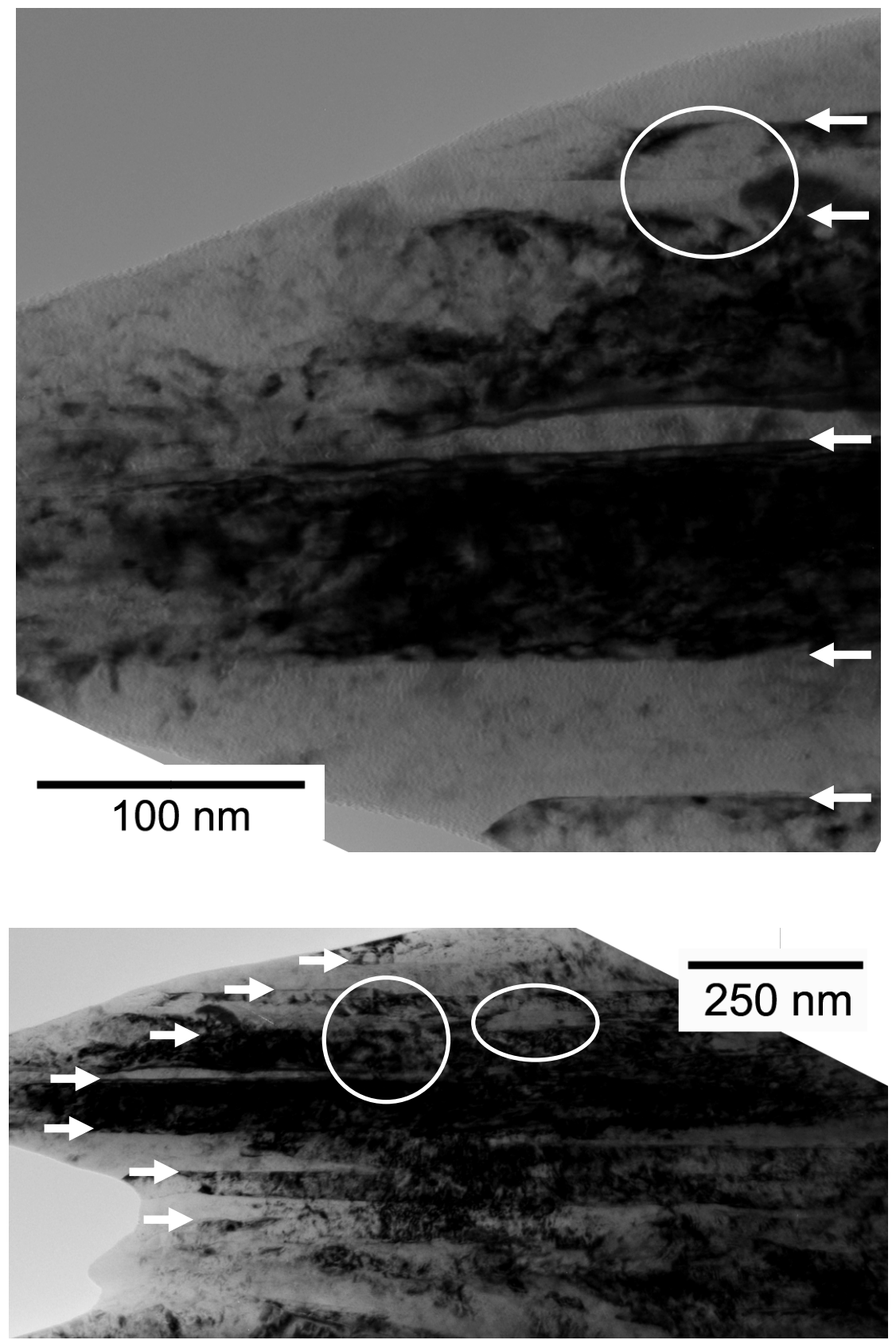

Figure 6.13 BF TEM images showing a layered structure in different regions of a multilayered electrodeposit prepared by the FIB method. Arrows indicate layer boundaries and grain growth through the boundaries are circled. 
channelling technique. Figure 6.13 also reveals grain growth through the layer boundaries. A similar microstructure is also observed from the SEM micrograph presented in Figure 6.6(d).

The TEM images presented in this chapter show similar microstructural features to what were observed in the SEM micrographs presented in 6.2.3. Although a direct comparison between the layer thickness measured from the TEM and SEM images cannot be made owing to the resolution limitations when using the electron channelling technique to obtain the SEM micrographs, the layered structure of the multilayered iron electrodeposit has been observed. The cross-sectional TEM images also revealed that the grain size in some of the layers is relatively large.

The FIB method allows for greater control in producing cross-sectional TEM samples compared to the ion milling method. Consequently, TEM images of the FIBbed samples exhibit more detailed microstructural features compared to TEM images of the ion milled samples. However, investigating the possibility of producing even thinner cross-sectional TEM samples of multilayered iron (i.e. $<100 \mathrm{~nm}$ ) via the FIB method for future microstructural analysis is recommended.

\subsubsection{XRD analysis of iron electrodeposits}

X-Ray diffraction patterns of the iron electrodeposits produced are presented in Figure 6.14. All diffraction lines from the iron coatings are located at the angles for bcc $\alpha-\mathrm{Fe}$ (JCPDS card \#6-0696). No trace of diffraction lines belonging to additional phases (e.g. iron oxides, hydroxides, carbides) was observed. The concentration of second phase

particles which may have been co-deposited are likely too low to be detected, with diffracted intensities too low to exceed the background noise in the XRD patterns presented.

X-Ray diffraction patterns presented in Figure 6.14 show soft iron exhibits a (110) preferred orientation while hard iron exhibits a (211) preferred orientation. The layered iron electrodeposits exhibit a (110) preferred orientation and a much weaker (211) 
component from the hard iron. There are no significant changes to the crystallographic texture of multilayered iron electrodeposits as the layer thickness is reduced, the most dominant preferred orientation remains (110) but the (211) component decreases for the $0.1 \mu \mathrm{m}$ (nominal layer thickness) multilayered iron. The crystallographic texture of the $0.1 \mu \mathrm{m}$ multilayered iron is similar to the monolithic soft iron owing to the unexpected transition from layered to coarse, columnar grain structure starting about half way through the deposit thickness (Figure 6.6(e)).

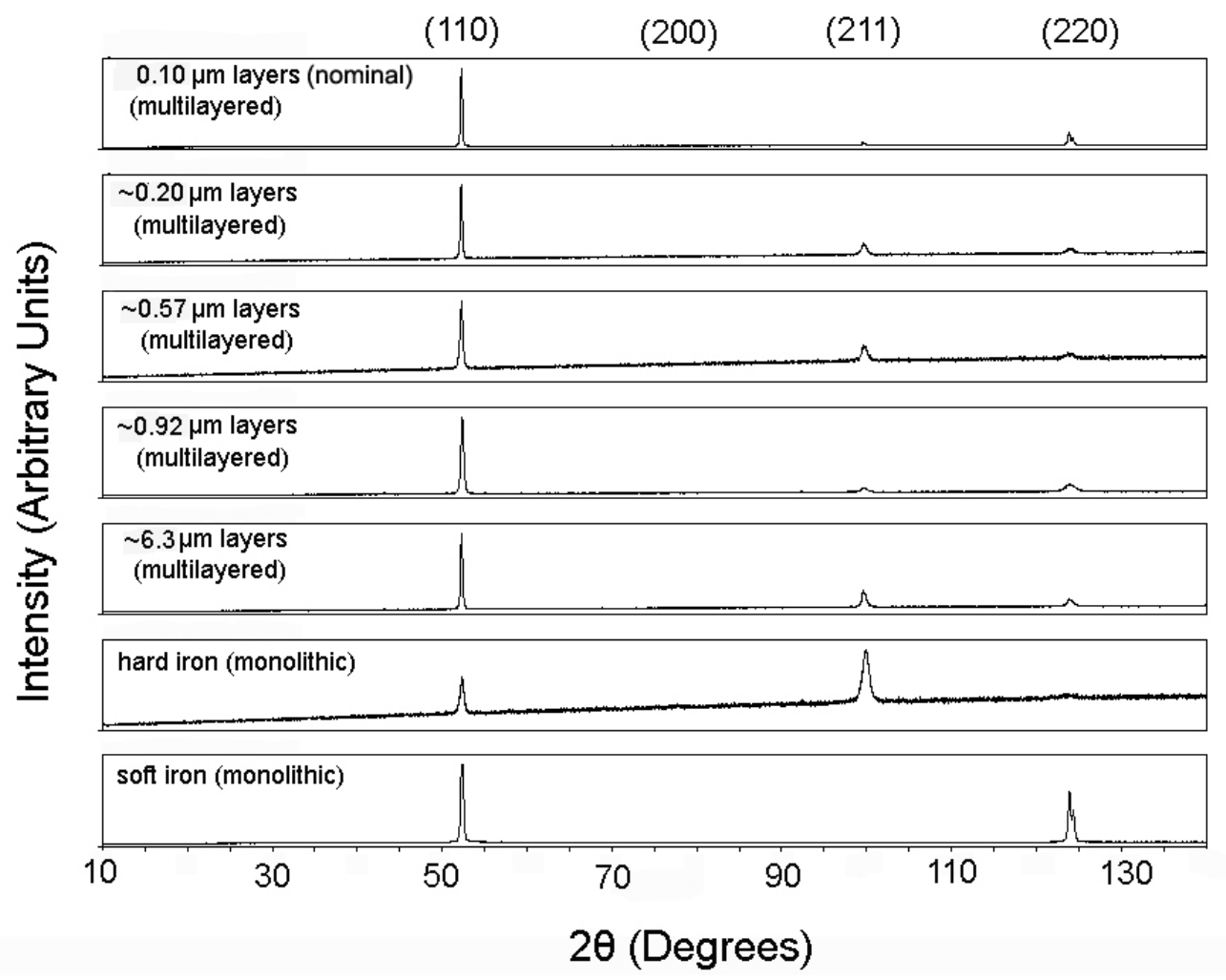

Figure 6.14 X-Ray diffraction patterns showing electrodeposited iron with a bcc crystal structure, and little texture variation with layer thickness in multilayered electrodeposits. 


\subsection{MECHANICAL CHARACTERIZATION OF IRON ELECTRODEPOSITS}

\subsubsection{Microhardness analysis}

The microhardness of multilayered electrodeposited iron was measured to investigate the dependence of hardness on layer thickness (Table 6.5). Also shown in this table are the hardness values for monolithic soft and hard iron electrodeposits. It should be noted that the multilayered structure produced according to condition 7 in Table 5.1 was not considered here because of the unexpected structural change from layered to mainly large grained with increasing deposit thickness, as discussed in Chapter 6.2.3. Figure 6.15 shows hardness data as a function of layer thickness for the multilayered iron electrodeposits studied. As defined in Chapter 6.2.3, the actual layer thickness (h) is the average layer thickness of the soft and hard iron layers, measured from SEM micrographs. It is observed from Figure 6.15 that hardness increases with decreasing layer thickness. Multilayered electrodeposits corresponding to the three largest layer thicknesses scale linearly according to $\mathrm{H}$ versus $\mathrm{h}^{-1 / 2}$, indicating that a Hall-Petch type relationship exists. The hardening of the multilayered electrodeposits is due to the finer microstructure and an increased number of layer boundaries as the individual layer thickness is reduced.

Table 6.5 Influence of layer thickness on the average hardness of monolithic and multilayered iron electrodeposits.

\begin{tabular}{|cccccc|}
\hline $\begin{array}{c}\text { Electrodeposition } \\
\text { Condition }\end{array}$ & $\begin{array}{c}\text { Type of Iron } \\
\text { Electrodeposit }\end{array}$ & $\begin{array}{c}\text { Actual } \\
\text { Layer } \\
\text { Thickness } \\
(\mathbf{h})(\boldsymbol{\mu m})\end{array}$ & $\mathbf{h}^{\mathbf{- 1 / 2}}$ & $\begin{array}{c}\text { Avg. } \\
\text { Hardness }^{\left(\mathbf{V H N}_{\mathbf{1 0 0 0 g}}\right)}\end{array}$ & $\begin{array}{c}\text { Avg. } \\
\text { Penetration } \\
\text { Depth }(\boldsymbol{\mu m})\end{array}$ \\
\hline 1 & monolithic soft & N/A & N/A & $177 \pm 7.14$ & 15 \\
2 & monolithic hard & N/A & N/A & $502 \pm 12.8$ & 8.7 \\
3 & multilayered & $\sim 6.3$ & 0.40 & $234 \pm 11.3$ & 13 \\
4 & multilayered & $\sim 0.92$ & 1.0 & $316 \pm 3.81$ & 11 \\
5 & multilayered & $\sim 0.57$ & 1.3 & $383 \pm 4.73$ & 10 \\
6 & multilayered & $\sim 0.20$ & 2.3 & $408 \pm 4.26$ & 10 \\
\hline
\end{tabular}

The Hall-Petch model appears to break down for the multilayered electrodeposit composed of $\sim 0.20 \mu \mathrm{m}$ thick layers. As discussed in Chapter 6.2.3, the period uniformity and interface sharpness is reduced as the layer thickness is reduced. In fact, the multilayered electrodeposit composed of $\sim 0.20 \mu \mathrm{m}$ layers exhibits a layer-like structure with diffuse interfaces (Figure 6.6(d)). It is speculated that the hardening mechanism for 
this sample is less effective than the other layered samples, as a consequence of the nature of the interfaces.

The hardness values of the monolithic hard and soft iron electrodeposits produced are also presented in Figure 6.15 as dotted lines. It can be observed that the multilayered iron electrodeposits exhibit intermediate hardness values compared to the monolithic iron electrodeposits, which is expected based on the microstructure of multilayered electrodeposits discussed in Chapter 6.2.

As evident from Figure 6.15, the hardness of soft electrodeposited iron can be improved with a multilayered design. However, the layer thickness cannot be reduced indefinitely. As individual layers become too thin, layer boundaries become diffuse and the structure evolves from layered to fibrous-columnar as shown in Chapter 6.2.3. There appears to be a minimum layer thickness that exists to maintain effective hardening mechanisms in the layered electrodeposits. For the layered iron electrodeposits studied here, hardening decreases when the individual layers are finer than $\sim 0.6 \mu \mathrm{m}$.

As discussed in Chapter 6.2.3, the volume ratio of soft to hard iron in the multilayered electrodeposits was estimated to be $\sim 56 / 44$. Therefore the theoretical hardness of the multilayered electrodeposits studied, calculated using the rule of mixtures principle, is $\sim 320 \mathrm{VHN}$. It is observed from Figure 6.15 that all of the multilayered iron electrodeposits, except for one, exhibit hardness values equal to or greater than $320 \mathrm{VHN}$. The multilayered iron electrodeposit composed of $\sim 6.3 \mu \mathrm{m}$ thick layers is $234 \mathrm{VHN}$, which is only $\sim 33 \%$ harder than the monolithic soft iron electrodeposit. The hardness of this particular multilayered iron electrodeposit is close to the hardness of the monolithic soft iron electrodeposit because just over half of the microstructure indented is composed of coarse, columnar grains. The average penetration depth of the hardness measurements was estimated from equation 5.1 and the values are listed in Table 6.5. For the $\sim 6.3 \mu \mathrm{m}$ multilayer the penetration depth is $\sim 13 \mu \mathrm{m}$ and the top layers primarily consist of coarse grains (Figure 6.6(a)). Consequently, the mechanical behaviour is strongly influenced by the coarse columnar grains of the soft iron layer. 
The multilayered electrodeposits composed of thinner layers exhibit hardness values higher than 320 VHN owing to the refined microstructure within individual layers, and the increased number of layer boundaries for the same penetration depth (Table 6.5).

The Hall-Petch relationship which describes the strengthening with grain refinement of microcrystalline and ultrafine crystalline metals (i.e. grain size greater than $100 \mathrm{~nm}$ ) is attributed to pile-up dislocations at grain boundaries (e.g. Kumar et al. 2003). The schematic diagram in Figure 6.16 illustrates a linear Hall-Petch relationship for metals in the microcrystalline and ultrafine crystalline regimes; however, the hardening rate (i.e. slope in the Hall-Petch plot) in the nanocrystalline region is different. In fact, it has been observed that strengthening rates for conventional grain sizes cannot always be extrapolated to grain sizes less than $100 \mathrm{~nm}$, and more importantly the strengthening rate in the nanocrystalline regime is usually lower (e.g. Meyers 2006). Kozlov et al. (1968) reported on the hardening behaviour due to grain size in the microcrystalline regime for monolithic iron electrodeposits. Figure 6.17 shows a graph of the replotted data. It can be observed that a linear Hall-Petch relationship exists. Data from the current study is superimposed onto the same graph and a similar linear relationship is observed for the multilayered electrodeposits with layer thicknesses between 6.3 and $0.57 \mu \mathrm{m}$. It should be noted that in Figure 6.17, $\mathrm{d}$ is used interchangeably to represent grain size and layer thickness for data presented by Kozlov et al. (1968) and for data from the current study, respectively. The data from the current study exhibit a different hardening rate (i.e. slope in the Hall-Petch plot) compared with the results reported by Kozlov et al. (1968). Similar Hall-Petch behaviour has been observed in other multilayered materials with layer thicknesses in the ultrafine grained and nanocrystalline regimes, as shown in Figure 3.4 (Misra et al. 2002, Roos et al. 1991, Ross 1994). Strengthening due to layer thickness refinement is similar to strengthening due to grain boundaries. Layer boundaries also act as barriers for dislocation pile-up.

Two conclusions can be drawn regarding the dependence of hardness on layer thickness in the multilayered iron electrodeposits studied in the current research: i) the hardness increases with the inverse square root of the layer thickness and ii) the 
hardening rate of micro and ultrafine multilayered iron electrodeposits is lower than the hardening rate of microcrystalline monolithic iron electrodeposits reported by Kozlov et al. (1968). As previously discussed, ultrafine grained materials exhibit high hardness; however, the hardness is not as high as the extrapolated Hall-Petch prediction from microcrystalline materials. Furthermore, the current study has shown that the diffused layer boundaries also contribute significantly to the effective hardening rates observed in multilayered iron electrodeposits. However, a direct comparison cannot be made regarding the effectiveness of grain boundaries and layer boundaries as barriers for dislocation pile-ups.

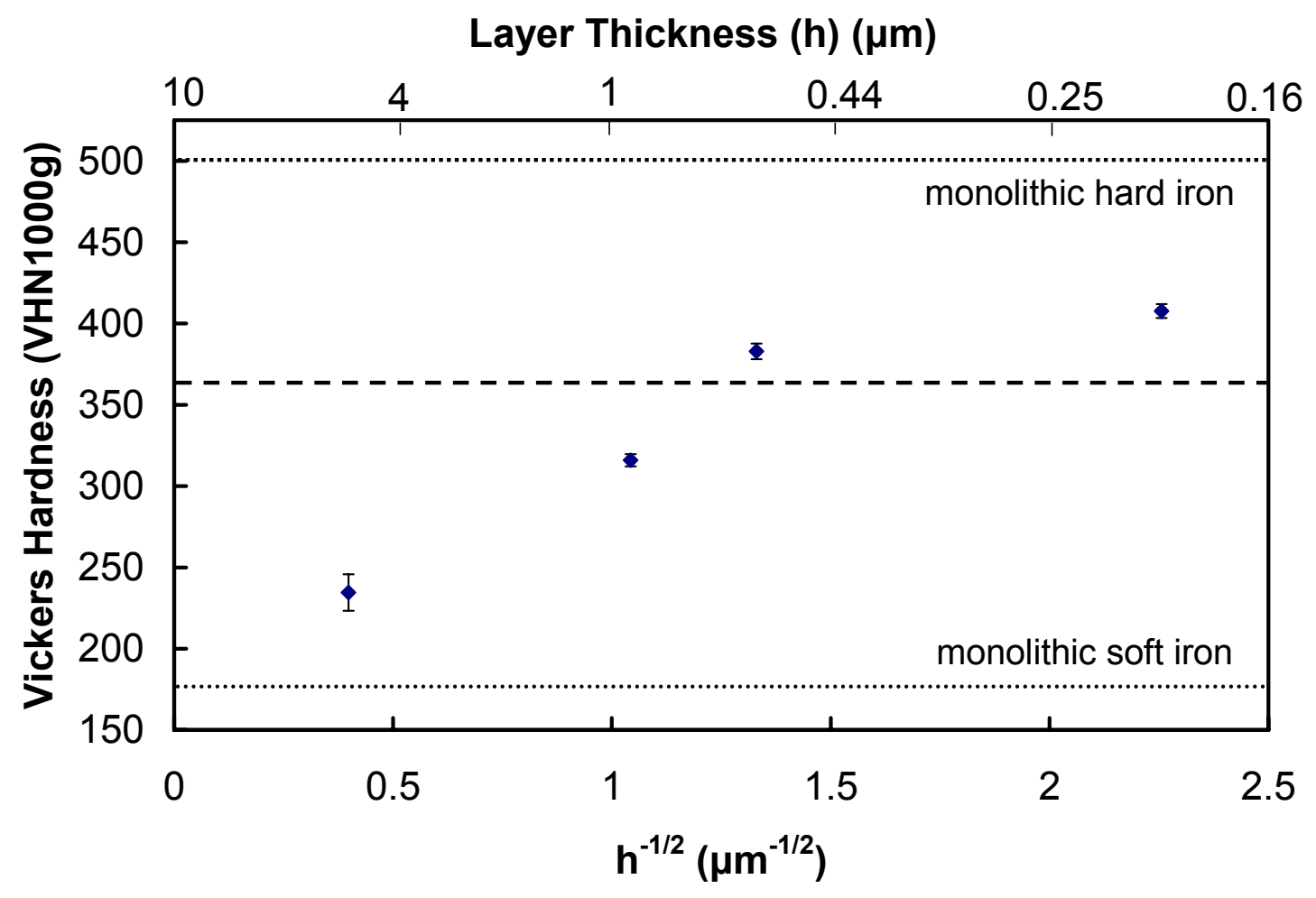

Figure 6.15 The dependence of hardness on layer thickness of multilayered electrodeposited iron. The average hardness of monolithic hard and soft iron is represent by $(\cdots \cdots)$ and $(\cdots \cdots \cdot)$, respectively. The average hardness for a $56 \%$ soft- $44 \%$ hard multilayered iron electrodeposit, calculated from a rule of mixtures is represented by $(---)$. 


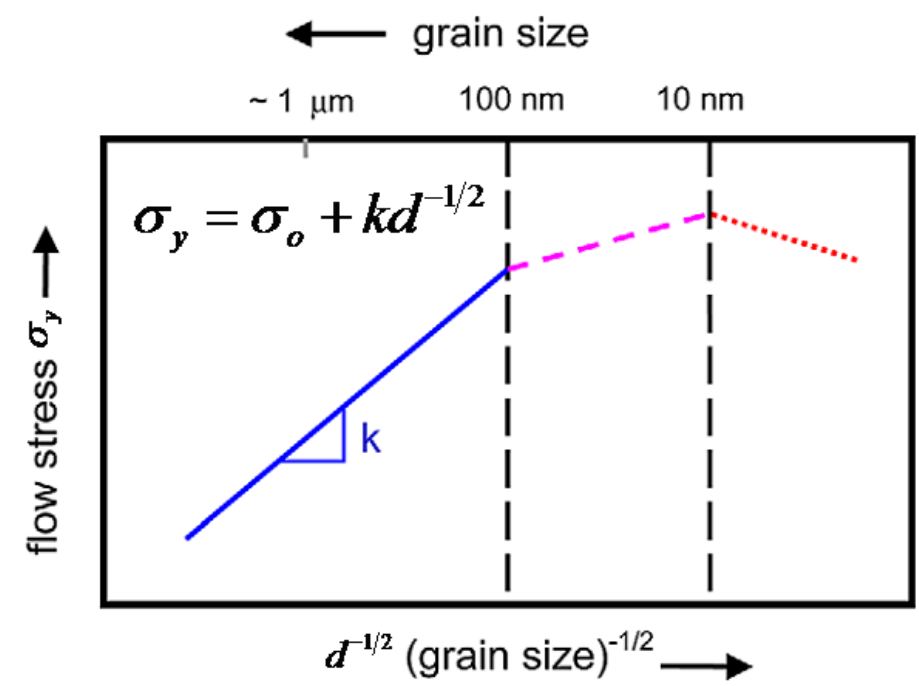

Figure 6.16 Schematic diagram illustrating the Hall-Petch relationship for metals in different grain size regimes (modified from Kumar et al. 2003).

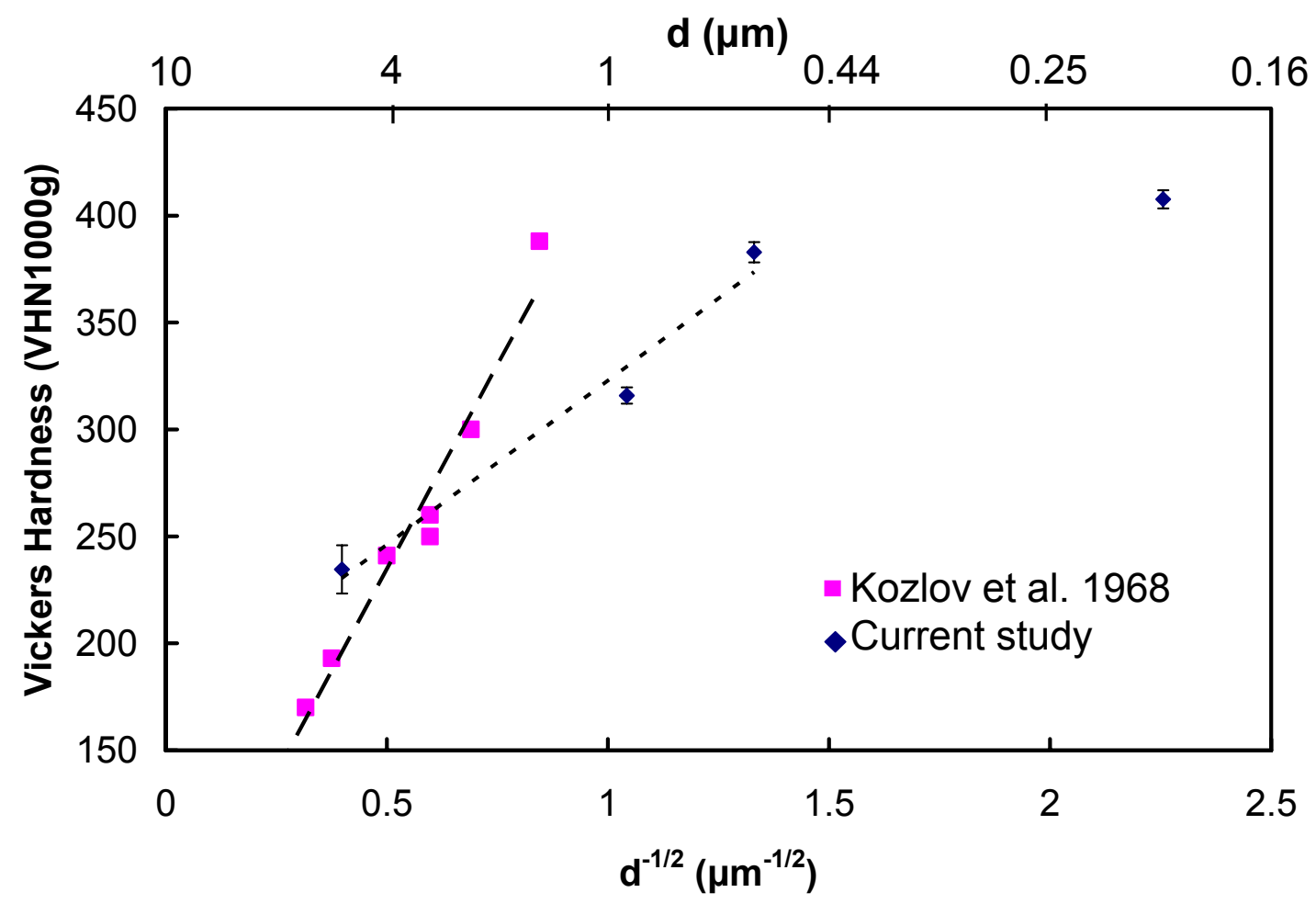

Figure 6.17 A comparison of the effectiveness of grain size and layer thickness as hardening mechanisms. Adapted from Kozlov et al. (1968). Linear fit showing Hall-Petch behaviour in monolithic iron (- - -) (Kozlov et al. 1968) and multilayered iron (.......) produced in the current study. d is used interchangeably to represent both grain size and layer thickness. 


\subsubsection{Flexural properties of multilayered iron electrodeposits}

One particular aim of this project was to investigate whether a multilayered structure design approach would be feasible in producing iron electrodeposits that exhibit a combination of high strength and high ductility (i.e. tough electrodeposits). Toughness is the ability of a material to absorb energy during deformation until it fractures (e.g. Callister 2005). The toughness of electrodeposited iron was investigated by plating coatings of iron onto a polyamide substrate, and measuring the flexural properties of the metal-polymer composite. Light weight composites that combine the strength of metallic coatings and the design flexibility of polymers are ideal for potential applications in many consumer, automotive, and aerospace products. A three-point bending test was performed to determine the toughness of the iron/polymer composites produced. The mechanical properties of electrodeposits are often assessed via tensile testing. However, brittle materials are prone to breakage in the sample grips. From the hardness measurements presented in Section 6.3.1, it was believed that some of the electrodeposited iron coatings may be relatively brittle. Therefore the three-point bending test was performed.

ASTM D 790-07, Standard Test Methods for Flexural Properties of Unreinforced and Reinforced Plastics and Electrical Insulating Materials [Metric] [2007], gives the equations for flexural stress and strain. These equations were modified to reflect the flexural properties of the iron/polymer composites produced in this study. Figure 6.18 shows a cross-sectional view of the samples tested. The modified flexural stress and flexural strain (henceforward labelled composite stress $\left(\sigma_{\mathrm{c}}\right)$ and composite $\operatorname{strain}\left(\varepsilon_{\mathrm{c}}\right)$ ) are:

$$
\begin{aligned}
& \sigma_{c}=\frac{3 P L}{2\left(b+2 t_{f}\right)\left(d+2 t_{f}\right)^{2}} \\
& \varepsilon_{c}=\frac{6 D\left(d+2 t_{f}\right)}{L^{2}}
\end{aligned}
$$

where, $\mathrm{P}$ is the applied load, $\mathrm{D}$ is the displacement, $\mathrm{L}$ is the support span length, $\mathrm{b}$ is the beam width, $d$ is the beam depth, and $t_{f}$ is the coating thickness. 


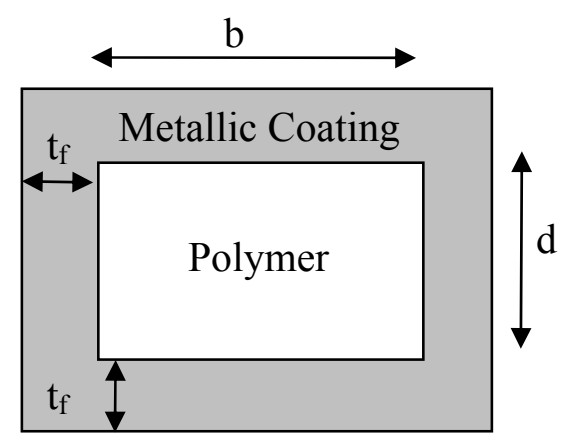

Figure 6.18 Schematic diagram showing the cross-sectional view of a metal-polymer composite

The iron/polymer composites produced in this study are listed in Table 6.6. The dimensions of these iron/polymer composites, which correspond to Figure 6.18, are also shown in this table. Examples of cross-sections of the iron/polymer composites studied are presented in Figure 6.19. As shown in Figure 6.19 iron coatings electrodeposited onto polymer substrates exhibit the same microstructures as iron coatings electrodeposited onto steel substrates (Figure 6.6). The soft iron sample exhibits coarse, columnar structure, while the multilayered iron samples exhibit layered microstructures. For the iron/polymer composite with the thickest layers (Figure 6.19(b)) a layered structure is clearly observed through the entire coating thickness. However for the iron/polymer composite with the thinnest layers (Figure 6.19(c)) the microstructure is more fibrous with regions that are fine-grained. SEM micrographs showing the layered structure of this sample at higher magnifications are presented in the Appendix. The layer thicknesses of the multilayered iron/polymer composites studied were measured from SEM micrographs, similar to the multilayered samples presented in 6.2.3.

Table 6.6 Iron/polymer composites produced under different electrodeposition conditions. Actual layer thickness corresponds to thickness of a single layer measured from SEM micrographs.

\begin{tabular}{|cccccc|}
\hline $\begin{array}{c}\text { Electrodeposition } \\
\text { Condition }\end{array}$ & $\begin{array}{c}\text { Type of Iron } \\
\text { Electrodeposit }\end{array}$ & $\begin{array}{c}\text { Actual Layer } \\
\text { Thickness } \\
(\boldsymbol{\mu m})\end{array}$ & $\mathbf{b} \mathbf{( \mathbf { m m } )}$ & $\mathbf{d}(\mathbf{m m})$ & $\mathbf{t}_{\mathbf{f}}(\mathbf{m m})$ \\
\hline 1 & monolithic soft & N/A & 10 & 4 & 0.100 \\
2 & monolithic hard & N/A & 10 & 4 & 0.084 \\
3 & multilayered & $\sim 7.0$ & 10 & 4 & 0.080 \\
4 & multilayered & $\sim 0.78$ & 10 & 4 & 0.082 \\
5 & multilayered & $\sim 0.44$ & 10 & 4 & 0.075 \\
\hline
\end{tabular}



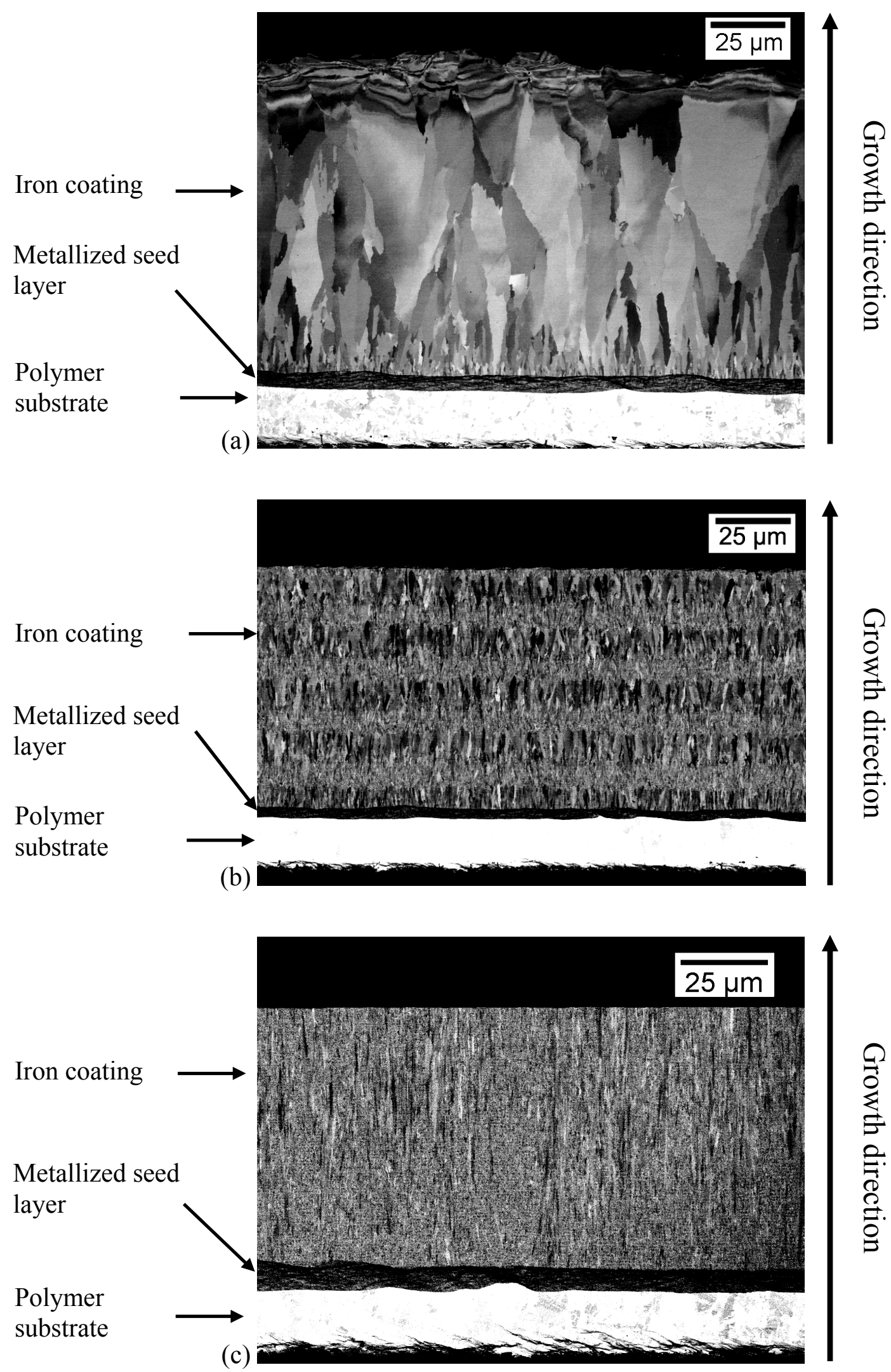

Figure 6.19 Backscattered SEM micrographs showing the cross-sections of iron/polymer composites (a) monolithic soft iron sample (b) $\sim 7.0 \mu \mathrm{m}$ multilayered sample (c) $\sim 0.44 \mu \mathrm{m}$ multilayered sample. 
Composite stress-strain curves were constructed from the force/displacement data points collected during the three-point bending tests. Figure 6.20 shows the stress-strain curves for the polymer substrate without any iron coatings, the monolithic samples coated with soft and hard iron, as well as the samples coated with multilayered iron coatings. All of the iron/polymer composites, except for the hard iron sample, exhibited higher strengths than the polymer substrate which would be expected when a polymer is metallized. However, only the soft iron sample exhibited any ductility compared to the polymer substrate.

The area under the stress-strain curves is referred to as the toughness of the iron/polymer composites studied. Toughness was determined by roughly estimating the area under the curves as a triangle. The values for the samples studied are listed in Table 6.7 in normalized form with respect to the highest value of $100 \%$ for the soft iron coating. The toughness of the multilayered iron samples is only $\sim 3-4 \%$ of the toughness of the monolithic soft iron. More importantly, the multilayered iron samples exhibit similar toughness values to the monolithic hard iron. It was initially hypothesized that the multilayered iron would exhibit greater ductility than the monolithic hard iron based on a rule of mixtures prediction (i.e. averaged ductility of soft and hard iron) and the toughness would vary depending on layer thickness. However, all of the multilayered iron samples were relatively brittle and toughness was more or less independent of layer thickness.

Table 6.7 Dependence of toughness (i.e. area under the stress-strain curve) on layer thickness for various iron/polymer composites.

\begin{tabular}{|cccc|}
\hline Sample Description & $\begin{array}{c}\text { Stress at Break } \\
\text { (MPa) }\end{array}$ & $\begin{array}{c}\text { \%Strain at } \\
\text { Fracture }\end{array}$ & $\begin{array}{c}\text { Relative Area Under } \\
\text { Curve* }\end{array}$ \\
\hline substrate & 31 & 5.8 & $38 \%$ \\
soft iron & 62 & 7.5 & $100 \%$ \\
hard iron & 29 & 0.48 & $3.0 \%$ \\
$\sim 7.0 \mu$ m layers & 37 & 0.54 & $4.2 \%$ \\
$\sim 0.78 \mu$ m layers & 38 & 0.42 & $3.4 \%$ \\
$\sim 0.44 \mu$ m layers & 36 & 0.37 & $2.8 \%$ \\
\hline
\end{tabular}

${ }^{*}$ As compared to the area under the stress-strain curve of monolithic soft iron/polymer composites. 


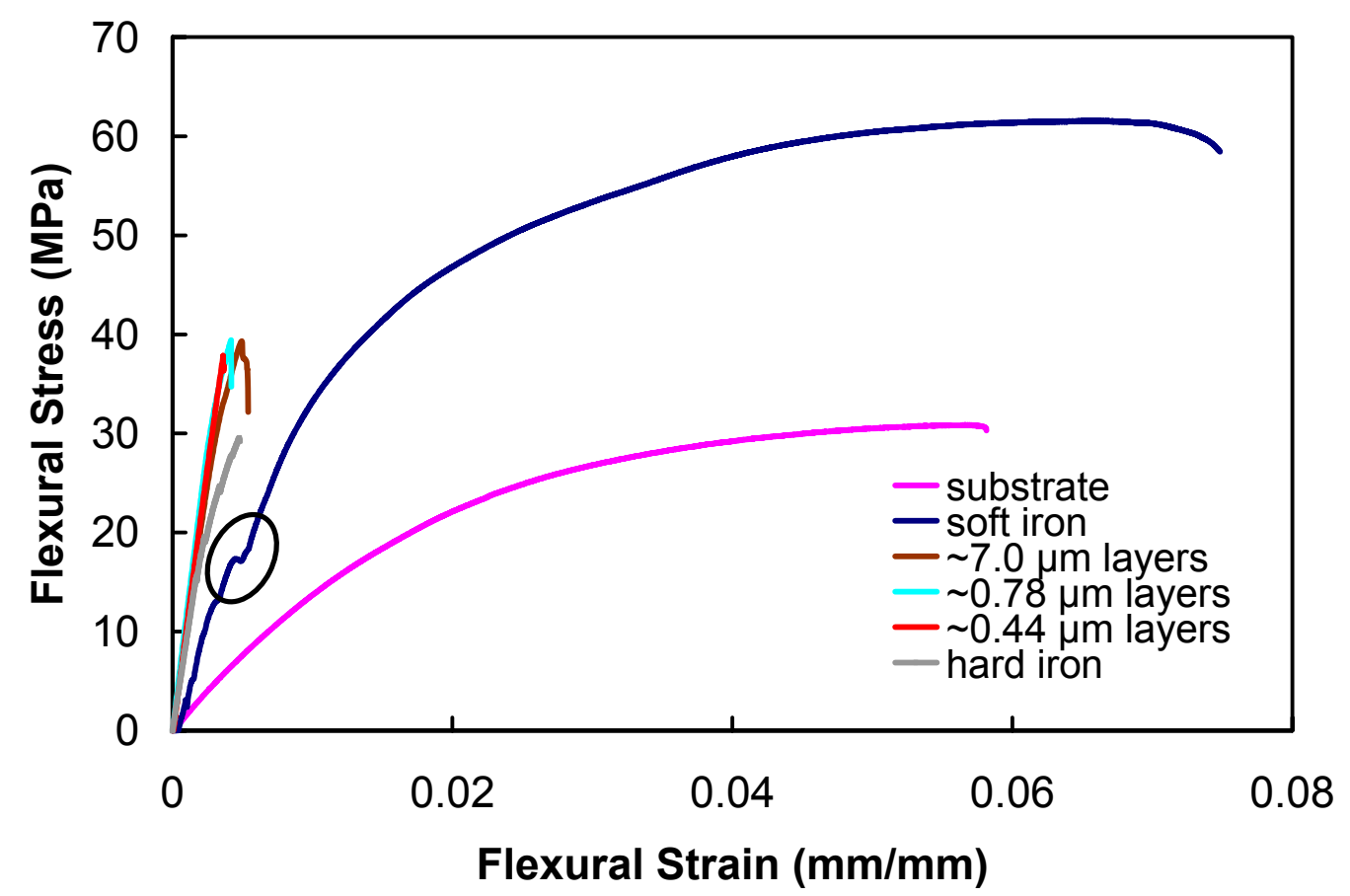

(a)

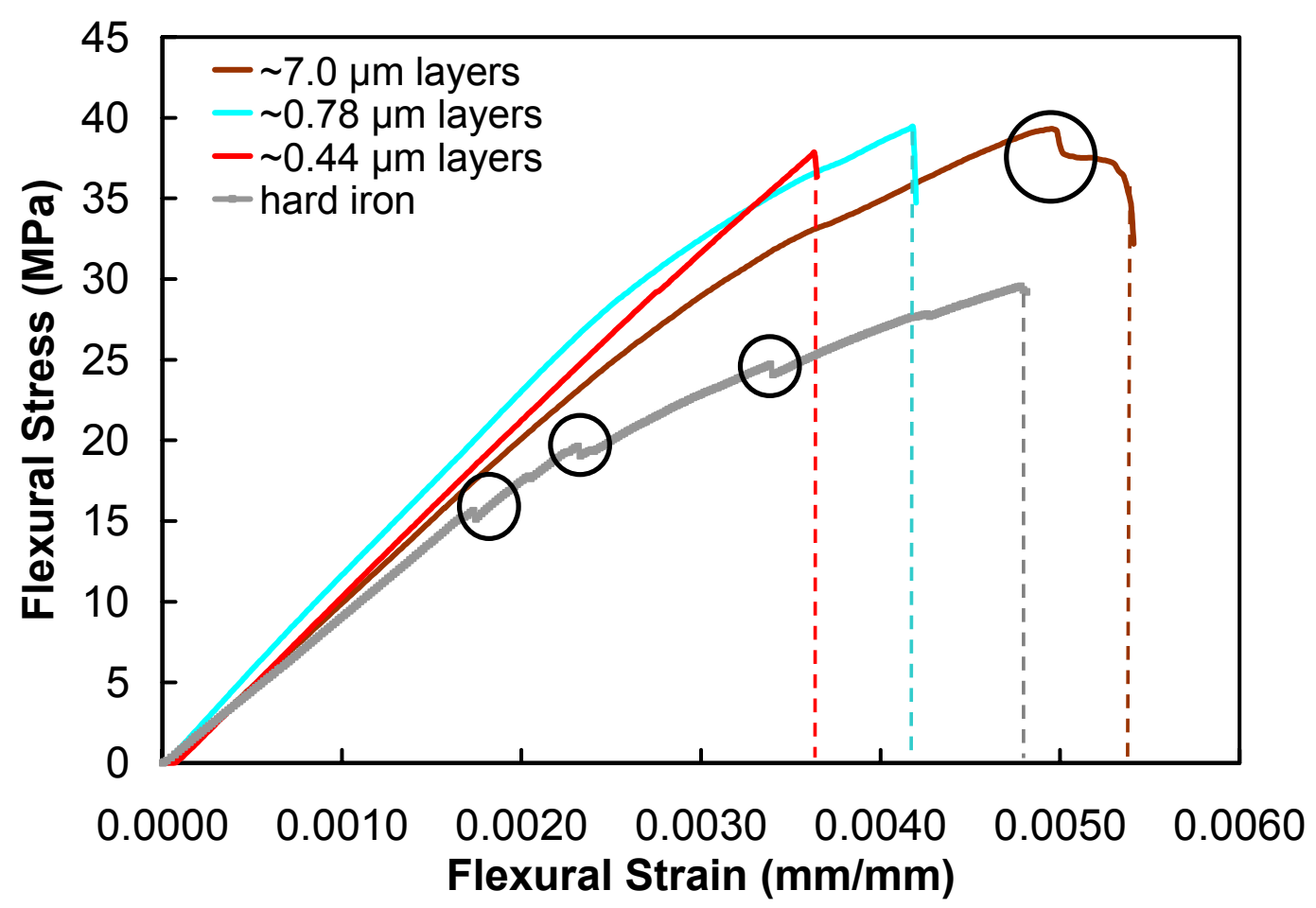

(b)

Figure 6.20 Flexural properties of iron/polymer composites produced in the current study. (a) Comparison between monolithic soft iron, monolithic hard iron, multilayered iron, and polymer substrate. (b) Enlarged portion of (a) showing a comparison between monolithic hard iron and multilayered iron. Dips in the stress-strain curves are circled. Area under the stress-strain curve is indicated by dotted lines and represents toughness of the iron/polymer composites. 
The ductility of layered materials is strongly influenced by the ductility of the bulk constituent materials (Leseur et al. 1996, Lee et al. 1991). Furthermore the susceptibility of the more brittle layer to cracking, the contribution of the interface to cracking, or the likelihood of delamination also influences the ductility of layered materials (Leseur et al. 1996). Lee et al. (1991) have shown that ultra high carbon steel (UHCS)/SS304 laminates exhibit lower ductility than what is predicted by a rule of mixtures approach, when the difference in ductility between the individual components is greater than $20 \%$. The low ductility values of the laminates were attributed to premature cracking of the more brittle UHCS layers, resulting in high stress concentrations at the interfaces and early failure of the more ductile SS304 layers (Lee et al. 1991). Similarly, the monolithic hard and soft iron produced exhibit very different fracture strains, as shown in Figure 6.20. It is assumed that strain incompatibility is a reason why the fracture strain of the multilayered iron is lower than what is predicted by a rule of mixtures approach, resulting in multilayered iron with low toughness.

It is believed that strain incompatibility caused cracking and delamination of the iron/polymer composites during the three-point bending tests which could explain the dips marked by circles observed in the composite stress-strain curves presented in Figure 6.20 .

Figure 6.21 shows a typical iron/polymer composite after it has been fractured in the three-point bending test. Cracking and delamination of iron/polymer composites were confirmed with SEM micrographs of the fractured surface. The fracture surface is indicated by the box in Figure 6.21. Figure 6.22(a), (b), and (c) are secondary SEM images, obtained using topography contrast, showing the fractured surfaces of a monolithic soft iron, hard iron and a multilayered iron, respectively. Delamination between the coating-substrate interface is observed in the monolithic soft and hard iron. Cracking at the corners of the monolithic hard iron is also observed. Delamination between iron layers and between the coating-substrate interface are observed in the multilayered iron. It should be noted that the initial metallized seed layer on the substrates is very thin relative to the electrodeposited iron, and is effectively a part of the 
iron coating. No delamination was observed between the metallized seed layer and the electrodeposited iron coating.

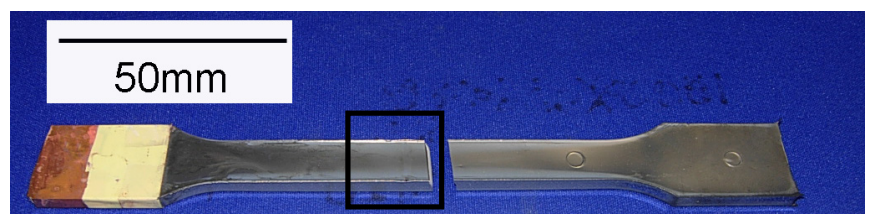

Figure 6.21 Photograph showing a typical iron/polymer composite after it has been fractured in a threepoint bending test. The box indicates the fractured surface examined in the SEM.

Another cause of cracking and delamination in the iron/polymer composites may be internal stress. Electrodeposited materials exhibit two types of internal stress: i) stress that is generated during the electrodeposition process and ii) residual stress that remains in the material after the electrodeposition process (Watanabe 2004). The latter is more industrially significant as electrodeposited materials with high internal stress often bend or crack during usage (Watanabe 2004). Weil (1971) suggests the internal stress in electrodeposited materials originate from: i) a crystallographic mismatch between deposit and substrate; ii) a compressive force generated by an attractive force between grains during grain growth; iii) stress resulting from high overpotentials; iv) stress resulting from co-deposited hydroxides; and v) stress resulting from co-deposited hydrogen. Of these mechanisms, Watanabe (2004) reports that co-deposited hydrogen is the most significant source of internal stress in electrodeposited materials. Co-deposited hydrogen can cause internal stress via volume expansion or shrinkage in the electrodeposited material (Watanabe 2004). Thus it is believed that co-deposited hydrogen and metalhydroxide are the root causes of internal stress, and likely promote cracking and delamination of the iron/polymer composites during the three-point bending tests. 
(a)
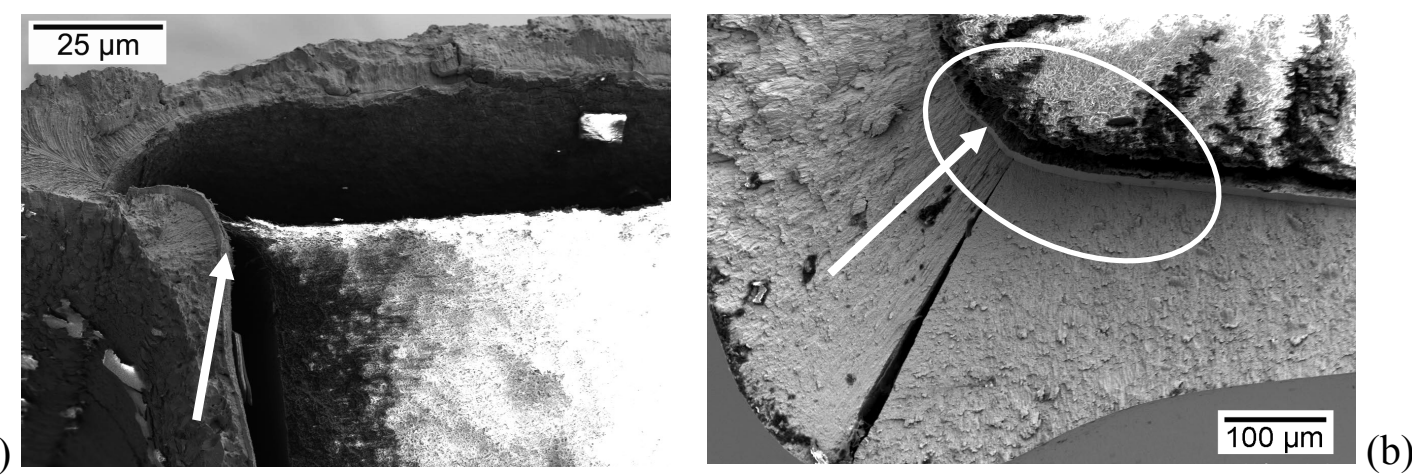

(b)

(c)

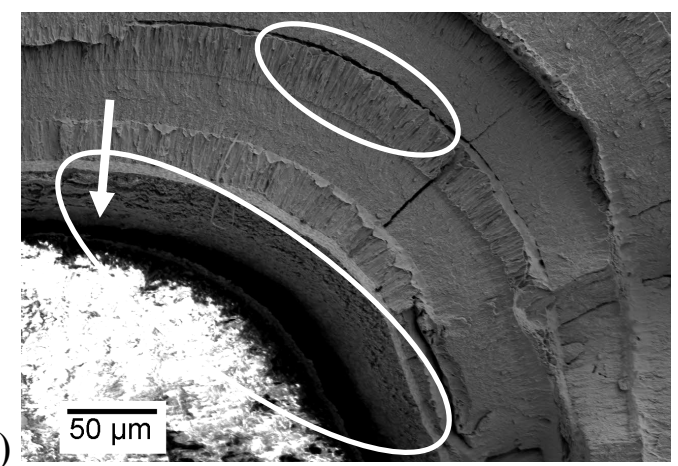

Figure 6.22 Secondary SEM micrographs showing cracking and delamination (circled) on the fractured surfaces of (a) a monolithic soft iron/polymer composite, (b) a monolithic hard iron/polymer composite, and (c) a multilayered iron/polymer composite. Arrows indicate the metallic seed layer.

In the chemical analysis of free-standing iron electrodeposits (Chapter 6.1) it was observed that free-standing monolithic hard iron contained more co-deposited impurities compared to monolithic soft iron. Similarly for the iron/polymer composites, it is believed that monolithic hard iron would contain greater amounts of co-deposited impurities compared to monolithic soft iron. Consequently both types of iron likely exhibit internal stress. However, the monolithic soft iron/polymer composites likely exhibited less internal stress owing to the lower concentration of impurities in the composites, and cracking does not occur (Figure 6.22). Therefore during the three-point bending test, monolithic soft iron composites undergo more plastic deformation before fracture, compared to all of the other iron composites.

Ductile materials generally exhibit lower strength then brittle materials. However, the results have shown that the monolithic soft iron is stronger than the other iron/polymer composites produced because of cracking and delamination that developed 
early on (i.e. at low strains) in the other iron/polymer composites during loading. Therefore the high strength of the monolithic hard iron and multilayered iron expected from their hardness is not achieved as a consequence of cracking, delamination, and premature fracture.

\subsubsection{SEM fracture surface analysis of iron electrodeposits}

Fractography was performed to further understand the failure mechanisms of the iron/polymer composites produced. Figure 6.23(a) shows the fractured surface of a monolithic soft iron composite. The surface is covered in dimples, common ductile fracture features. Microvoids are observed at the bottom of the dimples, which lead to fracture via microvoid coalescence. It should be noted that the average dimple size is several times larger than the average grain size $(\sim 1.87 \pm 0.63 \mu \mathrm{m})$, indicating the fracture initiation sites likely occur at triple junctions and at grain boundaries (Meyers 2006), or at co-deposited impurities. A fractured cross-section of the monolithic hard iron is presented in Figure 6.23(b). The fractured surface is composed of flat areas, reflecting the brittleness of the sample. Cleavage type fracture is apparent where each cleavage facet covers several thousand grains; the grain size in this material being $\sim 132 \pm 129 \mathrm{~nm}$. Little plastic deformation is observed on this fracture surface.

Figure 6.24 shows the fractured surfaces of a multilayered iron with layer thickness $\sim 7.0 \mu \mathrm{m}$. In Figure 6.24(a), the fractured surface exhibits both ductile and brittle fracture features, owing to the different fracture behaviours of the soft and hard iron layers, respectively. At higher magnification (Figure 6.24(b)) the fractured surface exhibits ductile fracture features (dimples) immediately adjacent to brittle fracture features (cleavage), further confirming the different fracture modes for soft and hard. Watanabe (2004) reported similar fracture features in layered nickel electrodeposits composed of large-grained layers and fine-grained layers.

It should be noted that the width of the ductile and brittle regions on the fractured surface of the $\sim 7.0 \mu \mathrm{m}$ iron/polymer composite vary from what would be expected based on the thickness of the soft iron and hard iron layers, respectively. In comparing the 
(a)
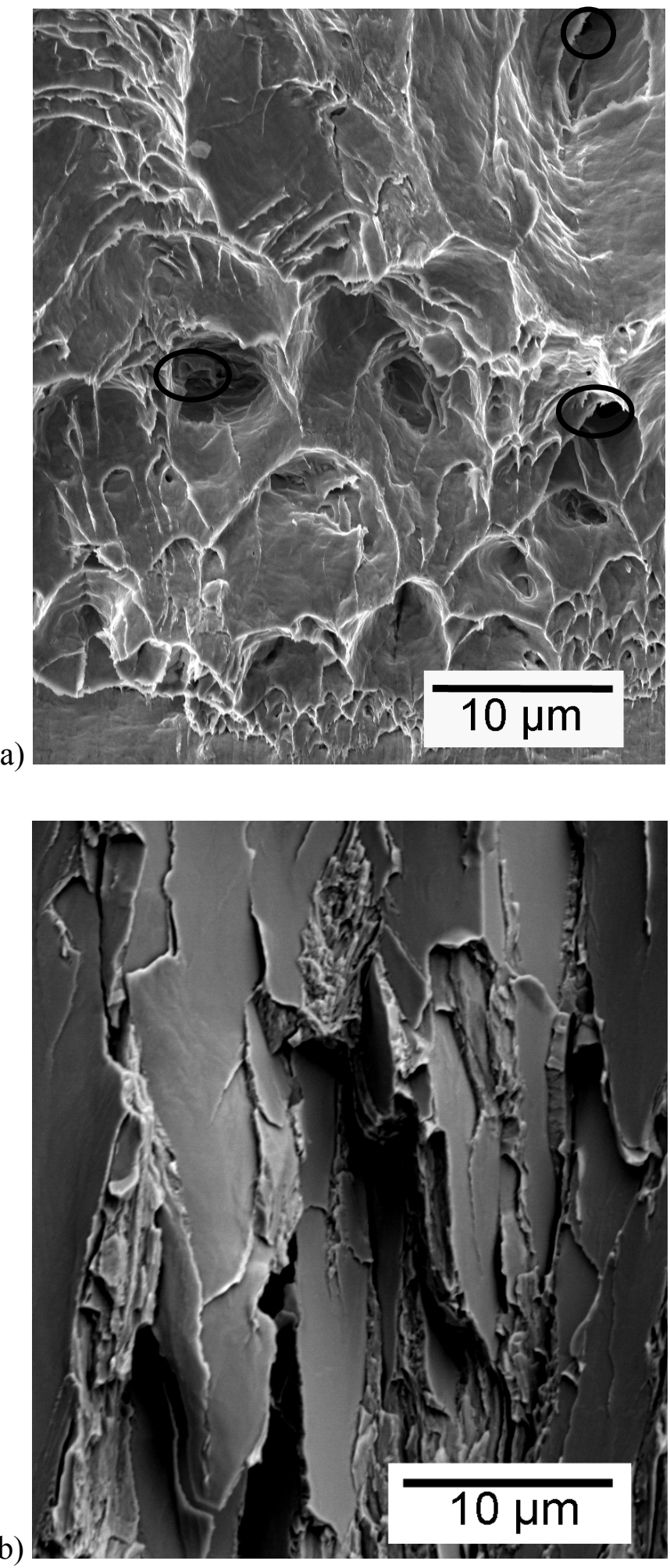

Figure 6.23 Secondary SEM micrographs of the iron/polymer composites. (a) Fractured surface of a monolithic soft iron/polymer composite exhibiting ductile fracture features. Holes representing potential sites for microvoid coalescence are circled in black. (b) Fractured surface of a monolithic hard iron/polymer composite exhibiting brittle fracture features. 

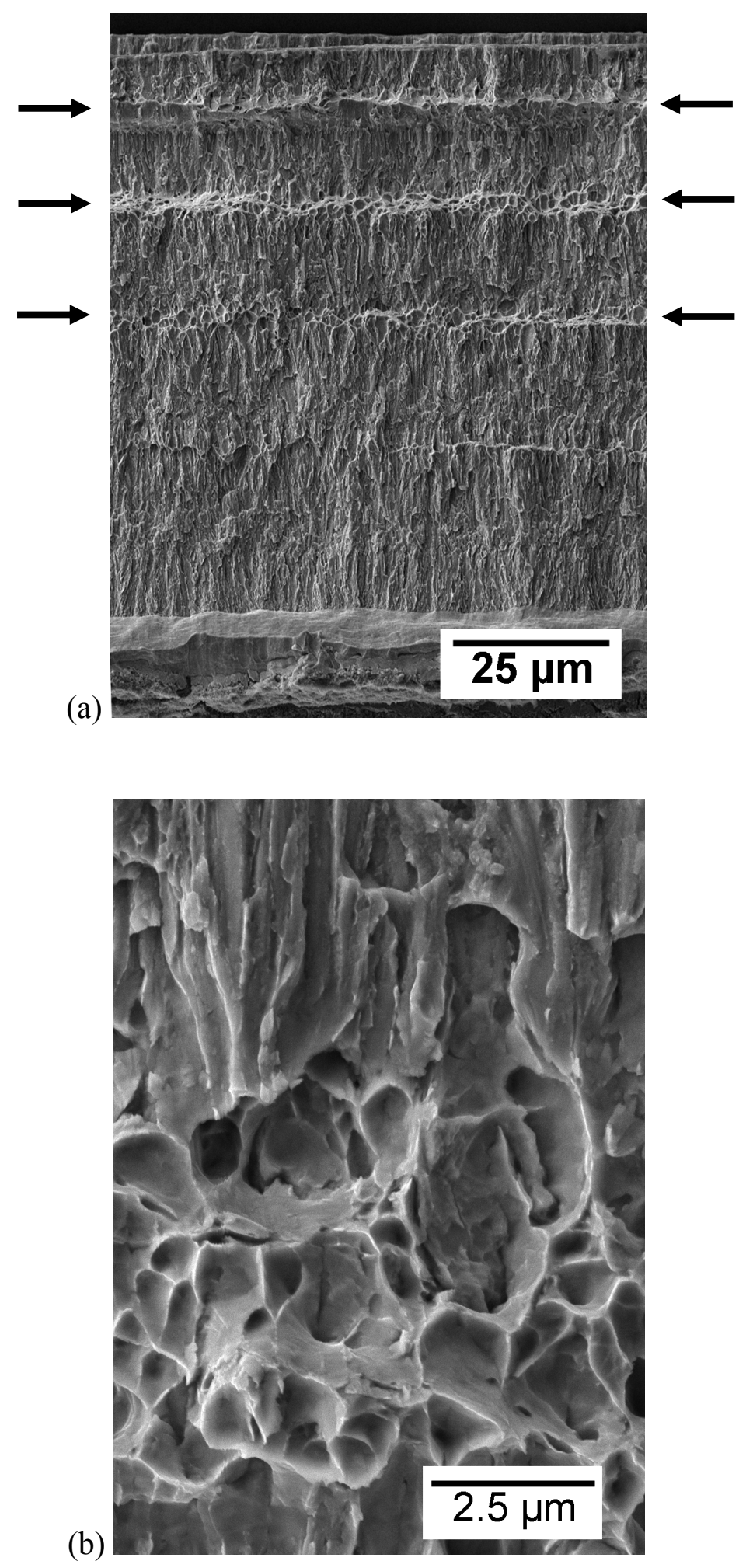

Figure 6.24 Secondary SEM micrographs of the fractured surface of a multilayered iron composite with $\sim 7.0 \mu \mathrm{m}$ thick layers. (a) At 1000x magnification showing regions of ductile and brittle fracture features. Arrows indicate regions of ductile fracture and brittle fracture occurs everywhere else. (b) At 11000x magnification showing an abrupt transition from ductile to brittle fracture. 
(a)

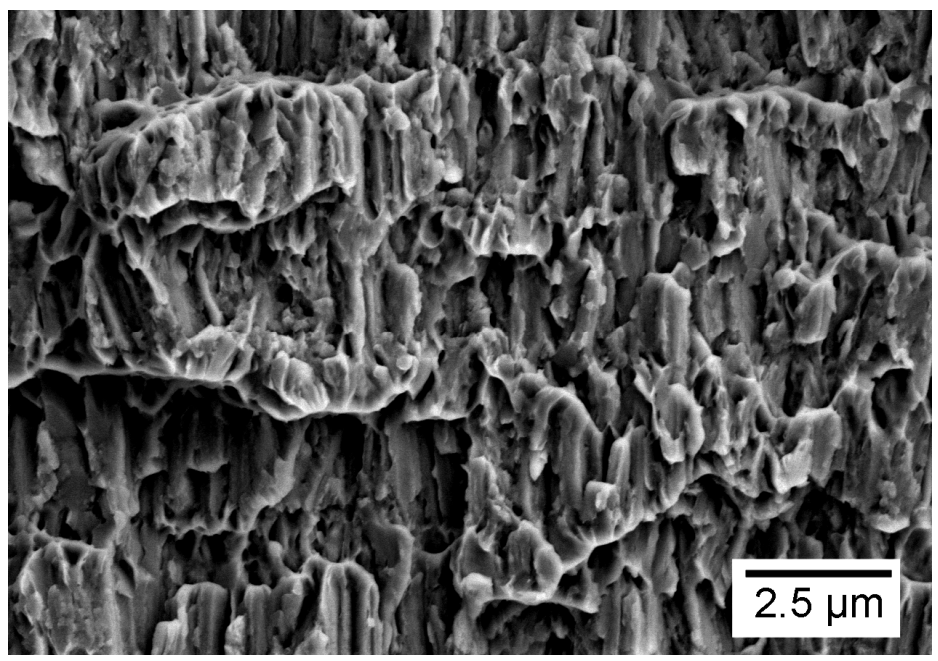

(b)

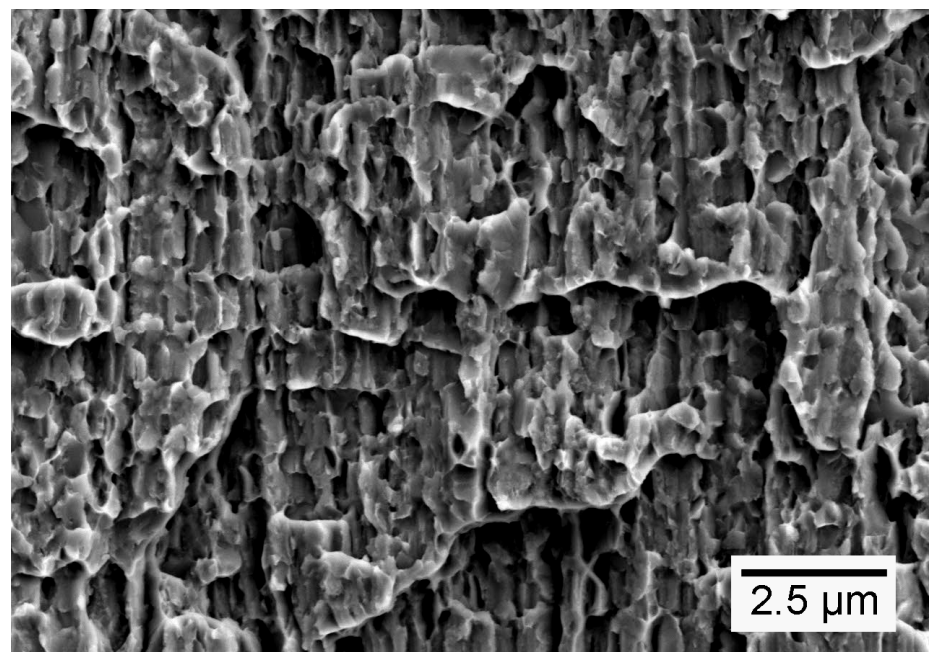

Figure 6.25 Secondary SEM micrographs showing the brittle fracture features observed on the fractured surfaces of multilayered iron composites with (a) $\sim 0.78 \mu \mathrm{m}$ thick layers, and (b) $\sim 0.44 \mu \mathrm{m}$ thick layers.

fractured surface shown in Figure 6.24(a) to the cross-section shown in Figure 6.19(b), the width of the ductile regions is less than half the thickness of soft iron layers while the width the brittle regions is more than double the thickness of hard iron layers. It is believed that strain incompatibility between the soft and hard layers resulted in brittle failure the edge of the soft iron layers. Thus the fracture surface exhibits predominantly brittle fracture features even though the volume ratio (i.e. thickness ratio) of the soft to hard iron layers is roughly equal. 
As the thickness of the layers is reduced, strain incompatibility begins to consume the whole of the soft iron layer. As such, iron/polymer composites with thinner layer thicknesses exhibit mostly brittle failure. Figure 6.25 shows a comparison of the fractured surface for multilayered iron composites with measured layer thicknesses of $\sim 0.78$ and $\sim 0.44 \mu \mathrm{m}$, respectively. Although some ductile features were observed on the fractured surface of the multilayered iron presented in Figure 6.25, the fractured surfaces exhibit predominantly brittle fracture features. All of the multilayered iron composites produced exhibit similar brittle fracture, and the fracture behaviour is relatively independent of layer thickness. The fracture features observed on the fractured surfaces of the iron composites produced are in good agreement with the composite stress-strain behaviour observed from the three-point bending tests (Figure 6.20). 


\section{CHAPTER 7}

\section{CONCLUSIONS}

\subsection{IRON ELECTRODEPOSITION AND MULTILAYERED STRUCTURE DESIGN}

Monolithic and multilayered iron electrodeposits were successfully synthesized by varying the electrodeposition conditions. Multilayered iron electrodeposits with layer thicknesses ranging from $\sim 0.20-8 \mu \mathrm{m}$ were produced via computer-controlled variations of the current density and time during the deposition process. The iron samples studied were electrodeposited onto various substrates to produce either free-standing electrodeposits, coatings, or composites structures.

\subsection{MICROSTRUCTURAL ANALYSIS}

Backscattered SEM images obtained via electron channelling contrast have revealed the microstructure of the iron electrodeposits studied. Soft and hard iron samples exhibit coarse, columnar grains and fine-grained structure, respectively. Structural characterization has shown the multilayered iron samples to be composed of alternating layers of soft and hard iron.

It has been observed that multilayered electrodeposits evolve from layered structures with discrete interfaces, to fibrous-columnar structures with diffuse interfaces as the layer thickness is reduced. The structural evolution is attributed to the amplified surface roughness with decreasing layer thickness.

To further investigate the microstructural differences between soft and hard iron electrodeposits, transmission electron microscopy was performed to assess texture and grain size. TEM diffraction patterns have revealed that the electrodeposited iron samples studied exhibit a BCC crystal structure. Analysis of the dark field and bright field TEM 
images have shown that the grain sizes of soft and hard iron electrodeposits are $\sim 1.87 \pm$ $0.63 \mu \mathrm{m}$ and $\sim 132 \pm 129 \mathrm{~nm}$, respectively.

The microstructure of one of the multilayered electrodeposits produced was also examined using cross-sectional TEM samples, prepared via ion milling and FIB. Electron transparent TEM samples were produced by both techniques and the layered structure was revealed in the TEM images.

X-Ray diffraction analysis confirmed the electrodeposited iron samples exhibit a BCC crystal structure. The preferred orientations of soft iron, hard iron and layered iron electrodeposits are: (110), (211), and (110), respectively. Evaluation of the XRD patterns has revealed the texture of multilayered electrodeposits is relatively independent of layer thickness.

\subsection{MECHANICAL PROPERTIES}

To assess the mechanical properties of monolithic and multilayered iron electrodeposits, microhardness measurements and three-point bending tests were conducted. Monolithic soft iron and hard iron electrodeposits exhibit average microhardness values of $177 \pm 7.1 \mathrm{VHN}$ and $502 \pm 12.8 \mathrm{VHN}$, respectively. Monolithic hard iron electrodeposits has only $\sim 3-4 \%$ of the toughness of monolithic soft iron electrodeposits.

Multilayered iron electrodeposits exhibit intermediate mechanical properties compared to the monolithic counterparts. However, tailoring the mechanical properties of multilayered electrodeposits is more challenging than simply taking an averaged value based on a rule of mixtures principle. Multilayered iron electrodeposits exhibit a HallPetch behaviour in which the average hardness increases with decreasing layer thickness. However, the effectiveness of the multilayered design as a hardening mechanism is dependent on layer thickness and interface quality (i.e. diffuse or discrete interfaces). The hardening rate decreases as the layer thickness is reduced below $\sim 0.6 \mu \mathrm{m}$. Strain incompatibility was also observed in the multilayered iron electrodeposits owing to the 
large difference in mechanical properties between the soft and hard iron electrodeposits. Consequently the toughness of the multilayered iron electrodeposits is significantly lower than what is predicted by a rule of mixtures principle.

In closing, the present work has shown that multilayered iron electrodeposits can be tailored over a range of layer thicknesses by controlling the deposition parameters. A better understanding of the microstructure and mechanical properties of these materials was gained through various characterization techniques. It is hoped the work presented here will promote future development of multilayered electrodeposits for potential applications in the various industries. 


\section{CHAPTER 8}

\section{RECOMMENDATIONS FOR FUTURE WORK}

This thesis research represents an advancement in the understanding of how mechanical properties of electrodeposited iron might be tailored by controlling the microstructure via a multilayered structure design. However, future work is required to further elucidate the influence of processing conditions on the structure-mechanical property relationships observed in electrodeposited iron; ultimately, allowing length-scale dependent properties to be optimized.

1. Both discrete and diffuse layer interfaces were observed in the multilayered iron electrodeposits produced in this study and layer boundary qualities were dependent on layer thickness. In order to develop better control for tailoring the microstructure, the effect of various electrodeposition parameters (e.g. levelling agents, current densities) should be studied to investigate whether the layer interface quality can be controlled via deposition conditions and further examine size effects on interface quality.

2. Some of the microstructural differences observed between the soft and hard iron electrodeposits produced in this study are attributed to a difference in oxygen content. Although it was suggested in Chapter Six that a difference in oxygen content did influence the mechanical properties of electrodeposited iron, it was not the main focus of this study. Future studies to produce thicker iron electrodeposits suitable for conducting impact tests would help to fully appreciate the effect of oxygen on the brittleness of electrodeposited iron.

3. It was observed that the iron electrodeposits produced exhibited sulphur impurities. Additional TEM investigations on impurity segregation could provide additional structural information, and contribute to a better understanding of the effects of impurities, such as sulphur, on the structure and mechanical properties of electrodeposited iron. 
4. As discussed in Chapter Six, the multilayered structure design was successful in producing relatively hard electrodeposits; however, they still lacked ductility. It is speculated that the toughness of the iron electrodeposits suffered as a consequence of the large difference in mechanical properties between the alternating layers. Layered electrodeposits composed of similar mechanical properties (e.g. soft and softer iron or medium hard and soft iron), which could potentially eliminate the issue of strain incompatibility, should be investigated as a potential design for producing tough multilayered iron electrodeposits. 


\section{REFERENCES}

Ashby, M.F. 1982. Philos. Mag. A 46 : 737.

ASTM Standard D 790-07, ASTM International, West Conshohocken, PA. 2007. 1-11.

ASTM Standard E 384 - 99, ASTM International, West Conshohocken, PA. 2000. 438 $-461$

Argoul, F., Arneodo, A., Grasseau, G., and Swinney, H. L. 1988. Phys. Rev. Lett. 61 : 2558.

Blum, W. 1921. Trans. Am. Electrochem. Soc. 40 : 307.

Bockris, J. O'M, D. Drazic, and A. R. Despic. 1961. Electrochimica Acta 4 : 325.

Bockris, J.O.M. and Razumney, G.A. 1967. Fundamental Aspects of

Electrocrystallization. New York : Plenum Press.

Bottger, R. 1846. Annu. Phys. Chem. $67: 117$.

Burgess, C.F. and Watts, O.P. 1906. Trans. Am. Electrochem. Soc. 9 : 229.

Callister, W. D. 2005. Fundamentals of materials science and engineering: An integrated approach. New Jersey : John Wiley \& Sons.

Cammarata, R.C., Schlesinger, T.E., Kim, C., Qadri, S.B. and Edelstein, A.S. 1990. Appl. Phys. Lett. $56: 1862$.

Choo, R.T.C., El-Sherik, A.M., Toguri, J. and Erb, U. 1995. J. Appl. Electrochem. 25 : 384.

Cleaves, H.E. and Thompson, J.G. 1935. The Metal-Iron. New York : McGraw-Hill Book Company Inc.

Cohen, U., Koch, F.B. and Sard, R. 1983. J. Electrochem. Soc. 130 : 1987.

Davis, B.M., Seidman, A., Moreau, A., Ketterson, J.B., Mattson, J. and Grimsditch, M. 1991. Phys. Rev. B. 43 : 9304.

Dini, J. W. 1993. Electrodeposition : The materials science of coatings and substrates. New Jersey: Noyes Publications. 
Dobrev, D., J. Vetter, N. Angert, and R. Neumann. 2001. Appl. Phys. A: Mat. Sci. \& Proc. $72: 729$.

El-Sherik, A.M., Erb, U., Palumbo, G. and Aust, K.T. 1992. Scr. Metall. Mater. 27 : 1185.

Erb, U. 1995. Nanostruct. Mater. $6: 533$.

Erb, U. 2006. J. Appl. Surf. Fin. $1: 16$.

Gadad, S. and Harris, T.M. 1998. J. Electrochem. Soc. 145 : 3699.

Gleiter, H. 1989. Prog. Mater. Sci. $33: 223$.

Gleiter, H. 1981. In Second Risø International Symposium on Metallurgy and Materials Science. N. Hansen, A. Horsewell, and H. Lilholt (Eds.). Denmark : Risø National Laboratory.

Gow, K.V., Iyer, S.P., Wu, H.H., Castelliz, K.M. and Hutton, G.J. 1979. Surf. Tech. 8 : 333.

Hall, E.Q. 1951. Proc. Soc. London. B64 : 747.

Hughes, W. E. 1920. J. Iron and Steel Inst. $101: 321$.

Hughes, W.E. 1921. J. Phys. Chem. $25: 495$.

Hughes, W. E. 1923. On the electro-deposition of iron, with an appendix containing a bibliography of the subject. London.

Jang, J.S.C. and Koch, C.C. 1990. Scr. Metall. Mater. 24 : 1599.

Jeong, D.H., Gonzalez, F., Palumbo, G., Aust, K.T. and Erb, U. 2001. Scr. Mater. 44 : 493.

Joint Committee on Powder Diffraction Standards (JCPDS) Powder Diffraction File (PDF) card No. 6-0696 (1986).

Joint Committee on Powder Diffraction Standards (JCPDS) Powder Diffraction File (PDF) card No. 22-0353 (1999).

Kasper, C. 1937. J. Res. Natl. Bur. Stand. 18 : 535.

Kozlov, V.M., Mamontov, Y. A., and Petrov, Yu. N. 1968. J. Metallogr. 26 : 186.

Kumar, K.S., Van Swygenhoven, H., and Suresh, S. 2003. Acta Mater. 51 : 5743. 
Kuriki, S.K., Sato, M., and Maeda, M. 1971. Jap. J. Appl. Phys. 10 : 604.

Le Brun, P., Gaffet, E., Froyen, L., and Delaey, L. 1992. Scr. Metall. Mater. 26 : 1743.

Lee, S., Wadsworth, J., and Sherby, O. D. 1991. J. Comp. Mat. 25 : 842.

Lesuer, D. R., Syn, C. K., Sherby, O. D., Wadsworth, J., Lewandowski, J. J., and Hunt Jr., W. H. 1996. Int. Mat. Rev. $41: 169$.

Levy, E.M., and Macinnis, R.D. 1968. J. Appl. Chem. 18 : 281.

Lowenheim, F.A., 1974. Modern Electroplating. $3^{\text {rd }}$ ed., New York : Wiley.

Mann, B. 2007. In Springer Handbook of Nanotechnology, $2^{\text {nd }}$ ed., B. Bhushan (Ed.), New York : Springer.

Matsuda, K. and Kaneta, M. 1996. Philos. Mag. A 74 : 1171.

Menezes, S. and Anderson, D.P. 1990. J. Electrochem. Soc. 137 : 440.

Meyers, M. A., Mishra, A., and Benson, D. J. 2006. Mater. Sci. 51 : 427.

Misra, A. and Kung, H. 2001. Adv. Eng. Mater. 3 : 217.

Misra, A., Hirth, J. P., and Kung, H. 2002. Philos. Mag. A $82: 20935$.

Nee, C.C. and Weil, R. 1985. Surf. Technol. 25 : 2052.

Palumbo, G., Thorpe, S.J., and Aust, K.T. 1990. Scr. Metall. et Mater. 24 : 1347.

Paunovic, M. and Schlesinger, M. (Eds.), 1998. Fundamentals of electrochemical

deposition. New York: Electrochemical Society.

Petch, N.J., J. Iron Steel Inst. 1953. $174: 25$.

Péter, L., Kupay, Z., Cziráki, Á., Pádár, J., Tóth, J., and Bakonyi, I. 2001. Am. Chem. Soc. $105: 10867$.

Puippe, J.Cl. and Leaman, F. (Eds.), 1986. Theory and Practice of Pulse Plating. Florida : AESF Soc.

Roos, J. R., Celis, J. P., and De Bonte, M. 1991. In Materials Science and Technology, R.W. Cahn, P. Haasen, and E.J. Kramer, (Eds.), Vol. 15. New York : VCH.

Ross, C. A. 1994. Annu. Rev. Mater. Sci. 24 : 159. 
Ruff, A.W. and Wang, Z. 1989. Wear. $131: 259$.

Safranek, W.H. 1957. U.S. Patent 2809156.

Safranek, W. H. 1974. The properties of electrodeposited metals and alloys.

New York: American Elsevier Pub. Co.

Schaffert, R.M. and Gonser, B.W. 1943. Trans. Electrochem. Soc. 84 : 319.

Smith, C. S., A History of Metallography. 1960. Massachusetts: MIT Press.

Stoddard Jr., W.B. 1947. U.S. Patent 2420403.

Suryanarayana, C. 1991. Int. Mat. Rev. $40: 41$.

Thomas, C.T. 1941. Trans. Electrochem. Soc. $80: 499$.

Wang, J., and Misra, A. 2011. Curr. Opin. Solid State Mater. Sci. 15 : 20.

Wang, N., Wang, Z., Aust, K.T. and Erb, U. 1997. Mater. Sci. Eng. 237 : 150.

Wang, W. and Singh, R.N. 1999. Mat, Sci. Eng. 271 : 306.

Wang, Y., Chen, M., Zhou, F. and Ma, E. 2002. Nature. 419 : 912.

Watts, O.P. and Li, M.H. 1914. Trans. Am. Electrochem. Soc. 25 : 529.

Watanabe, T. 2004. Nano-plating : Microstructure control theory of plated film and data base of plated film microstructure. Boston: Elsevier.

Weil, R. 1989. Annu. Rev. Mater. Sci. 19 : 165.

Weil, R. 1971. Plating 58 : 137.

Williams, D. B. 2009. Transmission electron microscopy : A textbook for materials science, C. B. Carter. (Ed.), $2^{\text {nd }}$ ed, London: Springer.

Yang, W.M.C., Tsakalakos, T., and Hillard, J.E. 1977. J. Appl. Phys. 48 : 876.

Yoshimura, S., Yoshihara, S., Shirakashi, T., and Sato, E. 1994. Electrochim. Acta. 39 : 589. 


\section{APPENDIX}

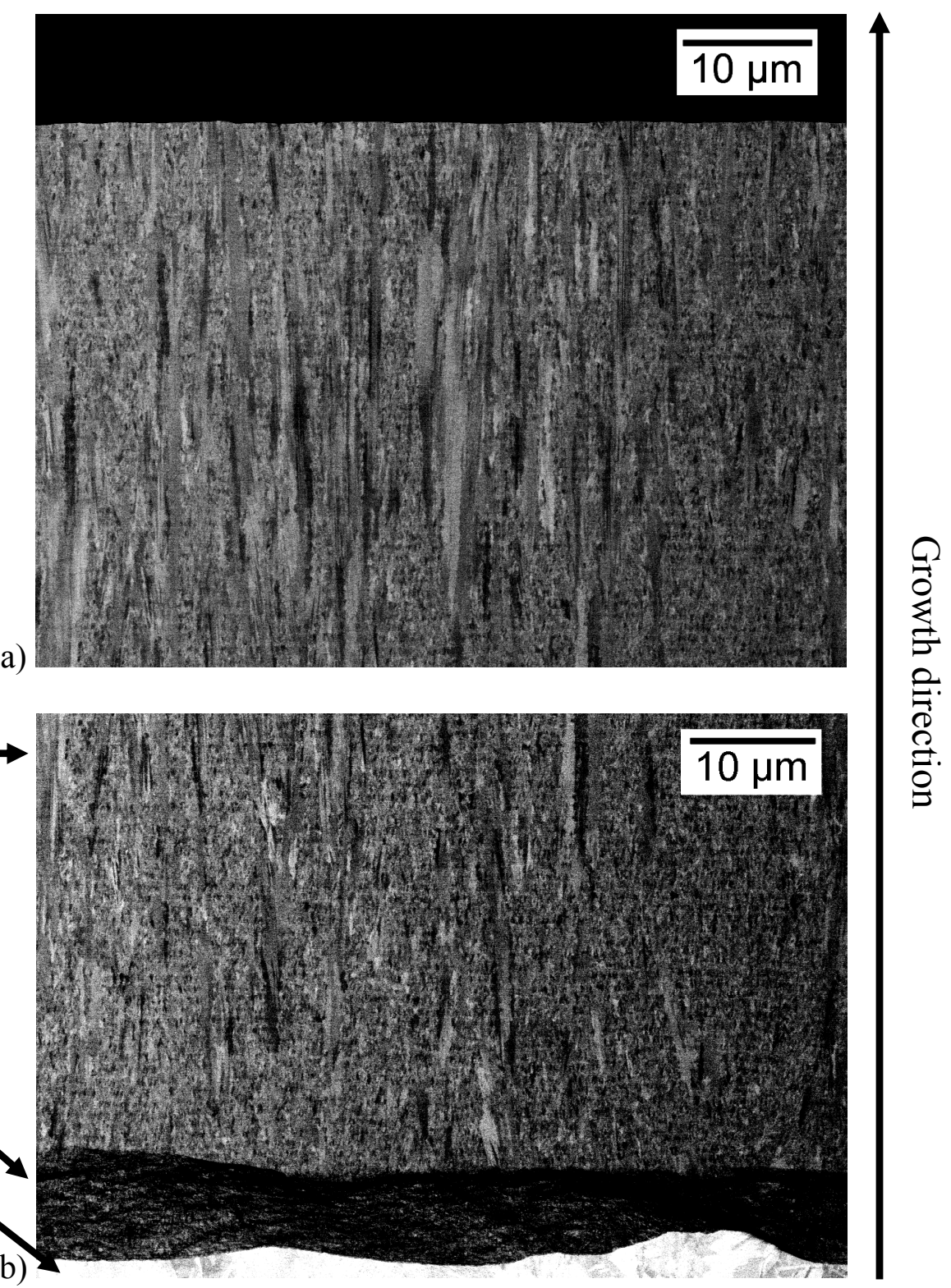

Figure A.1 Backscattered SEM micrographs showing the cross-section of a multilayered iron/polymer composite with $\sim 0.44 \mu \mathrm{m}$ thick layers. (a) Layered structure near the surface of the iron coating and (b) layered structure near the polymer substrate. 